\title{
An Experimental Evaluation on Air Conditioning Performance with Vairtex Air Director Applied on Residential Condenser Unit
}

\author{
by \\ Vien Nguyen, B.A.Sc \\ A thesis submitted to the Faculty of Graduate and Postdoctoral Affairs \\ in partial fulfillment of the requirements for the degree of \\ Master of Applied Science \\ in \\ Mechanical Engineering \\ Ottawa-Carleton Institute for Mechanical and Aerospace Engineering \\ Department of Mechanical and Aerospace Engineering \\ Carleton University \\ Ottawa, Ontario \\ January, 2017 \\ (C) Copyright \\ Vien Nguyen, 2017
}




\section{Abstract}

First invented by Gerard Godbout - co-founder of VairTEX Canada Inc., the US and Canadian patented-device called VairTEX Air Director is installed on top the air-cooled condenser top discharge to improve the efficiency of air condition-

ing/refrigeration systems. Through tests at their industrial partners in Canada and in the United States, the device has demonstrated its effectiveness by reducing compressor power consumption, where a highest saving of $21 \%$ was recorded. However, as VairTEX has chosen to focus on the industrial/commercial markets, no data has been obtained for residential air conditioning system to further validate the company claims.

An experimental study was carried out to evaluate the effectiveness of VairTEX Air Director device on a modified 1.5-ton air conditioner located in the thermodynamic laboratory at the Department of Mechanical and Aerospace Engineering Carleton University. The experiment was divided into two parts.

The first part included thermodynamic performance evaluations at two different refrigerant flow rates. In particular, coefficient of performance (COP), power consumption, refrigeration capacity were examined in order to provide comparisons of these parameters with and without the Air Director device implemented. As the Air Director was installed on the condenser unit, COP was improved by an appreciable 
amount of $4 \%$ and $5 \%$ on mean values while compressor power consumption was reduced by $3.7 \%$ and $4.5 \%$ with respect to mean values at two refrigerant flow rates, respectively.

The second part involved three directional velocity measurements to characterize air flow discharge from the condenser with and without the device, which then could help to clarify why such improvement existed on condenser performance in particular and for an air conditioning system as whole. A measuring method developed by King and modified by Janjua called - 'Six-orientation hot-wire probe technique', was explored to determine three velocity components using single-normal hot-wire probe. A compact experimental setup was also designed and constructed to perform calibration for velocity range in this study. In addition, a temperature correction method from Hultmark was validated and employed to make the experiment possible in non-isothermal flow field.

By modifying profiles of three velocity components, the Air Director has straightened exit flow where the radial component was significantly reduced while axial flow was greatly improved. As a consequence, an increase of $48.7 \%$ in volume flow rate was achieved. Tangential component at the Air Director exit resembled the profile found in cyclone devices. Temperatures collected at the Air Director exit demonstrated an increase in heat dissipation from the condenser unit compared to bare condenser case and hence, increased the heat transfer between the ambient and refrigerant. Thus, condenser performance was improved. 


\section{Acknowledgments}

First and foremost, I would like to thank my supervisor, Dr. Edgar Matida, for giving me the opportunity to pursue graduate studies. Thank you for your endless support, guidance, and encouragement throughout these few years.

I am also truly grateful to Debra and Gerard Godbout, as well as Therese and Leo Donlevy from VairTEX Ottawa Inc. for their collaboration and willingness to sponsor the project even during their company's financially challenging start-up phase. Thank you for always believing in me. Without their sacrifices, my study would not be completed, neither would I have the opportunity to obtain knowledge which I have today. I would also like to thank Ross Cowan (also from VairTEX) for helping me in proofreading the draft.

I would also like to extend my thanks to the technologists in the department: especially Stephan Biljan, Steve Truttman, first for giving permission to use the air conditioning system in the thermodynamic lab for my study. Thank you Stephan for his assistance in 3D print parts of my 'desktop' wind tunnel. To Steve, thank you for answering all technical matters related to the equipment that you allowed me to borrow. A special mention has to go to Ian Lloy in the machine shop for his help, not

only in manufacturing the six-axis rotating device, but also for his suggestion in the design process of this device. His 'perfectionist-mind' along with his machinist skills have been greatly appreciated. 
Many thanks go out to my friends and colleagues for providing social distractions during this challenging period; to Doma Slaman for his guidance in using the hot-wire anemometer and special thanks to Kenny Lee Slew for providing an insight numerous times during my experiment, as well as sharing his Fortran knowledge and assisting me to decode the script from previous studies, allowing me to develop my own script for post-processing experimental data. His advice, discussions, and encouragement must be acknowledged.

Last but not least, I would like to thank my parents for their love and encouragement. Their unlimited support has helped me obtain this achievement. Thank you Dad for your hard work and providing me with financial support for my expensive overseas study over the past 10 years. Thank you Mom for skyping with me every weekend, showing care and sharing recipes so I could relax and entertain myself from studying hour through cooking. 


\section{Table of Contents}

$\begin{array}{lll}\text { Abstract } & \text { ii }\end{array}$

Acknowledgments $\quad$ iv

Table of Contents vi

List of Tables $\quad x$

List of Figures $\quad$ xii

Nomenclature $\quad$ xvii

1 Introduction 1

1.1 Classification of Air Conditioning System . . . . . . . . . . . 2

1.2 Statistical Facts on an Air Conditioning System . . . . . . . . . 5

1.3 VairTEX Air Director . . . . . . . . . . . . . . 8

1.4 Motivation . . . . . . . . . . . . . . . . . . . 13

1.5 Structure of Thesis . . . . . . . . . . . . . . . . . 14

2 Literature Review and Background $\quad 15$

2.1 Improving Air Conditioning Performance . . . . . . . . . . 16

2.2 Applications with Add-on Shrouded Type Device . . . . . . . . . 22 
3.1 Principle of Vapour-Compression Air Conditioning Systems . . . . . . 25

3.2 Experimental Set-up . . . . . . . . . . . . . . . . . . 30

3.2 .1 Evaporator unit . . . . . . . . . . . . . . . . 30

3.2 .2 Condenser unit . . . . . . . . . . . . . . . . . . . 31

3.2 .3 Throttle . . . . . . . . . . . . . . . . . . . . 32

3.2 .4 Refrigerant flow meter . . . . . . . . . . . . . . . . 32

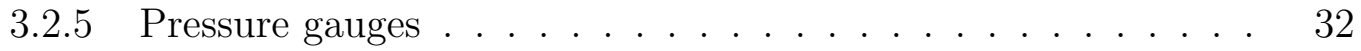

3.2 .6 Thermocouples . . . . . . . . . . . . . . . . . . 32

3.2 .7 Propeller anemometer . . . . . . . . . . . . . . . . 32

3.3 Experimental Procedure $\ldots \ldots \ldots \ldots$

3.4 Data Reduction . . . . . . . . . . . . . . . . . . . . . . . 34

3.4 .1 Assumption . . . . . . . . . . . . . . . . . . . 35

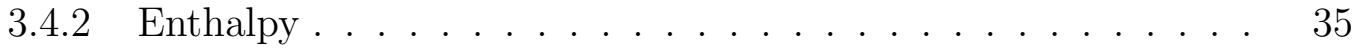

3.4 .3 Refrigeration flow rate . . . . . . . . . . . . 36

3.4 .4 Air flow rate . . . . . . . . . . . . . . . . 36

3.4 .5 Refrigeration capacity . . . . . . . . . . . . . 37

3.4 .6 Coefficient of performance . . . . . . . . . . . . . 37

3.4 .7 Energy efficiency ratio $\ldots \ldots \ldots \ldots$

4 Hot-wire SOM Technique $\quad 39$

4.1 Fundamental Concept . . . . . . . . . . . . . . . . . . . . . 41

4.1 .1 Operational Mode . . . . . . . . . . . . . . . . . . . . 42

4.1 .2 Response Equation . . . . . . . . . . . . . . . . 43

4.2 Multi-Position Measuring Techniques . . . . . . . . . . . . . 44

4.2 .1 Velocity equations $\ldots \ldots \ldots \ldots \ldots \ldots$ 
$4.2 .2 \quad$ Statistical analysis . . . . . . . . . . . . . 50

4.2 .3 Covariance . . . . . . . . . . . . . . . . . . . . . . 53

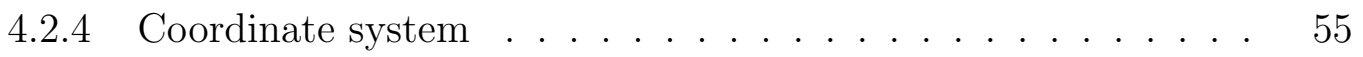

4.3 Calibration Setup . . . . . . . . . . . . . . . . . 55

4.4 Temperature Correction . . . . . . . . . . . . . 60

4.5 Experimental Setup . . . . . . . . . . . . . . . . 65

4.5.1 Hot-wire measurement . . . . . . . . . . . . . . . . . 65

4.5.2 Temperature measurement . . . . . . . . . . . . . 71

4.5.3 Experimental procedure . . . . . . . . . . . . 74

5 Results and Discussion $\quad 76$

5.1 Air Conditioning Performance Evaluation . . . . . . . . . 76

5.1 .1 Temperature measurements . . . . . . . . . . . 78

5.1 .2 Pressure measurements . . . . . . . . . . . . . . . . . 81

5.1 .3 Compressor power measurements . . . . . . . . . . . . 82

5.1 .4 Refrigeration capacity . . . . . . . . . . . . . 83

5.1 .5 Coefficient of performance $(\mathrm{COP}) \ldots \ldots \ldots \ldots$

5.1 .6 T-s Diagram . . . . . . . . . . . . . . . . . . . 87

5.2 Hot-wire Measurements . . . . . . . . . . . . . . . . . . . . . . . . . . 89

5.2 .1 Temperature component . . . . . . . . . . . . . . 89

5.2 .2 Radial velocity component . . . . . . . . . . . . . . . . 90

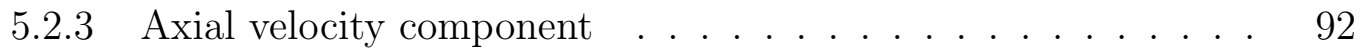

5.2 .4 Tangential velocity component . . . . . . . . . . . . . 93

5.3 Uncertainty Analysis . . . . . . . . . . . . . . . . . . 95

5.3 .1 Velocity measurement $\ldots \ldots \ldots \ldots$

$5.3 .2 \quad$ AC Performace Evaluation . . . . . . . . . . . . . 98 
5.3.3 Random error . . . . . . . . . . . . . . . . . . . 99

6 Conclusions and Recommendations 103

6.1 AC Performance Evaluation . . . . . . . . . . . . . . 103

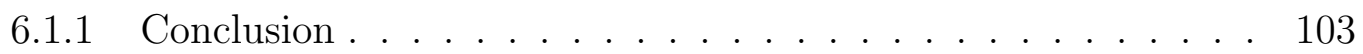

6.1.2 Recommendations . . . . . . . . . . . . . . . . 104

6.2 Velocity and Temperature Measurements . . . . . . . . . . . . 105

6.2.1 Conclusion . . . . . . . . . . . . . . . . . . 105

6.2.2 Recommendations . . . . . . . . . . . . . 106

$\begin{array}{lr}\text { List of References } & 116\end{array}$

$\begin{array}{ll}\text { Appendix A Uncertainty Quantification } & 117\end{array}$ 


\section{List of Tables}

1.1 Distribution of different air conditioning system across the United States in 2009. Survey performed by EIA. . . . . . . . . . . . . 8

3.1 Power consumption for different evaporator fan speeds [38] . . . . . . 31

3.2 Condenser fan specification . . . . . . . . . . . . . . . 31

3.3 Summary table for variables collected during AC experiment . . . . . 33

$4.1 \mathrm{AO}, \mathrm{BO}$, and $\mathrm{CO}$ values for corresponding equation set . . . . . . . 50

4.2 Corresponding $L_{e} / \mathrm{d}$ ratios for different Reynolds numbers. Reproduced from Frank M. White - Fluid Mechanics [68] . . . . . . . . . 58

4.3 Technical data for a miniature single-wire probe from Dantec Dynamics 69

5.1 Refrigerant temperature (measured in ${ }^{\circ} \mathrm{C}$ ) mean values obtained from three repeats at two refrigerant flow rates with and without the AD . 79

5.2 Air temperature (measured in ${ }^{\circ} \mathrm{C}$ ) mean values obtained from three repeats at two refrigerant flow rates with and without the AD . . . 80

5.3 Mean pressures [psi] measured at the condenser and evaporator gauges, obtained from three repeats at two refrigerant flow rates with and

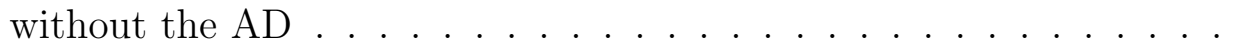

5.4 Mean values obtained from three repeats at two refrigerant flow rates with and without the $\mathrm{AD} \ldots \ldots \ldots$ 
5.5 Uncertainty deduces from temperature correction for calibration process and measurements . . . . . . . . . . . . . . . . 96

5.6 Summary p-values for several interested variables collected from AC

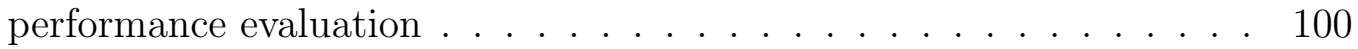

5.7 Maximum uncertainties for each component resulted from velocity measurements with and without AD . . . . . . . . . . . 101 


\section{List of Figures}

1.1 Three systems available for room cooling purposes: portable, window and mini-split or ductless air conditioners. Adapted from Ref. [2] . .

1.2 Typical central air conditioning system with two main components: the condenser unit and evaporator unit. Adapted from Ref. [3] . . . .

1.3 Percentage of different air conditioning systems installed within Canada. Reproduced from data provided in Ref. [4] . . . . . . . . . . 6

1.4 Percentage of houses equipped with air conditioning systems across the United States. Source: U.S. Energy Information Administration, 2009 Residential Energy Consumption Survey $[2]$. . . . . . . . . . . . . 7

1.5 An example of VairTEX Air Director device applied on (a) residential; (b) industrial condenser units . . . . . . . . . . . . . . .

1.6 Two views of the VairTEX air director used in this study (a) isometric view; (b) top view . . . . . . . . . . . . . . . . . . . 10

1.7 Typical VairTEX unit installation . . . . . . . . . . . . . . . 11

2.1 Commonly used residential condenser fan blades (a) Rectangular-shape two-blade; (b) Rectangular-shape three-blade; (c) Low-Noise threeblade; (d) Rectangular-shape four-blade [23] . . . . . . . . . . . . 18

2.2 Schematic of Parker's development on high efficiency air conditioner condenser fan system . . . . . . . . . . . . . . . . 
2.3 Model of outdoor air conditioner unit where (a) Old type outdoor unit; (b) Optimized unit with double fan, extended bell mouth and sigma shaped heat exchanger. Reproduced from Ref. [27] . . . . . . . . .

3.1 Schematic diagram of a basic ideal vapour-compression cycle in which it consists of four components: compressor, condenser, throttle and

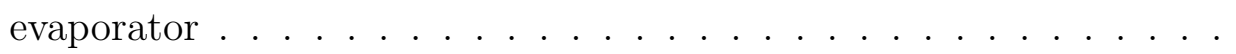

3.2 Typical T-s digram for actual and ideal vapour-compression refrigeration cycle where subscript i, r and s stand for ideal cycle, actual cycle, and isentropic stage respectively. Blue lines represent isobaric process while red lines illustrate isothermal process . . . . . . . . . . . .

3.3 Carrier air conditioning system and instrumentation - Adapted from MAAE2400 Lab Manual . . . . . . . . . . . . . . . . . . . .

3.4 Schematic of an evaporator unit where the dash line represents a control volume around the evaporator coil . . . . . . . . . . . . . . 37

4.1 Dantec single-straight sensor 55P11. Adapted from dantecdynamics.com $[45] \ldots \ldots \ldots \ldots \ldots \ldots \ldots$

4.2 Wheatstone bridge circuit in a constant temperature anemometer operation mode where hot-wire probe acts as one of the resistors in the bridge. Adapted from AA Lab Systems Ltd. [46] . . . . . . . . . . . . 42

4.3 Three Calibration Direction . . . . . . . . . . . . . . 46

4.4 Three Directional Calibration Curves . . . . . . . . . . . . . . . . 47

4.5 Six positions of measurement for single hot-wire probe . . . . . . . . 48

4.6 Hot-wire probe coordinate $\mathrm{u}, \mathrm{v}$, and $\mathrm{w}$ at position 1 in related to flow field coordinate system U, V and W . . . . . . . . . . . . 55

4.7 General geometry of diffuser section where $D_{1}$ is throat diameter, $D_{2}$ is exit diameter, $\mathrm{L}$ is diffuser length and $\theta$ is conical angle. . . . . . 
4.8 Schematic of the convergent nozzle with matched fifth order polynomial where $R_{1}$ and $R_{2}$ is are inlet and exit radii, $\mathrm{L}$ is the total length, $x_{m}$ is the distance from the inlet to the match point where the two polynomials of same curvature and slope meet $[70]$. . . . . . . . .

4.9 Schematic of a mini-version wind tunnel where calibrations in three

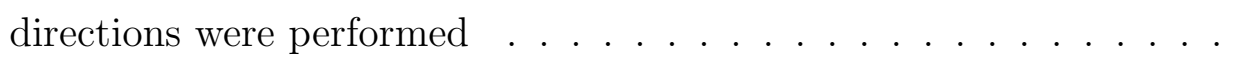

4.10 CTA mode calibration and correction curves from Hultmark's study . (a) Original calibration curves at different temperatures and (b) Curves replotted using similarity variable given by Equation 4.44. Reproduced from $\operatorname{Ref}[80] \ldots \ldots \ldots \ldots \ldots \ldots$

4.11 (a) In-house calibration curves at different temperatures and (b) Curves replotted following Hultmark's correction method . . . . . .

4.12 Six-orientation measurement device where blue labels represent different features of the main body part while orange labels show components of the hollow tube part .............. 66

4.13 Schematic of a 1D traverse system surrounding the condenser unit in room ME2230-30 at Carleton University. Note that all dimensions are

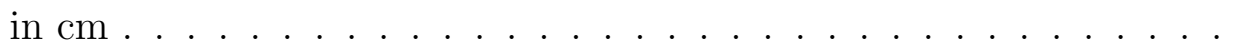

4.14 Hot-wire measuring locations in reference to the condenser (a) and Air Director (b) exit surfaces . . . . . . . . . . . . . . .

4.15 Three velocity components: Radial (a), Axial (b) and Tangential (c) were resolved after sampling at 1, 2, 4 and $8 \mathrm{kHz}$, where 'o' represented measurement taken for location 6 while ' $*$ ' stood for data points of location $7 \ldots \ldots \ldots \ldots \ldots$ 
4.16 Percent differences of average voltages between with and without TC installed at six measuring positions referred to Figure 4.5 where P1, P2, ..., and P6 represent position 1, position 2, ......, and position 6.72

4.17 Percentage difference between temperature recorded at exact hot-wire sensor and offset locations . . . . . . . . . . . . . . . 73

5.1 Carrier air conditioning system and instrumentation - Adapted from MAAE2400 Lab Manual . . . . . . . . . . . . . . . . . . . 77

5.2 Refrigerant temperatures recorded at five locations indicated in Figure 5.1 where (a), (b), (c), (d), and (e) corresponding to location 1, 2, 3, 4 , and 5 with and without the AD added on the condenser exit surface for two refrigerant flow meter readings 0.25 and $0.35 \mathrm{gal} / \mathrm{min}$. . . .

5.3 Air temperature recorded at the inlet and exit of evaporator for two flow rates with and without $\mathrm{AD}$ applied on the condenser where (a) and (b) correspond to inlet and outlet measurements, respectively . . 80

5.4 Pressured measured after (a) the condenser and after (b) the evaporator with and without VairTEX AD installed for two interested flow

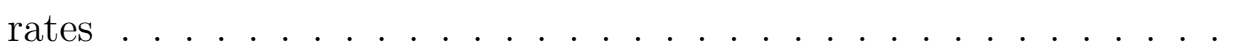

5.5 Power consumed by the compressor were recorded with and without VairTEX AD installed for two interested flow rates . . . . . . . . . . 82

5.6 A comparison of calculated refrigeration capacity with and without the VairTEX AD on condenser unit at different flow rates . . . . . . . . .

5.7 Propeller frequency measured for two designated flow meter readings with and without $\mathrm{AD} \ldots \ldots \ldots \ldots$

5.8 Amperage drawn by condenser fan with and without the VairTEX AD installed . . . . . . . . . . . . . . . . . 86

5.9 Computed COP for AC system . . . . . . . . . . . . . . . 87 
5.10 T-s diagram comparison with and without the $\mathrm{AD}$ at refrigerant flow rate reading $0.35 \mathrm{gal} / \mathrm{min} \ldots \ldots \ldots \ldots$

5.11 Temperature captured at condenser surface discharge and VairTEX AD exit top . . . . . . . . . . . . . . . . . . . . 89

5.12 Radial velocity component measured at condenser surface discharge and VairTEX AD exit surface . . . . . . . . . . . . . . . . 91

5.13 Axial velocity contour collected at condenser surface discharge and VairTEX AD exit surface . . . . . . . . . . . . . . . . . . . . . . 93

5.14 Tangential velocity profile obtained at condenser surface discharge and VairTEX AD exit surface . . . . . . . . . . . . . . . . . . . . 


\section{Nomenclature}

\section{Latin Letters}

A

Cross section area

$\left[m^{2}\right]$

A, $B, C \quad$ Calibration constants

$A 0, B 0, C 0 \quad$ Values in generalized solution function

$A_{2} / A_{1} \quad$ Area ratio

$\alpha$

Temperature coefficient of resistivity

$\left[{ }^{\circ} C^{-1}\right]$

$D$

Characteristic diameter

$d$

Hot-wire sensor diameter

$[m]$

$D_{1}, D_{2} \quad$ Diffuser throat and exit diameter

$[m]$

$\delta_{T}$

Difference between wire and ambient temperatures

$\left[{ }^{\circ} \mathrm{C}\right]$

$E$

Voltage

$[V]$

$\eta \quad$ Manipulative constant in covariance definition

$E_{w} \quad$ Output voltage based on reference temperature

$E_{w, r} \quad$ Corrected output voltage based on reference temperature 


\begin{tabular}{|c|c|c|}
\hline$F 1, F 2, F 3$ & Generalized solution for six-orientation method & {$[-]$} \\
\hline$G$ & Pitch factor & {$[-]$} \\
\hline$\gamma_{Z_{i} Z_{j}}$ & Correlation coefficient between two cooling velocities & {$[-]$} \\
\hline$h$ & Convection heat transfer coefficient & {$\left[W /\left(m^{2} K\right)\right.$} \\
\hline $\mathrm{h}$ & Enthalpy & {$[k J / k g]$} \\
\hline$i, j$ & Probe position & {$[-]$} \\
\hline$K$ & Yaw factor & {$[-]$} \\
\hline$k$ & Thermal conductivity of air & {$[W /(m K)]$} \\
\hline$K_{Z_{i} Z_{j}}$ & Covariance of the effective cooling velocities & {$[-]$} \\
\hline$L$ & Diffuser/Nozzle length & {$[m]$} \\
\hline$l$ & Hot-wire sensor length & {$[m]$} \\
\hline$L_{e}$ & Entrance length & {$[m]$} \\
\hline$\dot{m}$ & Mass flow rate & {$[\mathrm{kg} / \mathrm{s}]$} \\
\hline$n$ & Exponent in power law equation & {$[-]$} \\
\hline$N u$ & Nusselt number & {$[-]$} \\
\hline$\dot{\omega}$ & Propeller rotational speed & {$[\mathrm{rev} / \mathrm{s}]$} \\
\hline$P$ & Pressure & {$[P a]$} \\
\hline $\mathrm{P}, \mathrm{Q}, \mathrm{R}$ & Three selected measuring positions & {$[-]$} \\
\hline
\end{tabular}




\begin{tabular}{|c|c|c|}
\hline $\operatorname{Pr}$ & Prandtl number & {$[-]$} \\
\hline$Q$ & Volume flow rate & {$\left[m^{3} / s\right]$} \\
\hline$Q_{\text {in }}$ & Refrigeration capacity & {$[$ ton $]$} \\
\hline$Q_{\text {loss }}$ & Heat loss from the system & {$[W]$} \\
\hline$R e$ & Reynolds number & {$[-]$} \\
\hline$\rho$ & Fluid density & {$\left[\mathrm{kg} / \mathrm{m}^{3}\right]$} \\
\hline$R_{o}$ & Reference resistance & {$[\Omega]$} \\
\hline$R_{s}$ & Wire resistance & {$[\Omega]$} \\
\hline s & Entropy & {$[k J / k g K]$} \\
\hline$\sigma^{2}$ & Variance & {$[-]$} \\
\hline$t$ & Integration period & {$[-]$} \\
\hline$T$ & Temperature & {$\left[{ }^{\circ} \mathrm{C}\right]$} \\
\hline$T_{a}$ & Ambient temperature & {$\left[{ }^{\circ} \mathrm{C}\right]$} \\
\hline$\theta$ & Diffuser conical angle & {$\left[{ }^{\circ}\right]$} \\
\hline$T_{r}$ & Calibration (reference) temperature of hot-wire probe & {$\left[{ }^{\circ} \mathrm{C}\right]$} \\
\hline$T_{w}$ & Wire temperature of hot-wire probe & {$\left[{ }^{\circ} \mathrm{C}\right]$} \\
\hline $\mathrm{U}$ & Radial velocity component & {$[\mathrm{m} / \mathrm{s}]$} \\
\hline$\mu$ & Fluid dynamic viscosity & {$\left[N s / m^{2}\right]$} \\
\hline
\end{tabular}




$\begin{array}{lll}u, v, w & \text { Orthogonal velocity components seen by the hot-wire } & {[-]} \\ v & \text { Specific volume } & {\left[\mathrm{m}^{3} / \mathrm{kg}\right]} \\ \mathrm{V} & \text { Axial velocity component } & {[\mathrm{m} / \mathrm{s}]} \\ V & \text { Velocity } & {[\mathrm{m} / \mathrm{s}]} \\ \nu & \text { Fluid kinemetic viscosity } & {\left[\mathrm{m}^{2} / \mathrm{s}\right]} \\ \dot{V} & \text { Volumetric flow rate } & {\left[\mathrm{m}^{3} / \mathrm{s}\right]} \\ \phi & \text { Inverse function of calibration equation } & {[-]} \\ \text { W } & \text { Tangential velocity component } & {[\mathrm{m} / \mathrm{s}]} \\ W_{\text {input }} & \text { Work input to the system } & {[\mathrm{W}]} \\ Z & \text { Effective cooling velocity } & {[-]}\end{array}$

\section{Abbreviations}

AC Air conditioning

AD $\quad$ Air director

AS Aspect ratio

CFC Chlorofluorocarbon

CFM Cubic feet per minute

COP Coefficient of performance

CR Contraction area ratio 


$\begin{array}{ll}\text { CTA } & \text { Constant temperature anemometry } \\ \text { EER } & \text { Energy efficiency ratio } \\ \text { GPM } & \text { Gallon per minute } \\ \text { HFC } & \text { Hydrofluorocarbon } \\ \text { HVAC } & \text { Heating,ventilation, and air conditioning } \\ \text { HWA } & \text { Hot-wire anemometer } \\ \text { LPM } & \text { Litre per minute } \\ \text { NRCAN } & \text { Natural Resources Canada } \\ \text { PIV } & \text { Particle image velocimetry } \\ \text { RECS } & \text { Residential energy consumption survey } \\ \text { RMS } & \text { Root mean square } \\ \text { RPM } & \text { Rotation per minute } \\ \text { SEER } & \text { Seasonal energy efficiency ratio } \\ \text { SOM } & \text { Six-orientation method } \\ & \text { Thermocouple }\end{array}$




\section{Chapter 1}

\section{Introduction}

Once considered a luxury, air conditioning has become an essential, bringing comfort for houses, shopping malls, hospitals, data centres, laboratories, as well as other buildings that are vital to our daily lives and to our economy. Dr. John Gorrie a physician and inventor - initially proposed the idea of cooling a hospital for his patients by using ice in the 1840s. Later, he began experimenting with the concept of artificial cooling by designing an ice machine powered by a compressor and was granted a patent in 1851. Even though Gorrie was unable to market his technology, his idea and invention clearly laid a foundation for modern air conditioning and refrigeration systems [1]. Engineer Willis Carrier continued the quest for creating artificial cooling while working at Buffalo Forge Company in 1902. The first modern electrical air conditioning (AC) unit was created and patented, as Carrier solved a humidity problem on magazine papers at Sackett-Wilhelms Lithographing and Publishing Company in Brooklyn.

In later years, Carrier debuted cooling systems, which were modified from his previous design for the Metropolitan Theatre in Los Angeles and the Rivoli Theatre in New York. Despite advancements in cooling technologies, there were still challenges implementing these cooling systems for residential use due to their size and cost. 
Frigidaire introduced a split-type room cooler system to the market in 1929 while Frank Faust improved this design by customizing a self-contained room cooler. In 1932, Schultz and Sherman patented a window-ledge air conditioning unit. A more compact and less expensive version of a window air conditioner became popular in 1947 by development of Henry Galson. Finally, in the 1970s, central air conditioning systems made their way into American homes. However, after this period, modifications on air conditioning systems mainly focused on operating the system more environmentally friendly or increasing the efficiency.

This chapter classifies residential air conditioning systems currently in-use in Canada and the United States and provides statistical information on the penetration of different types of air conditioning systems across both countries. Finally, the motivation that drives this work as well as the structure of the thesis will also be presented.

\subsection{Classification of Air Conditioning System}

For residential use, depending on budget, existing set-up, and area required for cooling, there are two basic systems to choose from:

1. Room air conditioners: These air conditioners offer low-cost approach, minimum installation effort yet effective to provide comfort in small spaces such as a single room apartment, individually room temperature setting, etc. This type can be categorized into three divisions: portable, window, and ductless mini-split, as shown in Figure 1.1 (a),(b) and (c).

- Portable $A C$ : This free-stand evaporative cooler unit is easily moved between rooms and requires temporary ducting to the outdoors. However, 


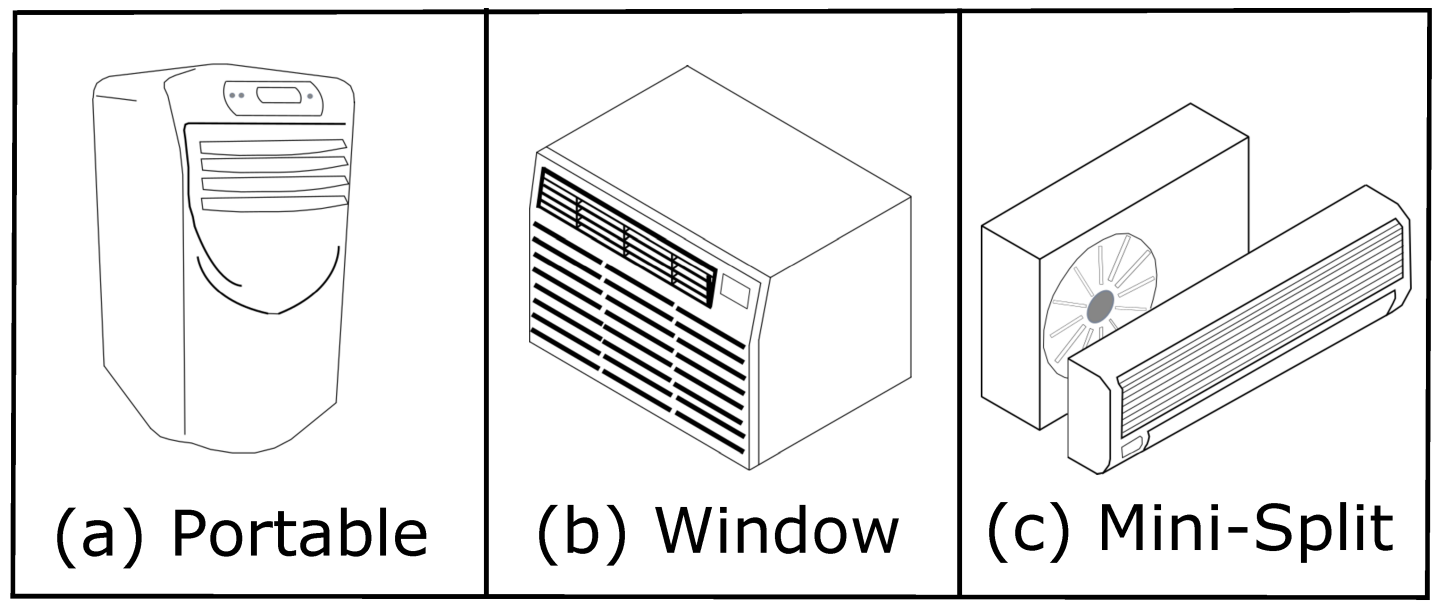

Figure 1.1: Three systems available for room cooling purposes: portable, window and mini-split or ductless air conditioners. Adapted from Ref. [2]

maintenance is necessary as cleaning of drain duct should be performed regularly to prevent a potential molding problem.

- Window $A C$ : Used to be the most popular cooling system, the windowmounted air conditioner is available for installation for different window types, for example: sliding window, single and double-hung window. Despite being the most affordable piece of all air conditioners, this type of room AC still suffers a downside as it has a short life span compared to the other two room air conditioners. Furthermore, improper installation can result in significant air leakage.

- Ductless mini-split AC: This two-piece system consists of a outdoor cabinet where compression, condensation and heat releasing processes take place while an indoor cabinet expands and evaporates the refrigerant and absorbs heat. This system is typically installed for houses without distribution ducting systems. Requiring minimal ductwork, small size, easy to install, it is also a good choice for a small apartments or for room additions where extending or setting up distribution ductwork is not feasible. Moreover, the 
advantage of this system is that it allows individual temperature control for each zone in the house. However, the main drawback of such systems is cost, where normally a ton of cooling capacity costs approximately $\$ 1,500$ to $\$ 2,000$ US dollars.

2. Central air conditioners: A central AC system is installed where cooling for an entire place is needed and ductwork already exists. Traditionally, this system comprises two main units: condenser and evaporator units which are located outside and inside the house accordingly. Similar to other types of systems, central air conditioners is powered by electric and runs on basic refrigeration principles. Besides, an air handler or furnace usually accompanies the system in order to pump chilled air throughout the house via a ducting system.

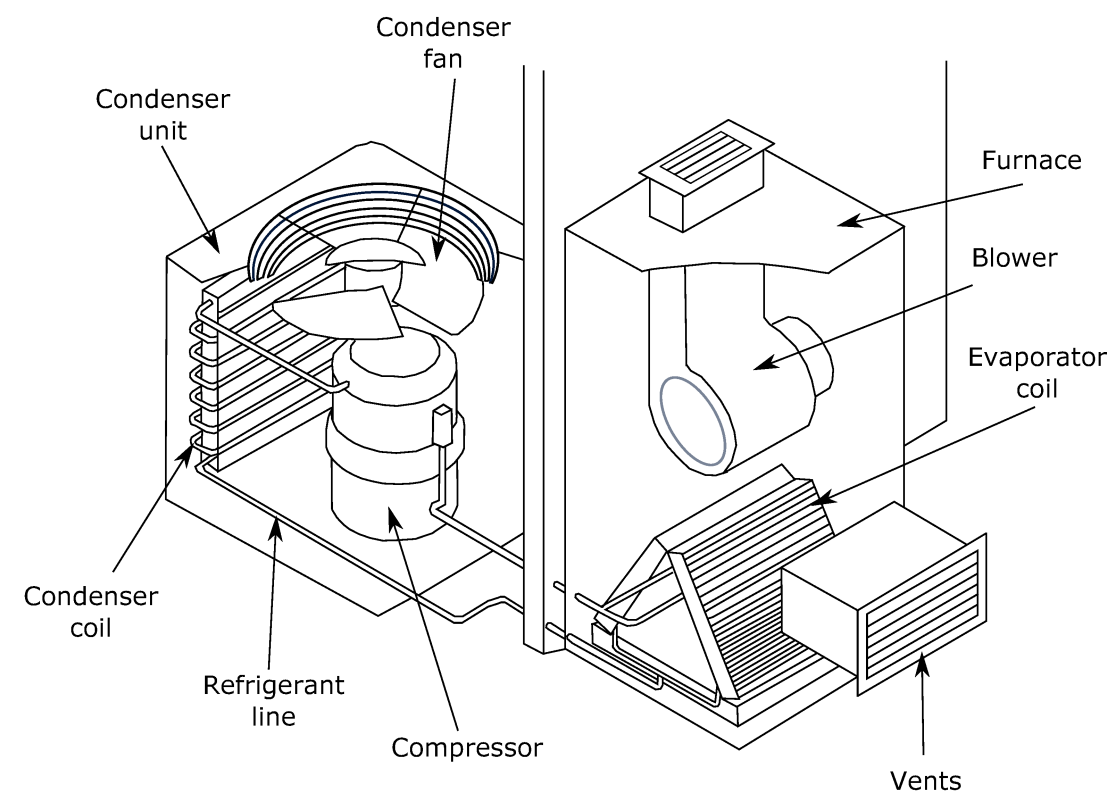

Figure 1.2: Typical central air conditioning system with two main components: the condenser unit and evaporator unit. Adapted from Ref. [3] 
Most central AC systems run on the vapour-compression principle. The refrigerant is compressed and condensed at the condenser unit. Then heat from refrigerant is released outside so that the cooled/liquid refrigerant can be expanded and sent to the evaporator unit. As a thermostat detects a rise of temperature, the air handling unit draws hot air from various parts of the house and pushes it across the evaporator coil where heat exchanging between hot air and cool refrigerant takes place. As a result, air is cooled down and forced back into the house through other ducts. The cycle is repeated until the desired temperature reaches throughout the house. Schematic of a central AC system can be seen in Figure 1.2. A central AC system is proven to be a cost-effective option if ductwork exists in the house. Also, it is more quiet, efficient and convenient to operate and produces better air quality control for an entire house than window types.

\subsection{Statistical Facts on an Air Conditioning Sys- tem}

According to the most recent energy survey conducted by Natural Resources Canada (NRCAN) in 2011, almost $60 \%$ of Canadian households had an air conditioning system although there were distinct variations amongst the Atlantic, Alberta and the remainder parts of Canada, as depicted in Figure 1.3.

Across Canada, for those who had an air conditioner installed, over $30 \%$ had central air. Again, the penetration rate was different amongst regions, notably - the most populated province (Ontario) almost $80 \%$ of more than 4 million households had a central air system, compared to the Atlantic region where approximately only 


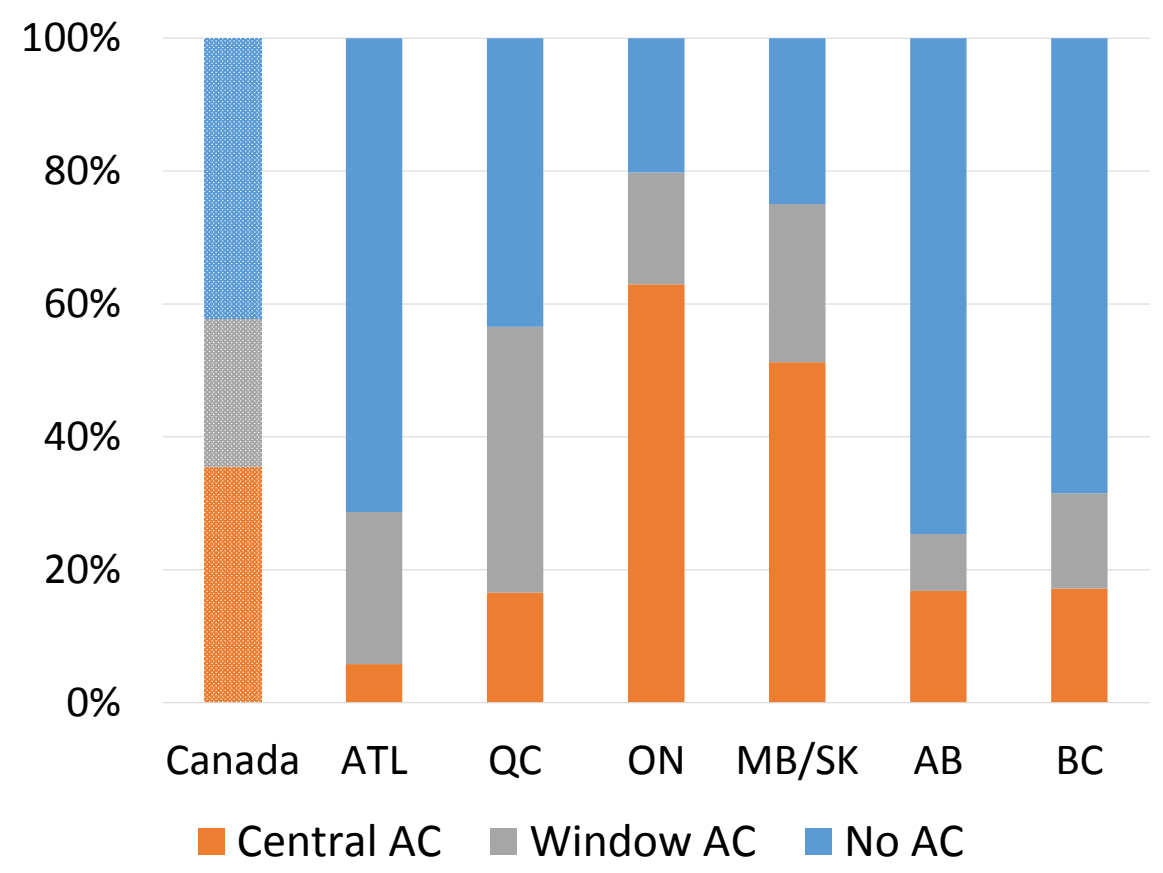

Figure 1.3: Percentage of different air conditioning systems installed within Canada. Reproduced from data provided in Ref. [4]

$20 \%$ of households owned the same system [4]. Moreover, the amount of cooling floor space almost tripled in 2011 compared to in 1990. It means that more Canadians live in larger and air-conditioned homes. Therefore, this resulted in the rising energy consumption of $150 \%$ (from 10 PJ to $25 \mathrm{PJ}$ ) over the same period [5]. The increase in energy consumption would have been more profound if there was no energy efficiency regulations established. According to the NRCAN, on average - an ENERGY STAR certified system uses $8 \%$ less energy than a standard model [6]. This certification requires a central air conditioners' seasonal energy efficiency ratio (SEER) rating of minimum 13.0, where SEER is the cooling output during annual cooling season [Btu], divided by the total electricity consumed by the air conditioning system during the same season [7]. However, only $36 \%$ of central air systems possessed an ENERGY STAR label across Canada. Definitely, there was no other option than to replace old 
systems with more modern units, for those $64 \%$ remaining that were still running inefficiently.

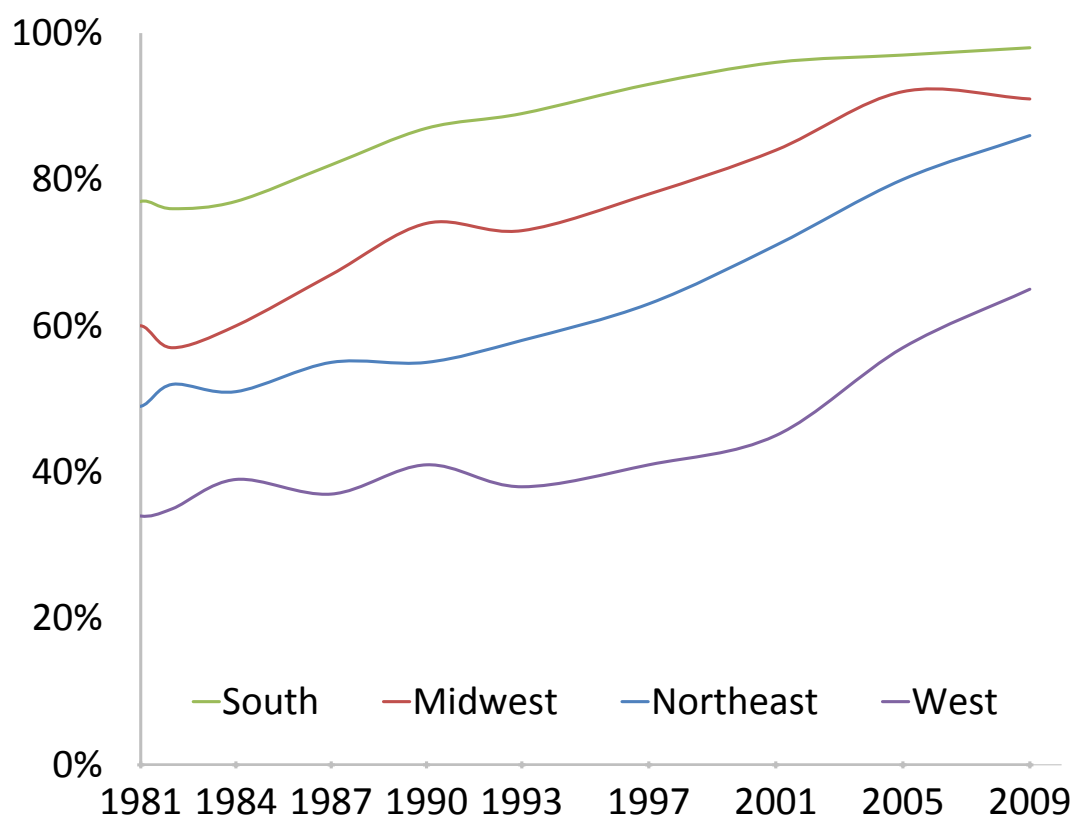

Figure 1.4: Percentage of houses equipped with air conditioning systems across the United States. Source: U.S. Energy Information Administration, 2009 Residential Energy Consumption Survey [2]

In the United States, a steady rise in air conditioner possession in all regions has been observed among all types of housing from 1981 and since 2009 this piece of equipment has become standard in most U.S. homes. As demonstrated in Figure 1.4, the latest survey revealed that on average $87 \%$ of households were equipped with $\mathrm{AC}$ systems, while the southern states have approached $100 \%$ AC coverage.

Of those homes equipped with AC system, Table 1.1 below demonstrates regional difference between various types of $\mathrm{AC}$ system. In particular, central air systems were most commonly used in the Midwest, South and West regions while in the Northeast region, it was more common to see room air conditioners. In addition, housing type and age also drove variation in type of AC systems. As result, some houses had both central and window air conditioners as the total added up to more than $100 \%$. 
Data from Residential Energy Consumption Survey (RECS) also indicated that less efficient cooling alternatives were found in low-income homes.

\begin{tabular}{ccccc} 
& Northeast & Midwest & South & West \\
\hline Central AC & $44 \%$ & $76 \%$ & $85 \%$ & $74 \%$ \\
Window AC & $58 \%$ & $26 \%$ & $16 \%$ & $27 \%$ \\
\hline
\end{tabular}

Table 1.1: Distribution of different air conditioning system across the United States in 2009. Survey performed by EIA.

For a total of 113.6 million housing units across the U.S., in a 2009 RECS survey (excluding electricity consumed by household appliances, electronics device and lighting) air conditioning had consumed 186 billion kWh which surpassed electricity consumption for space heating, water heating, and refrigeration. Again, the Southern region alone consumed 129 billion kWh compared to the rest of the country.

So, for residential end-users, besides installing or replacing air conditioning systems with ENERGY STAR rated ones, what other options are available to reduce energy spending for cooling purposes? The following section will introduce an add-on device that could be a breakthrough in terms of reducing power consumption for the residential as well as commercial cooling industry.

\subsection{VairTEX Air Director}

Industrial air-cooled condensers are normally installed on the rooftops of grocery stores as part of their refrigeration systems, while residential condensers are placed on a concrete slab outside the house. Due to the simplistic design in the commonly used axial fans in these condenser units (a compromise between overall costs, robustness, and performance), the air flow does not help to extract the heat from the condenser coil effectively. In addition, temperature of incoming air to those coils of a condenser 
could be influenced by the heated flow escaping from the condenser outlet due to its exit angles [8]. A study from Khankari also indicated that with an increase in crosswind, the hot plume discharging from the condenser exit bent downward and almost reached the ground in case of higher wind speed [9].

Invented by Gerard Godbout - founder of VairTEX Canada Inc. to address the inefficiencies of commercial, industrial and residential cooling and refrigeration systems, the Air Director (AD) is a passive energy reduction device which can be added to the top of the axial fans of industrial or residential condensers.

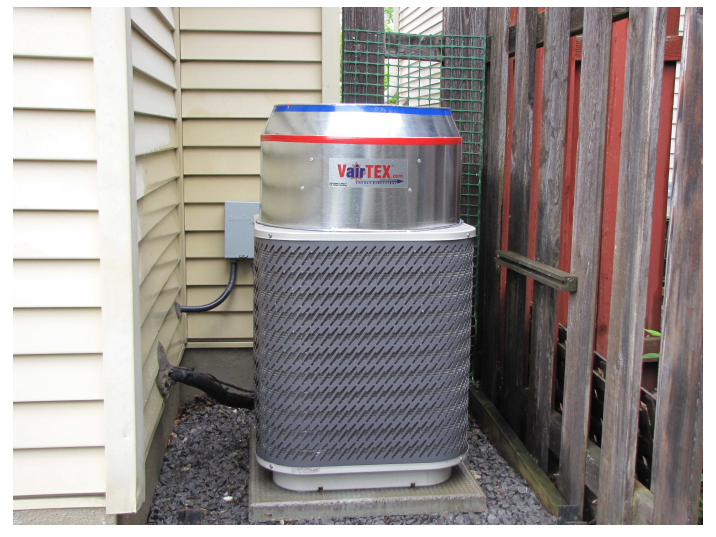

(a)

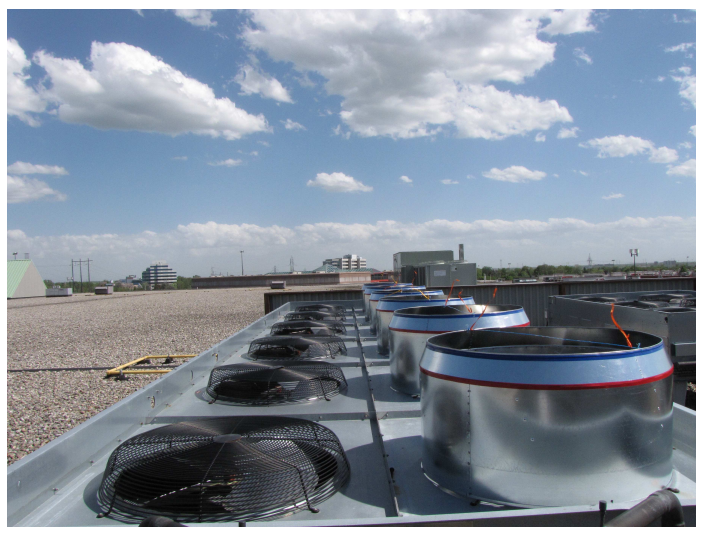

(b)

Figure 1.5: An example of VairTEX Air Director device applied on (a) residential; (b) industrial condenser units

As illustrated in Figure 1.5, VairTEX units were neatly placed on top of residential and industrial condensers. The passive device has cylindrical structure with six fixed blades that redirect the flow upwards with additional swirling and mass flow. Hence, this device helps improve the performance of the AC unit by reducing power consumption of electrical fan motors. According to VairTEX US Patent document [10], the Air Director consists of three main components: 
1. Cylindrical body: is used to direct the air flow exiting the condenser. The tube's diameter has the same dimension as the condenser exit.

2. Fixed blades: a series of six fixed blades is attached to the interior of a tube in order to generate turbulence

3. Top cowling: is designed to reduce diameter of the cylindrical tube, hence accelerates the exit flow. This section is attached to the upper part of a tube.

Depending on existing configuration of condenser fan (i.e. clockwise or counterclockwise rotation), the VairTEX AD blades are configured in counter arrangement. For example, if the condenser fan rotates in a clockwise direction, VairTEX AD blades will be positioned in counter-clockwise direction. Due to variation in condenser sizes, the tube diameter is customized to produce a seamless add-on device.

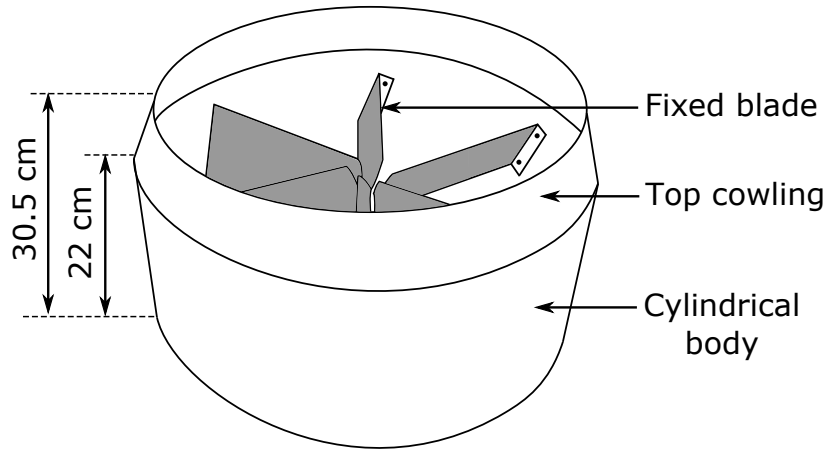

(a)

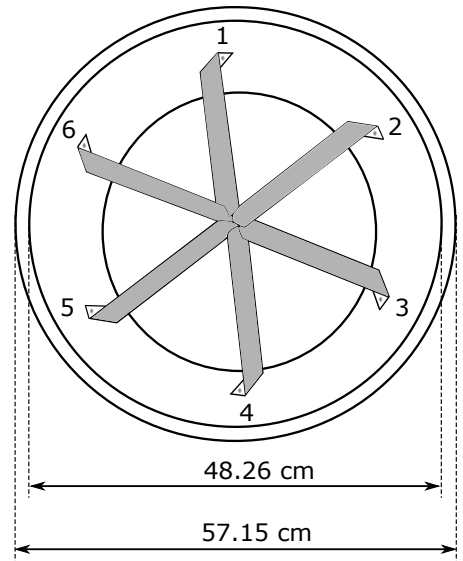

(b)

Figure 1.6: Two views of the VairTEX air director used in this study (a) isometric view; (b) top view

Figure 1.6 illustrates isometric and top views of the residential Air Director units along with its dimensions that will be used in this study. The cowling creates a total 
reduction of $3.5^{\prime \prime}(8.9 \mathrm{~cm})$ from the main body. Six blades with width of $4^{\prime \prime}(10.2 \mathrm{~cm})$ each are fixed at $75^{\circ}$ from horizontal plane. It should be noted that as blades are only jointed in pairs (i.e. 1 and 6,2 and 5, 3 and 4), this leaves 2 small gaps in the centre of the device.

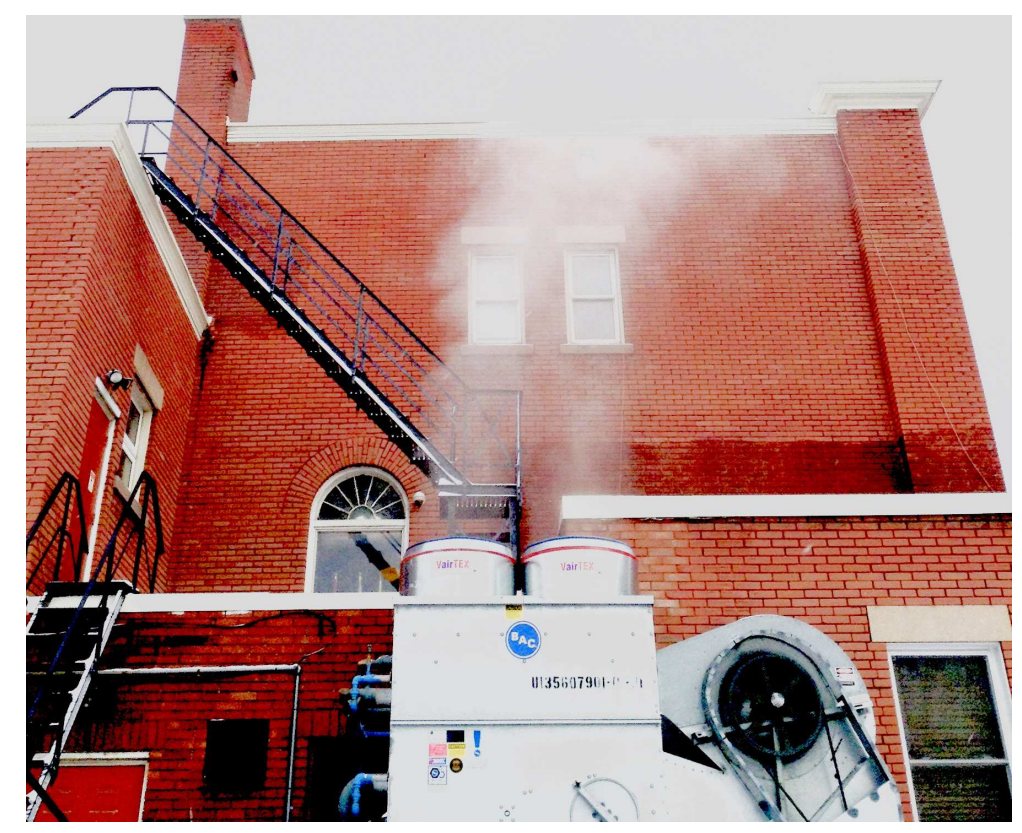

Figure 1.7: Typical VairTEX unit installation

VairTEX has been interacting with several companies and institutions: Sensplex, Loblaws, Startec, National Research Council, Rockcliffe Flying Club, LPTi Inc., Hydro Ottawa, Diflo Mechanical Limited - among others, to test, validate, demonstrate and promote the Air Director. Subsequent testing in an industrial application showed a power reduction in the range of $10 \%$. This was on the four-fan condenser for a 7,500 square feet industrial freezer at a food manufacturer. An independent measurement and verification test was conducted on the $\mathrm{AC}$ for a 30,000 square feet manufacturing facility in Ottawa in the summer of 2016 . The result was a $16.7 \%$ reduction in $\mathrm{kWh}$ on an annual basis. Another test was conducted on the evaporative cooling system of the Ottawa Curling Clubs ice plant in 2017. This test also resulted in energy savings, 
and more importantly the exhaust water vapour was directed up and away from the building, as shown in Figure 1.7. Moreover, VairTEX's business partner in the United State reported an energy reduction in the range of 16-21\% [11].

The VairTEX Air Director is a clean-technology - as it reduces energy consumption of the AC systems, requires no moving parts or maintenance, ease of installation, with seamless integration with the design of existing condensers. Several years of extensive testing on commercial condensers of various sizes and brands have consistently demonstrated the following benefits:

1. Increased air flow hence reduced energy consumption by the condenser

2. Lower head pressure therefore increased thermal exchange

3. Lower ambient intake air temperature by restricted air recirculation at the condenser

4. Protection of the interior components of the condenser from the elements

5. Meeting or exceeding the rated refrigeration capacity with less energy consumption

6. Superior condenser performance in adverse weather conditions (i.e cross wind) 


\subsection{Motivation}

Through their collaboration with several industrial partners, the VairTEX Air Director has proven its effectiveness in air conditioning and refrigeration systems by reducing power consumption. Besides the commercial/industrial market, VairTEX Canada Inc. is also interested (long term) in pursuing residential market in Canada and in the United States. For residential air conditioning systems, there has not been any verification regarding VairTEX device's benefits as well as quantifying the differences when applying the device. To successfully promote VairTEX's product to residential customers, it is crucial to perform a study in order to provide quantitative and qualitative results scientifically. Moreover, statistical surveys on household electricity consumed by air conditioners in Canada and in the United States indicated that hundreds of billions $\mathrm{kWh}$ have been used for cooling purpose. In terms of environmental concerns, $1 \%$ decrease in the amount of electricity would benefit not only the users but also the environment.

The work performed in this thesis was a collaboration between the Department of Mechanical and Aerospace Engineering and VairTEX Canada Inc. to conduct experimental testing of the VairTEX Air Director on residential air conditioning system. Thermodynamic analysis was performed to show the advantages of the Air Director listed above. In addition, the hot-wire six-orientation measurement technique was explored and implemented to yield mean velocities in three directions at the condenser exit. Velocity measurements were used to confirm the air flow increase created by the Air Director. 


\subsection{Structure of Thesis}

This thesis consists of 6 chapters. Chapter 2 provides a literature review on existing add-on devices for cooling/refrigeration systems and also on similar performanceenhancing add-on devices in wind turbines. Chapter 3 introduces the principle of vapour-compression cycle in residential air conditioning system and compares the ideal and actual cycles. The air conditioner experimental set-up and the data reduction procedures are also outlined in Chapter 3. Chapter 4 starts up with the fundamental concept of hot-wire measuring technique, followed by detailing the theory and implementation of the six-orientation hot-wire measurement technique, as well as the temperature correction technique. This chapter also describes the calibration set-up along with the experimental set-up for hot-wire measurements. Next, in

Chapter 5, results and discussions of experimental data are presented, in addition to the uncertainty analysis. Finally, Chapter 6 draws a conclusions on the project and provides some suggestions for future work. 


\section{Chapter 2}

\section{Literature Review and Background}

Air conditioning systems are used to provide living comfort condition for humans in residences. Air conditioning is defined as "the process of treating air in an internal environment to establish and maintain required standards of temperature, humidity, cleanliness, and motion" [12]. Air-cooled condensers in a residential central AC system are widely used due to its cost-effective and satisfactory performance as opposed to a more expensive option, requiring intensive maintenance (water cooling). However, the performance of these condensers is greatly affected by the ambient air temperature surrounding the condenser.

Residential air-cooled condensers are often constructed with copper finned tube to allow heat exchange between the refrigerant and the surrounding environment. Heat is transferred to the attached fins as hot refrigerant passes through the condenser coil. An electrically powered axial fan draws air from outside, across those fins to remove heat from the refrigerant and allows condensation and sub-cooling processes of refrigerant taking place prior to the expansion valve. The majority of residential central AC systems apply the principle of a vapour-compression refrigeration cycle. The cycle coefficient of performance (COP) depends upon various parameters, for example: pressures at sub-cooling and superheating processes, compressor's inlet and 
outlet pressures. In addition, the COP is largely impacted by power demanded from the compressor as this is the major power consumption in the system. As condenser temperature rises, its pressure increases and as a consequence, the compressor requires more work. Moreover, high condenser temperature also reduces cooling capacity of the cycle due to the reduction of liquid content in the evaporator [13]. Hence, high condenser temperatures are not desirable as COP of the system decreases.

\subsection{Improving Air Conditioning Performance}

Several efforts to increase COP focused on improving compressor performance. For example, Kandpal (1978) examined high performance of an air conditioner compressor by the use of low loss steel (better grade of steels) in the motors, capacitor start and run (CSR) design motors, or higher values of run capacitance, improved muffling, or gas handling and valves [14]. Sakuda et al. (2001) introduced a scroll compressor type with new sealing-oil supply mechanism to optimized oil flow rate in order to achieve performance improvement of the compressor [15].

Recently, research attempted to improve AC system performance by investigating shading effect on the condenser. Sonne et al. (2002) conducted experimental study on three homes over a two year period to quantify space cooling energy savings from shading condenser units. However, the most optimistic result demonstrated an improvement of air conditioner efficiency by only 1\% [16]. Furthermore, this study also indicated the potential hazards of localized condenser shading as some shading methods (for example: planting trees and shrubs) may interfere with airflow across the condenser. A study from ElSherbini and Maheshwari (2010) concluded that AC performance efficiency would not exceed a maximum of $1 \%$ suggested that shading method alone, without evapo-transpiration, is not effective to boost $\mathrm{AC}$ performance 
nor reduce electrical demand [17]. Donovan and Butry (2009) estimated a saving of $5.2 \%$ in electricity consumption in summertime when trees were planted on the west and south sides of 460 single-houses in Sacramento, California [18].

Another alternative way to improve residential air conditioning system is to introduce an evaporative condenser. Hoeschele et al. (1998) pointed out that evaporative condensers may become the next generation for residential AC systems as this technology can provide significant operating cost savings in hot and dry climates [19]. Furthermore, Parker et al. (2014) reported an improvement in AC efficiency by 20$30 \%$ by combining high efficiency fan and diffuser stage coupling with an evaporative condenser pre-cooler [20].

Improving air flow across the condenser could help lower power consumption, thus increase the COP of the system. Elsayed and Hariri suggested in their study that a $10 \%$ reduction in compressor power consumption was achieved by increasing the condenser air flow of about 50\% in split-type air conditioners [21]. So the problem can be solved by optimizing the axial-flow fan, a design not changed in decades.

There are three types of axial-flow fans: propeller, tube-axial and vane-axial. Out of these three, the propeller type fans are widely used in both residential and commercial air conditioning systems. They deliver large volume of air with less horsepower than the centrifugal fans but can develop low static pressure problem. As the system resistance increases, the horse-power also increases. This is in contrast to the centrifugal fan in which the horsepower decreases with an increase in the system resistance. Thus a propeller fan used for an air-cooled condenser can draw more electric current when the condenser fins get choked with dust. Also, the air quantity delivery goes down [22]. Overall fan performance is sacrificed by robustness, cost and ease of manufacturing. Clearly, the blade design is one of the problems. Condenser axial fans are commonly made by extruding or stapling aluminium sheets. The number 
of blades varies from two to four, while two common shapes can be found in HVAC company catalogues, as illustrated in Figure 2.1.

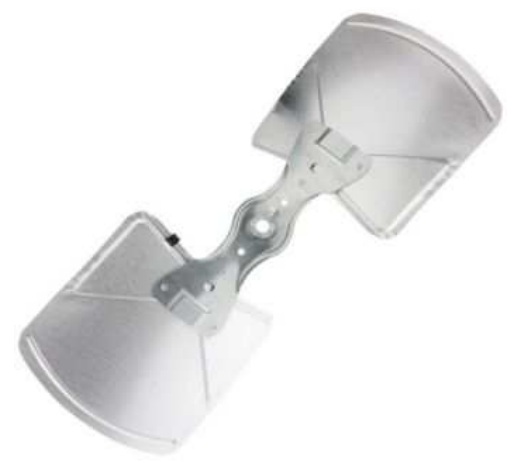

(a)

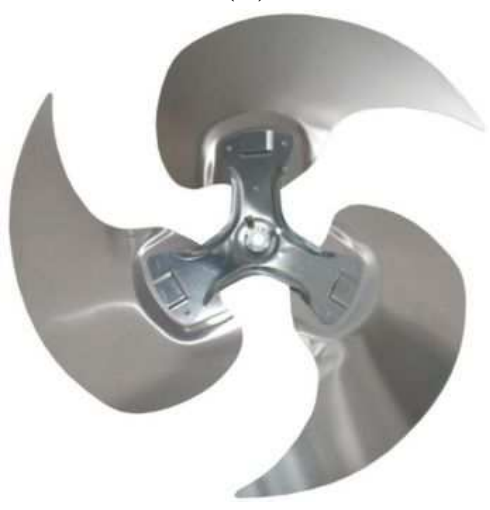

(c)

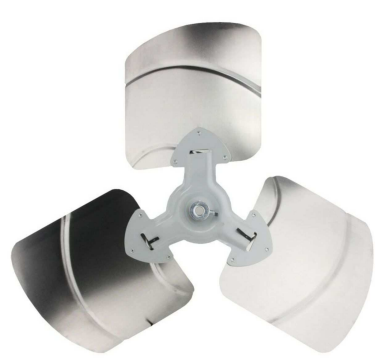

(b)

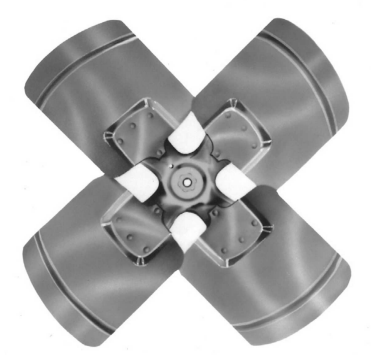

(d)

Figure 2.1: Commonly used residential condenser fan blades (a) Rectangularshape two-blade; (b) Rectangular-shape three-blade; (c) Low-Noise three-blade; (d) Rectangular-shape four-blade [23]

At the Seventh Turbomachinery Symposium in Houston Texas in 1978, Robert C. Monroe presented his paper on 'Improving Cooling Tower Fan System Efficiencies' in which he identified the inefficient air flow from poorly design conventional fan blades. Monroe concluded that increasing air flow would significantly improve the efficiency of the condenser. However, he also claimed that to increase the air flow by $10 \%$ would require an additional 35\% in energy consumption [24]. 
In order to increase air flow across the condenser unit, the condenser fan blade could follow a similar process as in aerospace industry by re-designing and optimizing its shape. However, within the extent of the current literature survey, no full optimization effort for the condenser fan blade design was found in the literature. A different approach was presented by Danny S. Parker et al. (2005) in which true-airfoil flat fan blades were embedded in a conical diffuser [25]. Unlike a conventional condenser, where whole fan assembly (blades and motor) was surrounded by condenser coils, the new design fan assembly was covered by a conical diffuser housing situated on top of those coils. Figure 2.2 shows the design schematic of the enhanced fan system.

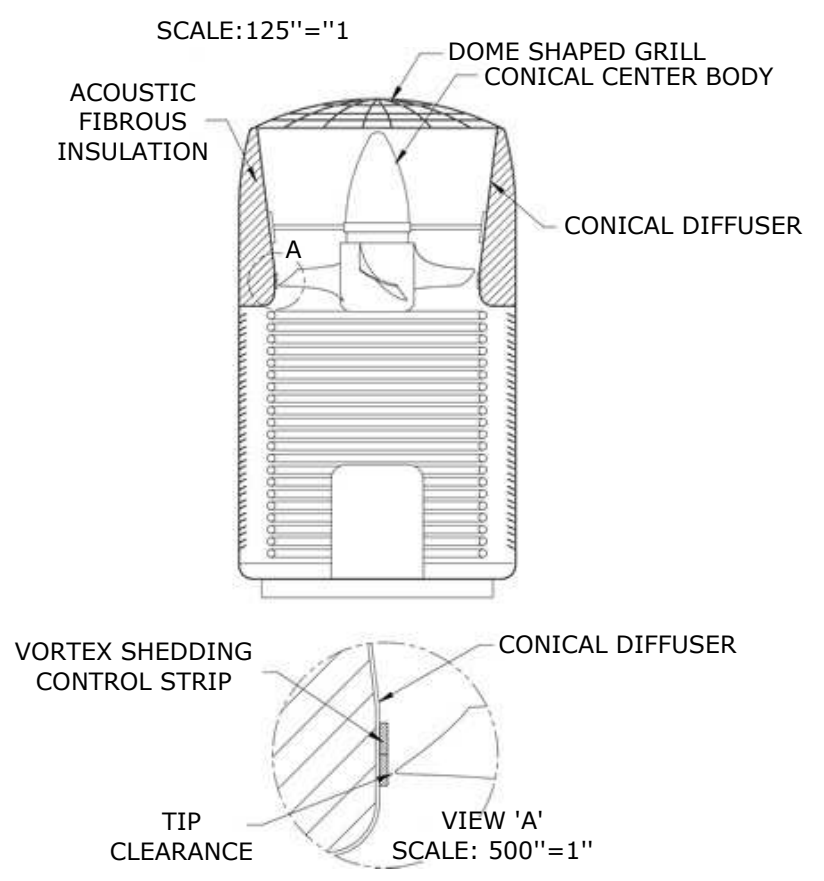

Figure 2.2: Schematic of Parker's development on high efficiency air conditioner condenser fan system

In Parker's study, his objective was to create the most efficient design with robust characteristics and provide good performance over a range of static pressure while reducing fan noise at the same time. A total of five designs were developed based on blade shapes and blade numbers (ranging from 3 to 5 blades) where each design 
was consisted with different sub-variations. The most striking design - coded as fan A5 was composed of 5 asymmetrical blades (centred unevenly around the rotating motor hub) which followed the technology explored to reduce noise level for helicopter rotors in 1999 by Kernstock [26]. As sound rushed through uneven spacings between blades, resonance frequency was reduced and hence a lower ambient sound level was produced from the condenser unit. Over one hundred tests for all fan designs were conducted at 850 RPM and 1075 RPM.

Based on the relationship between high efficiency propeller design and its housing, Parker's diffuser was extended to a length of $18^{\prime \prime}(46 \mathrm{~cm})$ to provide an additional $25 \%$ pressure recovery while divergent angle had a value of $7^{\circ}$. The diffuser increased its diameter from $19.75^{\prime \prime}(50 \mathrm{~cm})$ to $24^{\prime \prime}(61 \mathrm{~cm})$ at the grill top providing both aesthetic appearance and sizing acceptance from consumers. The motor and fan blades were located at the bottom of the assembly. Through trial and error, the design was refined to a smooth conical centre body to increase air flow across the fan blade and thus reduce power consumption.

Parker's research can be summarized into two main parts. First, for the conventional condenser's motor and body, a new twisted and tapered propeller air foils demonstrated greater air moving efficiency, which defined as the ratio between air flow rate $\left[\mathrm{ft}^{3} / \mathrm{min}\right]$ over power consumption $[\mathrm{W}]$, while saving $21 \%$ of power consumption. Secondly, the study also revealed that by inserting an elongated conical diffuser after the fan motor, air moving efficiency $\left[\mathrm{ft}^{3} / \mathrm{minW}\right.$ ] was improved by over $16 \%$ for standard Original Equipment Manufacturer (OEM) fans and over 27\% for high performance fans designed in Parker's project. Through the use of porous foam strip, air flow performance increased while helping to reduce noise level. Moreover, when equipped with an enhanced diffuser, fan A5 allowed an increase in air moving efficiency of $46 \%$ or equivalent to a $5 \%$ addition in air flow $\left[\mathrm{ft}^{3} / \mathrm{min}\right]$, and also reduced 
power consumption by $26 \%$. Parker also reported an overall increase on Energy Efficiency Ratio (EER) and COP of approximately 2 - $4 \%$, depending on configuration.

Iwase et al. (2016) pointed out that high efficiency AC performance of an outdoor unit could be achieved by improving the heat exchanger shape, bell mouth as well as increasing the number of fans. Figure 2.3 illustrates old type outdoor unit (on the left) as opposed to new development unit (on the right).

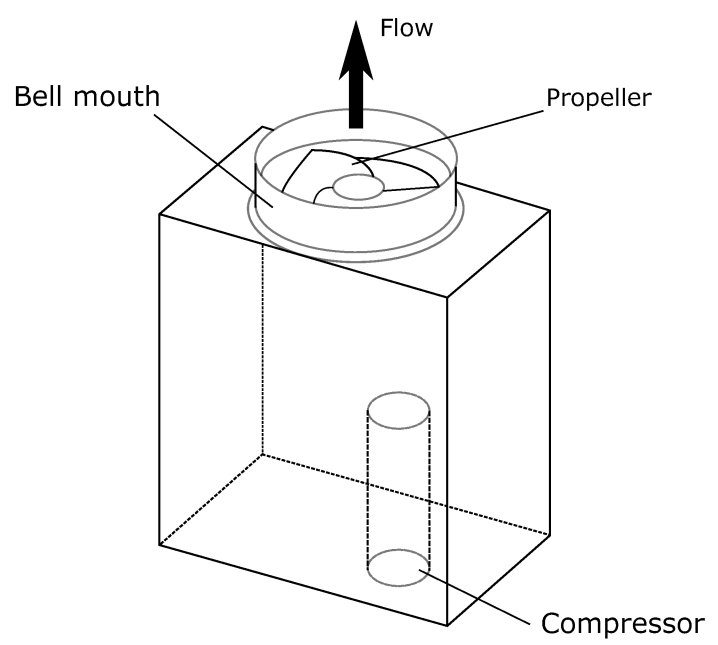

(a)

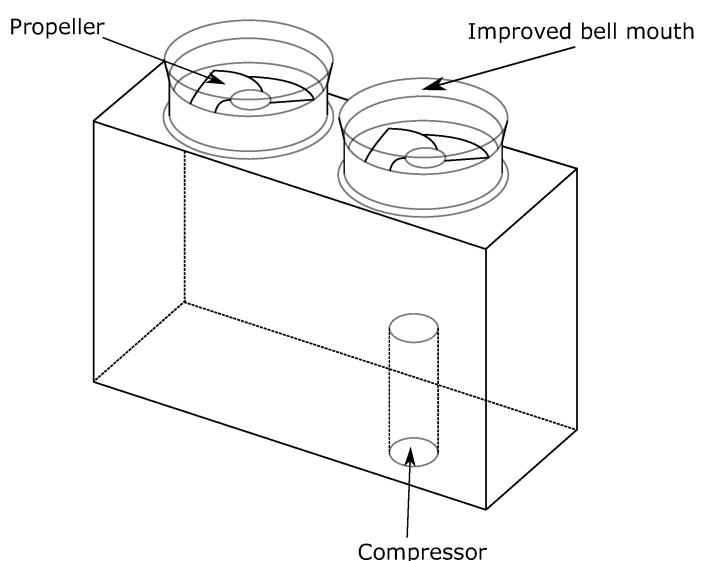

(b)

Figure 2.3: Model of outdoor air conditioner unit where (a) Old type outdoor unit; (b) Optimized unit with double fan, extended bell mouth and sigma shaped heat exchanger. Reproduced from Ref. [27]

Within this study, the fan propeller shape was optimized independently from other components of the outdoor unit. Iwase proposed a new design with a combination of two-fan system, sigma shape heat exchanger and long bell mouth to improve system performance. First, the increase in the number of fans not only helped decrease outlet loss as the propeller outlet increases, but also decreased inner loss by changing the high efficiency operating flow rate. Secondly, the improvement of bell mouth reduced greatly outlet loss by uniforming velocity distribution at propeller outlet. 
Lastly, with sigma-shaped, pressure loss from heat exchanger was minimized. By using ANSYS ICEM computational fluid dynamics (CFD) software, Iwase employed an incompressible Reynolds-averaged Navier-Stokes (RANS) model and a total components simulation, flow rate and fan shaft power were predicted. Iwase confirmed that new development fan systems cut back fan power by $50 \%$ [27].

Formed in 2003 by the merging of three companies in Germany, ebm-papst Group is currently the world's leading manufacturer of electric motors and fans serving diverse industries such as HVAC, household appliances, IT/telecommunications applications, and automotive and commercial vehicle engineering. Among those products, the company also focuses on developing and implementing energy-saving centrifugal and axial fans systems where a passive device of height $18 \mathrm{~cm}$ - called AxiTop Diffuser is applied on top of axial fan exhaust [28].

Ebm-papst claims that the retrofit diffuser device minimizes discharge losses by converting dynamic airflow energy into static pressure. Thus, this pressure-boosting device creates a substantial improvement in efficiency as well as reduced operating noise. With an assistance from the AxiTop diffuser, an axial fan system could save $27 \%$ on energy consumption with unchanged airflow at the same time dropping 7.2 $\mathrm{dB}(\mathrm{A})$ in acoustic pressure. Moreover, the device also increased air volume flow $\left[\mathrm{m}^{3} / \mathrm{h}\right]$ by $9 \%$. However, currently the Axitop Diffuser is only available for commercial axial fan system of size $800 \mathrm{~mm}$ and $910 \mathrm{~mm}$ [28].

\subsection{Applications with Add-on Shrouded Type De- vice}

A significant increase in research for wind turbine has been seen over the past 30 years where maximizing power output has always been a top target. The idea of enclosing 
the wind turbine inside a specially designed shroud has been suggested in numerous papers and research [29]. A shrouded wind turbine, also called wind lens, is a new type of wind power system where a simple ring structure encloses the rotor, causing greater wind to pass through the turbine. As a consequence, the turbine's efficiency of capturing energy from the wind gets dramatically increased. Wind lens appear in different shape which resulted in several configurations, for example: straight diffuser, nozzle-diffuser combination, brimmed diffuser augmented and nozzle augmented wind turbine. By increasing the mass flow, a wind turbine with a brimmed diffuser has demonstrated 2 - 5 times additional power extraction from a bare wind turbine, given the same rotor diameter and incoming wind speed [30,31].

Kosasih et al. (2012) reported an experimental comparison on different diffuser augmented horizontal axis micro wind turbine type. His study revealed that straight diffuser enhanced performance by $56 \%$ compared to a bare wind turbine while the nozzle-diffuser improved performance by $61 \%$ - slightly better than diffuser only [32].

For nozzle augmented type wind turbine, Balaji et al. (2014) confirmed a greater power output (of approximately 40\%) by nozzle augmented wind turbine as opposed to a bare horizontal axis wind turbine [33]. In addition, study from Pambudi et.al (2017) confirmed nozzle lenses successfully increase the efficiency of wind turbines where wind was insufficient to drive turbine blades [34].

Through several examples found in literature and despite variation in shapes and configurations of shrouded structure around the wind turbines, their performance were proven to be greatly improved as opposed to a bare conventional wind turbine.

Passive (add-on) devices have proven to improve performance of not only AC systems but also for wind turbines. Therefore, the effectiveness of the AD is promising and will be evaluated on residential AC system, located in the Thermodynamic Laboratory at Carleton University. Two main performance parameters: refrigeration 
capacity and coefficient of performance will be investigated. 


\section{Chapter 3}

\section{Air Conditioning Performance with The Add-on VairTEX Air Director}

\subsection{Principle of Vapour-Compression Air Condi- tioning Systems}

Vapour-compression cycle is no doubt the most commonly used method which has been widely applied for both residential and commercial cooling purposes, for example: refrigerators, freezers, air conditioners, hockey rinks, etc. In 1920s, a large number of refrigerants used in the vapour-compression cycle was compounds of ammonia and sulphur dioxide. These compounds however, were toxic and flammable. Subsequently, they were replaced by halogenated paraffin hydrocarbons refrigerants, also called chlorofluorocarbons (CFCs). These CFCs were marketed under trade names

such as Freon ${ }^{\circledR}\left(\right.$ R-12) and Genetron ${ }^{\circledR}$ (R-22) [35]. CFC-based refrigerants were discovered to cause ozone depletion in the stratosphere by professor F. Rowland and his post-doctoral fellow M. Molina [36]. Due to this reason, CFC refrigerants were substituted by hydrofluorocarbons (HCFs), which include R-134a, R-407C or R-410A. Schematic diagram of a basic vapour-compression cycle is illustrated in Figure 3.1, 
followed by the details of its operation which can be described in 4 processes.

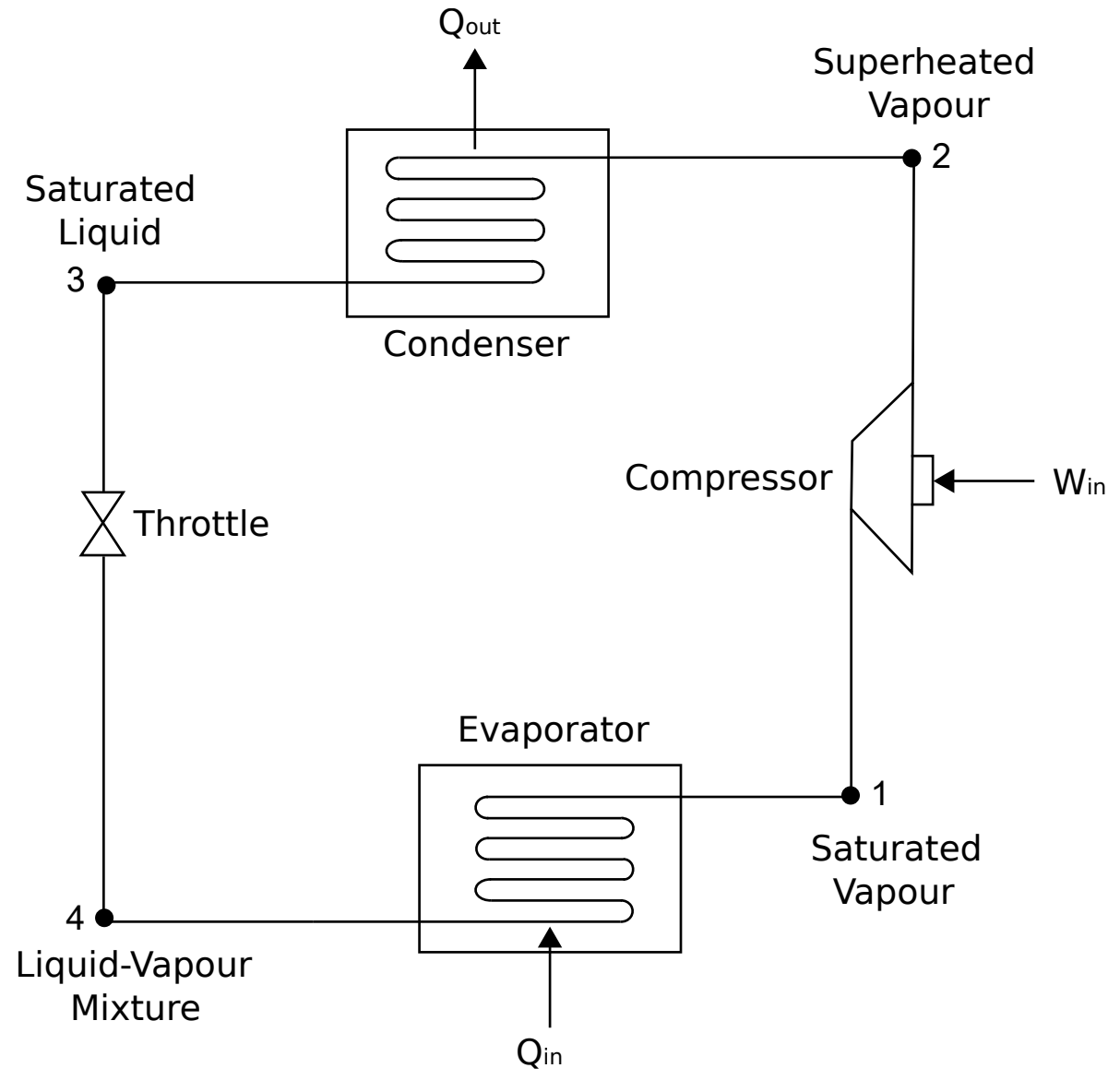

Figure 3.1: Schematic diagram of a basic ideal vapour-compression cycle in which it consists of four components: compressor, condenser, throttle and evaporator

1. Compression (state 1 - state 2 ): The refrigerant in saturated vapour form enters the compressor at low pressure, low temperature. Here, the compression process takes place to raise the pressure and temperature of the refrigerant. At this point, the refrigerant is hotter than the surrounding environment and leaves the compressor to enter the condenser as superheated vapour.

2. Condensation (state 2 - state 3 ): The condenser fan draws air from the surrounding environment to flow across the condenser coil. The heat is transferred from the refrigerant to air at constant pressure. Hence, the temperature of the 
refrigerant is reduced to its saturation point and changed to its saturated liquid phase.

3. Throttling and expansion (state 3 - state 4): The refrigerant then enters the throttling valve which expands and releases its pressure. As a result, the refrigerant becomes a liquid-vapour mixture at low temperature.

4. Evaporation (state 4 - state 1): The cooling effect takes place at the evaporator as refrigerant passes through the evaporator coil and causes a heat exchange between room warm air, drawn in by an evaporator fan, and cold refrigerant. The air is cooled and is distributed back to the room while the refrigerant undergoes a phase change to become saturated vapour and enters the compressor to repeat the cycle.

The performance of the vapour-compression refrigeration cycle can be further investigated on a T-s diagram, as shown in Figure 3.2 where yellow and green loops represent ideal and actual cycle, respectively. It can be seen that several features of the actual cycle depart from the ideal cycle. The heat transfer between the refrigerant and the warm and cold regions are not accomplished reversibly. Specifically, the refrigerant temperature in the condenser is greater than the warm region temperature $T_{H}$ in the ideal cycle, while on the other hand, the refrigeration temperature in the evaporator is less than the cold region temperature $T_{C}$ in the ideal cycle. As a result, the coefficient of performance (COP) decreases as the average temperature of the refrigerant in the evaporator decreases and as the average temperature of the refrigerant in the condenser increases [37].

For the actual cycle, the dashed line in Figure 3.2 suggests an isentropic process where specific entropic remains constant during the entire compression stage. However the actual cycle experiences an adiabatic irreversible process which increases the 


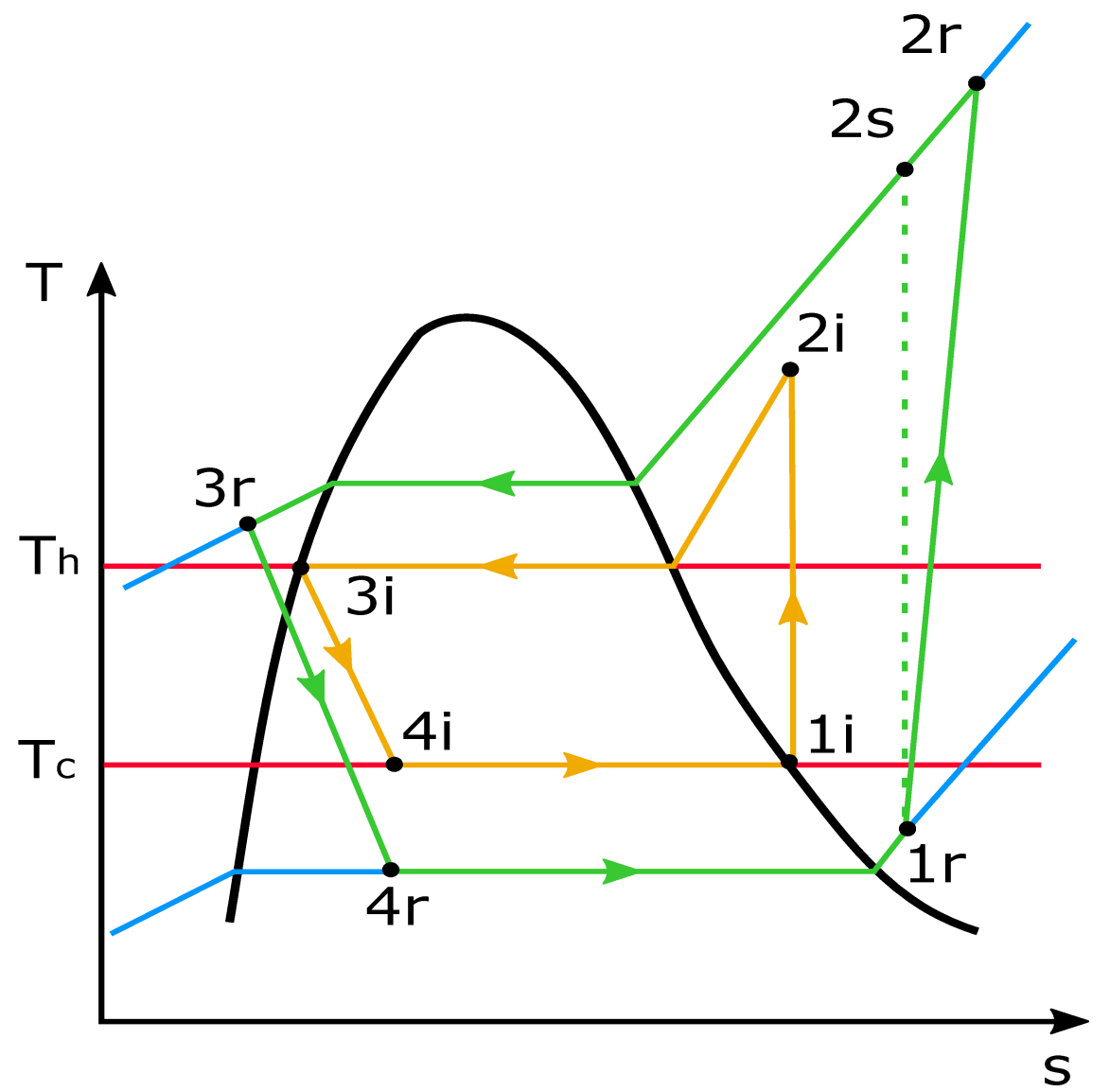

Figure 3.2: Typical T-s digram for actual and ideal vapour-compression refrigeration cycle where subscript i, r and s stand for ideal cycle, actual cycle, and isentropic stage respectively. Blue lines represent isobaric process while red lines illustrate isothermal process

specific entropy. Comparing between the isentropic and irreversible processes, the refrigeration capacity would be the same for both cases. However, the compressor work input would be greater in the case of irreversible compression, hence reducing the cycle's efficiency.

Moreover, the refrigerant condition at the evaporator exit of the ideal cycle changes from saturated vapour to a superheated vapour condition in the actual cycle. Also at the condenser exit, the refrigerant could be at a subcooling condition in actual cycle instead of a saturated liquid condition in an ideal cycle. 


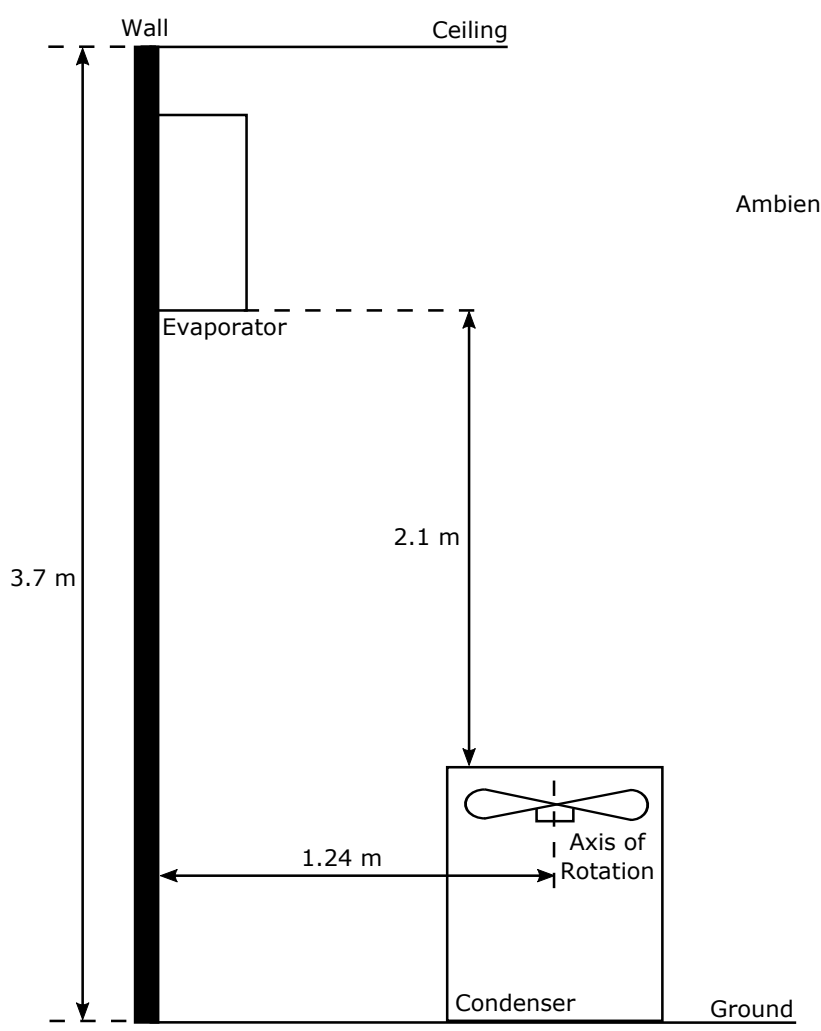

Side View

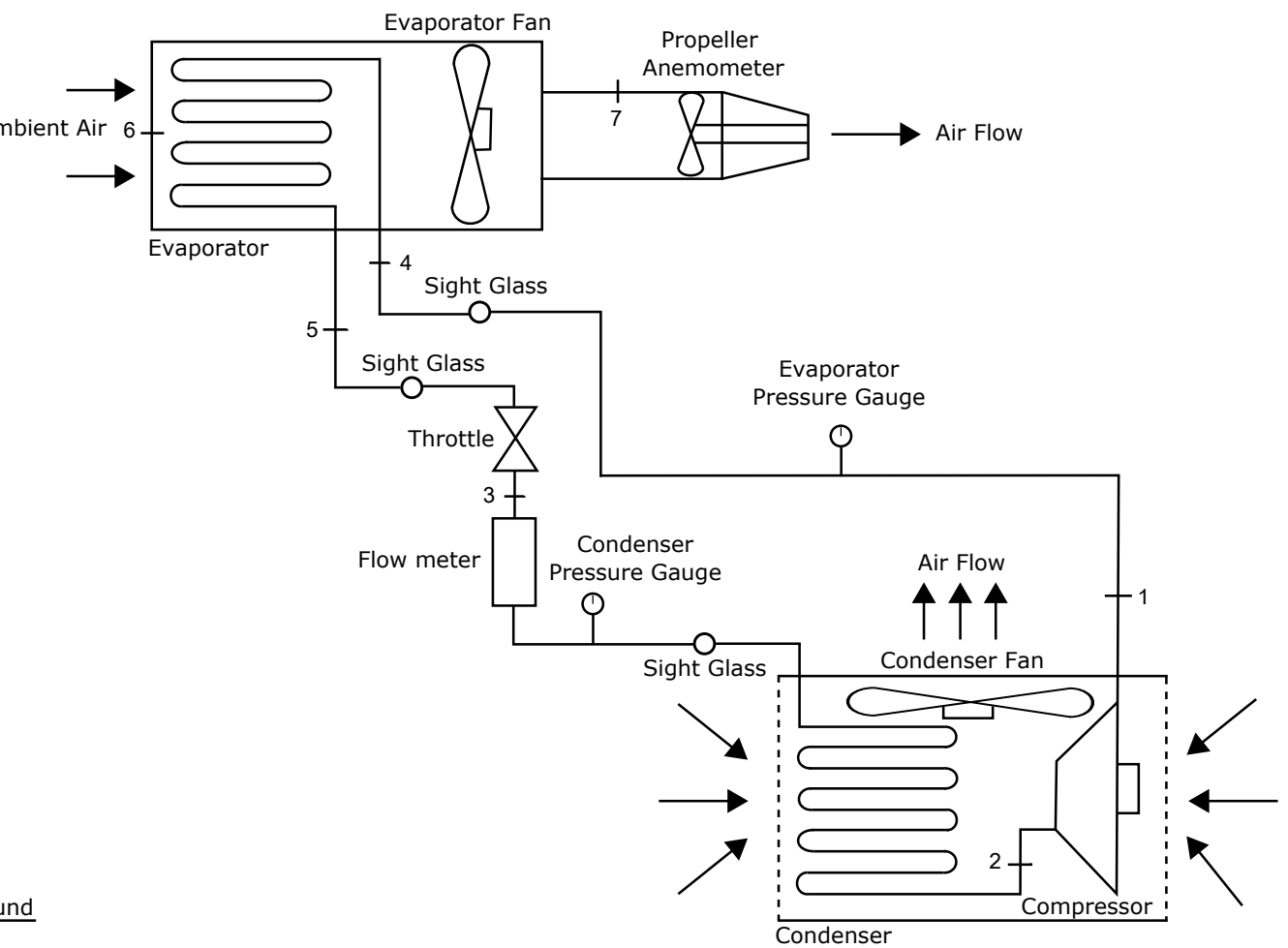

Front View

Figure 3.3: Carrier air conditioning system and instrumentation - Adapted from MAAE2400 Lab Manual 


\subsection{Experimental Set-up}

A typical residential Carrier air conditioner, which is installed in room ME 2230 (Thermodynamics Laboratory), is equipped with temperature, pressure and power measurement instruments. The vapour-compression refrigeration cycle in this system uses R-22 as the refrigerant. The air conditioner consists of two main units: evaporator and condenser units. The evaporator coil and evaporator fan make up the evaporator unit while the condenser unit comprises of a compressor, condenser coil and the condenser fan. Being attached to the wall, the evaporator unit is installed above the condenser unit. The condenser, on the other hand, is mounted on the floor where its fan centre of rotation is $1.24 \mathrm{~m}$ away from that wall. Also there is an open perimeter around both evaporator and condenser units. Schematic of the set-up is illustrated in Figure 3.3. The data collected from these instruments are used in the performance analysis for two study cases: with and without the VairTEX Air Director. The description for each instrument and component in this set-up are described in the following section.

\subsubsection{Evaporator unit}

The evaporator fan forces air to pass through rifled copper tubes which contains the refrigerant. It has three operational speeds which can be controlled through a switch located at the control panel. The corresponding power consumption by the fan is listed in Table 3.1. Despite three speed settings available, preliminary study indicated that evaporator fan speed did not change COP value of the system between two study cases: with and without the AD. Hence, experiments performed on the AC system with and without AD used the 'low' setting for evaporator fan speed. 


\begin{tabular}{|c|c|}
\hline Fan Setting & Power Consumption $[\mathrm{kW}]$ \\
\hline Low & 0.26 \\
\hline Medium & 0.30 \\
\hline High & 0.36 \\
\hline
\end{tabular}

Table 3.1: Power consumption for different evaporator fan speeds [38]

\subsubsection{Condenser unit}

The condenser copper coil is surrounded by aluminium fins in order to increase surface area, hence to enhance heat transfer between air and refrigerant. Air flow through the condenser unit is driven by a General Electric motor. The specifications of the motor are shown in the table below.

\begin{tabular}{|c|c|}
\hline Air Flow $[\mathrm{CFM}]$ & 1900 \\
\hline Horse Power $[\mathrm{HP}]$ & $1 / 12$ \\
\hline Voltage $[\mathrm{V}]$ & $208-230$ \\
\hline Amperage $[\mathrm{A}]$ & 0.50 \\
\hline Rotation $[\mathrm{RPM}]$ & 1100 \\
\hline Phase & 1 \\
\hline Frequency $[\mathrm{Hz}]$ & 60 \\
\hline
\end{tabular}

Table 3.2: Condenser fan specification

The compressor is a hermetic-scroll type which operates at $3450 \mathrm{rev} / \mathrm{min}$. It is equipped with an internal temperature-sensitive and current-sensitive overload sensor. A Wavetek DM7 power meter is calibrated in V-DC scale to measure power consumed by the compressor in $\mathrm{kW}$. The accuracy of the power meter is $0.8 \%$ on DC Voltage setting [39]. 


\subsubsection{Throttle}

The throttle is a stainless steel metering valve with an $8^{\circ}$ stem point and $0.125^{\prime \prime}$ orifice. To prevent complete shut off, a spacer is installed in the valve.

\subsubsection{Refrigerant flow meter}

A V-groove flow meter type, from Kobold Intruments Inc., was used to adjust refrigerant flow rate. The meter's range is from $0.1-0.7 \mathrm{gal} / \mathrm{min}(0.38-2.65 \mathrm{~L} / \mathrm{min})$ with an accuracy of approximately $\pm 4 \%$ of the full scale.

\subsubsection{Pressure gauges}

Two Ashcroft 2071A Contractor pressure gauges (range from vacuum - 600 psi) were used to measure pressures of the refrigerant after the condenser and after the evaporator. The accuracy for the range of measurement in this experiment is $2 \%$ of span [40].

\subsubsection{Thermocouples}

Both the refrigerant and air temperatures at measurement points indicated in Figure 3.3 were measured using J-type thermocouples. Measurements number 1 to 5 indicate refrigerant temperatures while measurement 6 and 7 are for air temperatures.

\subsubsection{Propeller anemometer}

In order to measure velocity of the air flow through the evaporator, hence to calculate the mass flow rate, a fast-response gill propeller anemometer was installed at the exit duct after the evaporator. The propeller has a diameter of $0.2 \mathrm{~m}$ and a pitch (air passage per revolution) of $0.294 \mathrm{~m}$, or equivalent to $0.294 \mathrm{~m} / \mathrm{s}$ per rev/s. The 
rotational speed of the propeller is proportional to the frequency response of a photochopper transducer which reads by the frequency counter in $\mathrm{Hz}$.

\subsection{Experimental Procedure}

First, the atmospheric pressure was monitored before and after each trial. It was noted that values of 13 necessary variables recorded from the AC system stabilized after 20 minutes. As a caution, the AC system was let to run for 40 minutes before any recording action was taken place. In order to evaluate the performance of the AC system with and without VairTEX AD, data were recorded every 5-minute intervals for 40 minutes. This interval allowed sufficient time to log data for all 13 variables.

\begin{tabular}{|c|c|}
\hline Measurement & Variable \\
\hline Refrigerant temperature & $\mathrm{T} 1, \mathrm{~T} 2, \mathrm{~T} 3, \mathrm{~T} 4, \mathrm{~T} 5$ \\
\hline Air temperature & $\mathrm{T} 6, \mathrm{~T} 7$ \\
\hline Pressure & Condenser: $P_{\text {cond }}$, Evaporator: $P_{\text {evap }}$ \\
\hline Propeller frequency & $\dot{\omega}$ \\
\hline Refrigerant flow rate & $\dot{V}_{H_{2} O}$ \\
\hline Compressor power & $W_{i n}$ \\
\hline Condenser fan amperage & $I_{f a n}$ \\
\hline
\end{tabular}

Table 3.3: Summary table for variables collected during AC experiment

Each trial set included a test with and without the AD which was performed in one day to ensure the test environment remained constant. The experiment without the $\mathrm{AD}$ was performed in the morning with a total time of approximately 80 minutes (40 minutes stabilizing period and 40 minutes for data recording). The AC system was then let to rest for three hours before the experiment with AD was tested. This 
resting period ensured that the same refrigerant temperature and conditions applied with the AD experiment. Three trial sets were conducted on three different days for two study cases. The following procedures were implemented for both study cases: with and without the AD.

- Main power was turned on. Evaporator fan speed was switched to 'Low'.

- After 2 minutes, adjusted the throttle to obtain desired refrigerant flow meter reading (i.e $0.25 \mathrm{gal} / \mathrm{min}(0.95 \mathrm{~L} / \mathrm{min})$ or $0.35 \mathrm{gal} / \mathrm{min}(1.32 \mathrm{~L} / \mathrm{min}))$. The flow meter should be monitored constantly throughout the steady state running period.

- The multimeter, thermocouple meter and frequency counter were all turned on.

- The system was allowed to run for 40 minutes to reach steady state before data was taken.

- Data of 13 variables (see Table 3.3) were recorded in sequence every 5 minutes for 40 minutes.

For each study case, a total of 24 data points taken was output in a .txt file before feeding into MATLAB script to evaluate performance of the AC system.

\subsection{Data Reduction}

Enthalpy calculations represented a time-consuming process which sometimes required double-integration. A MATLAB script was written first to resolve enthalpy values at each measuring location. Secondly, the script was used to perform calculation following the data reduction methodology, specifically refrigeration capacity and COP for each trial. 


\subsubsection{Assumption}

Measuring locations are labelled in Figure 3.3. By applying the first law of thermodynamics, refrigeration capacity and COP are examined in order to compare the system performance between operating with and without the VairTEX AD. A few assumptions are made in order to make calculations possible:

1. A control volume at steady state is applied for each component in the cycle.

2. No heat transfer in connecting pipe lines since all pipes in this system were well-insulated.

3. Neglect kinetic and potential energy changes across each component.

4. Neglect pressure drops through the condenser and evaporator. Hence

$$
P_{1}=P_{4}=P_{5}=P_{\text {evaporator }}
$$

and

$$
P_{2}=P_{3}=P_{\text {condenser }}
$$

5. Enthalpy remains constant across the throttle or

$$
h_{3}=h_{5}
$$

\subsubsection{Enthalpy}

Temperature and pressure measurements were used to find corresponding enthalpy at each location, based on refrigerant R-22 and air properties provided in Table A7 and Table A22 [37]. 


\subsubsection{Refrigeration flow rate}

The flow meter provides readings on water scale, therefore, the conversion to volumetric flow rate of refrigerant is established in the formula below

$$
\dot{V}_{R 22}=\left[\left(1.56 \cdot 10^{3}\right) \cdot v_{R 22}-0.556\right]^{\frac{1}{2}} \cdot\left[\dot{V}_{H_{2} O}\right] \cdot\left[6.31 \cdot 10^{-5}\right]
$$

where $\dot{V}_{R 22}$ is refrigerant volumetric flow rate $\left[\mathrm{m}^{3} / \mathrm{s}\right] \cdot \dot{V}_{\mathrm{H}_{2} \mathrm{O}}$ is reading from flow meter [gal $/ \mathrm{min}] . v_{R 22}$ is the specific volume $\left[\mathrm{m}^{3} / \mathrm{kg}\right]$ of the refrigerant which is evaluated based on temperature and pressure measured at location 3 in Figure 3.3. Hence, the mass flow rate of the refrigerant $\dot{m}_{R 22}[\mathrm{~kg} / \mathrm{s}]$ can be determined by applying the following formula:

$$
\dot{m}_{R 22}=\frac{\dot{V}_{R 22}}{v_{R 22}}
$$

\subsubsection{Air flow rate}

Based on the frequency recorded from the propeller, velocity of the air stream can be determined by the following equation

$$
V_{\text {air }}=0.294 \cdot \dot{\omega}
$$

where $\dot{\omega}$ is the rotational speed $[\mathrm{rev} / \mathrm{s}]$ of the propeller.

Then the air mass flow rate at the evaporator exit can be calculated using the expression below

$$
\dot{m}_{\text {air }}=\frac{V_{\text {air }} \cdot A_{\text {anemometer }}}{v_{6}}
$$

where $A_{\text {anemometer }}$ is the cross-sectional area of the anemometer and $v_{6}$ is the specific 
volume of air at the propeller anemometer.

\subsubsection{Refrigeration capacity}

First, as shown in Figure 3.4, a control volume is drawn around the evaporator coil. The refrigeration capacity, denoted as $Q_{i n}$, is calculated as

$$
\dot{Q}_{i n}=\dot{m}_{R 22}\left(h_{4}-h_{5}\right)
$$

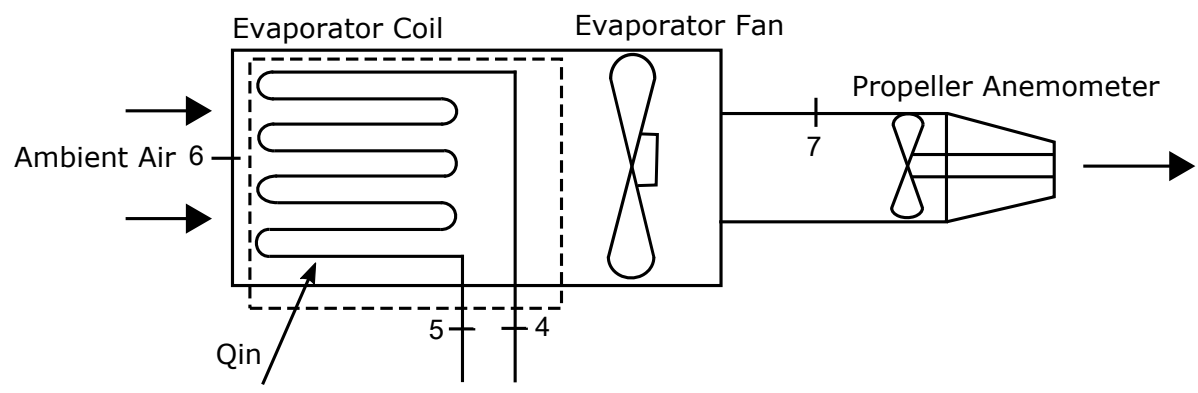

Figure 3.4: Schematic of an evaporator unit where the dash line represents a control volume around the evaporator coil

\subsubsection{Coefficient of performance}

The COP is defined as the ratio between cooling effect over the total power input, hence

$$
C O P=\frac{\dot{m}_{R 22}\left(h_{4}-h_{5}\right)}{\dot{W}_{\text {input }}}
$$

\subsubsection{Energy efficiency ratio}

In this study, the condenser was placed indoor, where temperature was kept around $20^{\circ} \mathrm{C}$ for all measurements. The recorded data does not reflect the influence of outside temperature on the performance of the condenser in particular and the system in 
general, in evaluating seasonal energy efficiency ratio (SEER) value. Therefore, only the energy efficiency ratio (EER) is considered in this study and can be calculated by the ratio between cooling capacity [Btu] over total power input [W], as followed

$$
E E R=\frac{\dot{Q}_{\text {in }} * 12000}{\dot{W}_{\text {input }} * 1000}
$$




\section{Chapter 4}

\section{Hot-wire Six-Orientation Measurement Technique}

Initially particle image velocimetry (PIV) technique was used as a tool to measure velocity at the condenser exhaust. PIV is a non-intrusive method which produces twodimensional or even three-dimensional vector fields. However, due to an unforeseeable technical problem, the PIV system broke down. The available fund for this project could not afford a replacement of a similar system. Therefore, other options had to be explored for velocity measurement. With the availability of hot-wire anemometer (HWA), it became an alternative method despite a disadvantage as this technique gives velocity at a single point. Measurements from the HWA are going to be used to explain the thermodynamic performance differences of an AC system between two study cases: with and without the VairTEX AD.

Hot-wire anemometers have been used since the late 1800s when experimentalists in fluid mechanics first built their own constant current anemometers [41]. As early as 1909, Riabouchinsky, and group of Kennelly, Wright and Van Bylevelt derived the concept of electrical anemometry. First publications on HWA design were done by

Bordoni in 1912, then by Retschy in 1913. Later years saw improvements in hot-wire 
measuring techniques, for example: in 1917, research from Fay discovered the use of auxiliary wire to improve velocity measurement and in 1920, Thomas applied glass coating on wire used in chemical medium [42].

Although the hot-wire anemometer is a well-known instrument for measurement in air, it can also be used to measure flows in various mediums such as fresh water, sea water, polymer solutions, blood, mercury, glycerine, oil and luminous gases. Hot-wire is also used to collect measurements in different flow types for example: compressible flows, two-phase flows or gas mixture concentrations. For turbulence flow measurements, hot-wire is an ideal research tool due to its excellent frequency response - from $20-50 \mathrm{kHz}$ up to $400 \mathrm{kHz}$, low signal-to-noise ratio, low-cost, wide velocity range. In addition, hot-wire is sensitive to low velocity, has good spatial resolution, well-defined calibration characteristics and is convenient for data analysis [43].

For heated wire type, the sensor is made from materials that are sensitive to change in temperature such as tungsten, platinum, or platinum alloys, while the prongs are usually made of steel or nickel. The size of wire sensors are relatively small to minimize interference with the flow, which range from $0.25 \mu \mathrm{m}$ to $12 \mu \mathrm{m}$ in diameter [43]. For measurement of fluid temperature less than $1500^{\circ} \mathrm{C}$, tungsten wires are commonly used, while for high temperature velocity measurement $\left(1500^{\circ} \mathrm{C}\right.$ $\left.<\mathrm{T}<7500^{\circ} \mathrm{C}\right)$, platinum and its alloys are often employed.

The most popular used hot-wire probe and the least expensive type is single-wire sensors which are made of tungsten or platinum. These filaments have a length of 1 $\mathrm{mm}$ and a diameter of about $5 \mu \mathrm{m}$ [44]. Figure 4.1 shows a typical tungsten single-wire sensor which was made by Dantec Dynamics. 

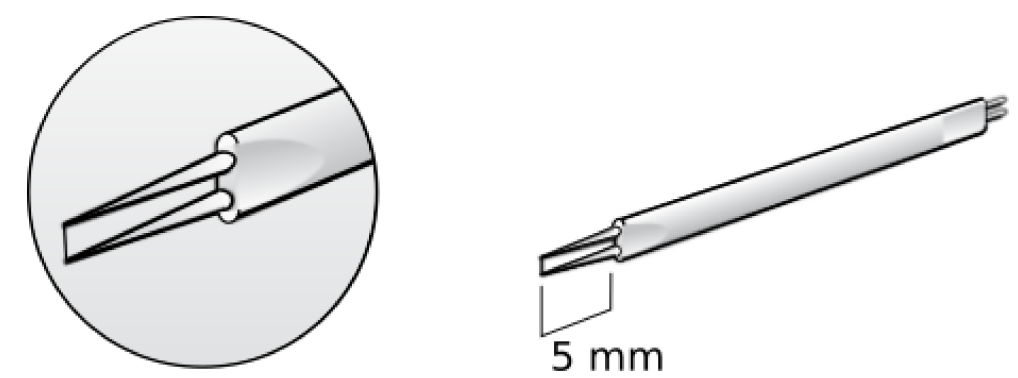

Figure 4.1: Dantec single-straight sensor 55P11. Adapted from dantecdynamics.com [45]

\subsection{Fundamental Concept}

Hot-wire is used to measure mean and fluctuating velocity or temperature components at a point in a turbulent flow field. The principle of HWA is based on convective heat transfer of a heated wire or film element due to a change in the fluid flow condition. Hot-wire consists of a cylinder filament which is attached between the tip of two supports by arc welding or soldering, and is electrically heated [41]. The heat transfer of the filament can be modeled as an infinite long wire element (neglect thermal conductive end losses) or finite length wire (account for conductive end losses). The rate of heat loss when the fluid passing over the heated wire is determined by four factors:

1. The flow relative velocity.

2. The difference between fluid and heated wire temperatures.

3. The properties of fluid such as density, viscosity, specific heat capacity, thermal conductivity and pressure.

4. The properties and dimensions of the sensor, for example: type of material, its length and diameter. 


\subsubsection{Operational Mode}

HWA can be operated in three main modes: constant temperature, constant current, and constant voltage anemometry. The most common operation mode is the constant temperature anemometer (CTA). The sensor heating current varies with the fluid velocity to maintain constant sensor resistance, hence keep the sensor temperature constant [41]. The CTA consists of a feedback amplifier, and its heart - the Wheatstone bridge circuit, in which the hot-wire sensor acts as one resistor in the circuit, as illustrated in Figure 4.2

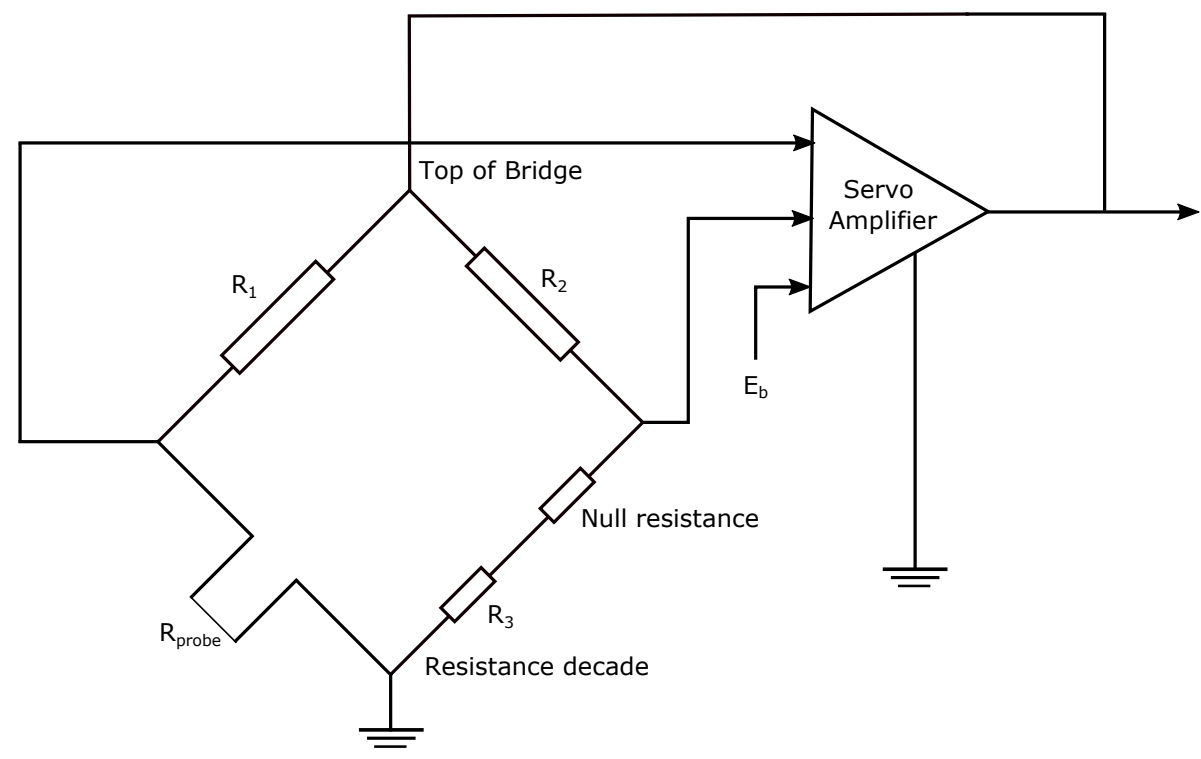

Figure 4.2: Wheatstone bridge circuit in a constant temperature anemometer operation mode where hot-wire probe acts as one of the resistors in the bridge. Adapted from AA Lab Systems Ltd. [46]

Change in flow velocity causes change in heat transfer rate and sensor resistance, and thus cause the wire to cool off or heat up. As this happens, the Wheatstone bridge becomes unbalanced. The differential feedback amplifier detects the imbalance and adjusts the current flowing to the sensor in order to return the bridge to balance mode. Since the feedback amplifier response time is short, the thermal inertial effect 
can be neglected and the sensor temperature always remains constant $[41,47]$. The output voltage across the bridge, seen by the feedback amplifier, is proportional to the fluid velocity. Hence the indication of magnitude and instantaneous velocity vector are provided through the wire.

\subsubsection{Response Equation}

The output voltage $\mathrm{E}$ of the hot-wire and flow velocity $\mathrm{U}$ are followed by a non-linear relationship. The response equation was derived by King (1914), given as

$$
E^{2}=A+B U^{n}
$$

where $\mathrm{A}, \mathrm{B}$ and $\mathrm{C}$ are calibration constants. King suggested that $n=0.5$ for a limited range of velocity [47] while studies from Van Thinh (1969), Bruun (1976), Bruun and Tropea (1980, 1985), Swaminathan et al. (1983) and Pitts and McCaffrey (1986) have demonstrated the optimum value of $n$ for $5 \mu \mathrm{m}$ tungsten hot-wire ranges from 0.4 to 0.45 for moderate velocity range (i.e. from $5-60 \mathrm{~m} / \mathrm{s}$ ) [48]. An approach from Davies and Patrick (1972) and Siddall and Davies (1972) shown an excellent fit for a calibration curve over a large range of velocity, from 1 - $60 \mathrm{~m} / \mathrm{s}$ [49], using an extended power law in the form

$$
E^{2}=A+B U^{0.5}+C U
$$

In one dimensional flow, the wire is placed perpendicular to the mean velocity, hence the output voltage of the HWA represents the true velocity, also known as the effective cooling velocity through Equation 4.3. When the wire is placed in three dimensional flow, the components of turbulence affect the instantaneous velocity seen by the wire. Hence, it is necessary to express the effective cooling velocity $\mathrm{Z}$ in terms 
of all three orthogonal velocity components $u, v$ and $w$. The relationship is derived by Jorgensen [50] as follows

$$
Z^{2}=v^{2}+G^{2} u^{2}+K^{2} w^{2}
$$

where $\mathrm{G}$ and $\mathrm{K}$ are referred to pitch and yaw factors.

According to Jorgensen, the pitch factor is defined as the ratio between the sensitivity of $v$ component to the sensitivity of $u$ component, as shown in Equation 4.4; whereas the yaw factor is defined as the fraction between the sensitivity of $v$ component to $w$ component, as described in Equation 4.5, for a constant voltage square $\left(E^{2}\right)$.

$$
G=\frac{v}{u}
$$

and

$$
K=\frac{v}{w}
$$

with $u, v$ and $w$ components are obtained at zero velocity in the other two directions.

\subsection{Multi-Position Measuring Techniques}

Having obtained the calibration procedure for the HWA, it is now necessary to determine the best method to solve three velocity components. Turbulence measurement of a complex flow field has always been a challenge for engineers and physicists. A single hot-wire can be used to measure the time-mean velocity and the root-mean-square of the streamwise components in one-dimensional flow. A double wire probe is able to determine the time-mean velocities of the streamwise and cross stream turbulence 
intensities, and also the cross correlation between the two components of the velocity fluctuations [51-53]. In the case of a three-dimensional flow field, the velocity components and their corresponding fluctuations require a minimum of three simultaneous equations and can be solved by implementing either of the two following methods:

1. A multi-wire probe placed at a single orientation.

2. A single-wire probe placed at multi-orientation.

The multi-wire method employs three-wire probe which permits simultaneous reading of three response equations since all three wires lie within the same volume of the flow field. These equations must be expressed in form of the effective cooling velocity. However, the multi-wire probe technique faces several drawbacks, such as:

1. Three-wire probe requires three identical or closely matched anemometer units.

2. It produces significant aerodynamic prong interference unless each sensor is placed at a certain spatial offset, or the probe is orientated relative to the mean velocity and turbulence intensity is low.

3. Thermal-wake interference from one wire to another can generate spurious readings.

Dvorak and Syred [54] derived a method using a single normal hot-wire rotated at three different positions which were separated by $45^{\circ}$ from each other. The velocity vector was decomposed into three orthogonal components using pitch and yaw factors as defined above by Jorgensen. However, with this method, information from the measurement was insufficient to obtain the quantities of turbulence. Hence, Dvorak and Syred introduced the use of a cross-wire probe to obtain the covariances between 
voltages of the two adjacent orientations. Again, this method posed the same problem as the multi-wire probe. In addition, another difficulty was that position of a single normal probe must be made exactly the same for the cross-wire probe.

King C.F [49] modified Dvorak and Syred's method by having measurements at six different positions. Each orientation was separated by $30^{\circ}$ from the adjacent one. The data obtained at each location was in the form of mean and root-mean-square (RMS) voltages. By applying some assumptions regarding the statistical nature of turbulence, one would be able to solve three time-mean velocities, three normal turbulent stresses, and also three turbulent shear stresses.

\subsubsection{Velocity equations}

Similar with the three-orientation method from Dvorak and Syred, the six-orientation method (SOM) requires a single, straight hot-wire probe to be calibrated at three different directions in order to determine the pitch and yaw factor, following Jorgensen's definition above. Each calibration curve was obtained with zero velocity in the other two directions, as shown in Figure 4.3.

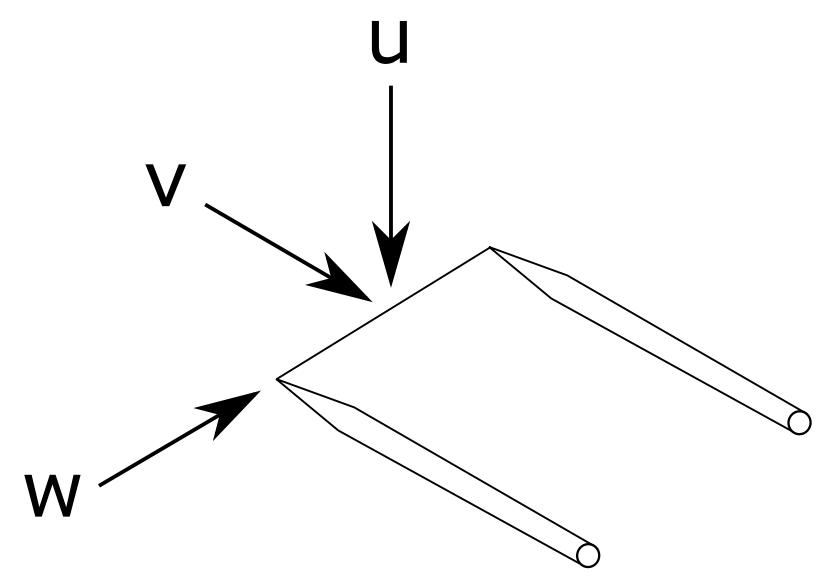

Figure 4.3: Three Calibration Direction

The three-direction calibration curves for the DANTEC 55P11 probe is shown in 
Figure 4.4. It is observed that the hot-wire is most efficiently cooled when the flow is in $\mathrm{u}$ direction and inefficiently cooled in $\mathrm{w}$ direction.

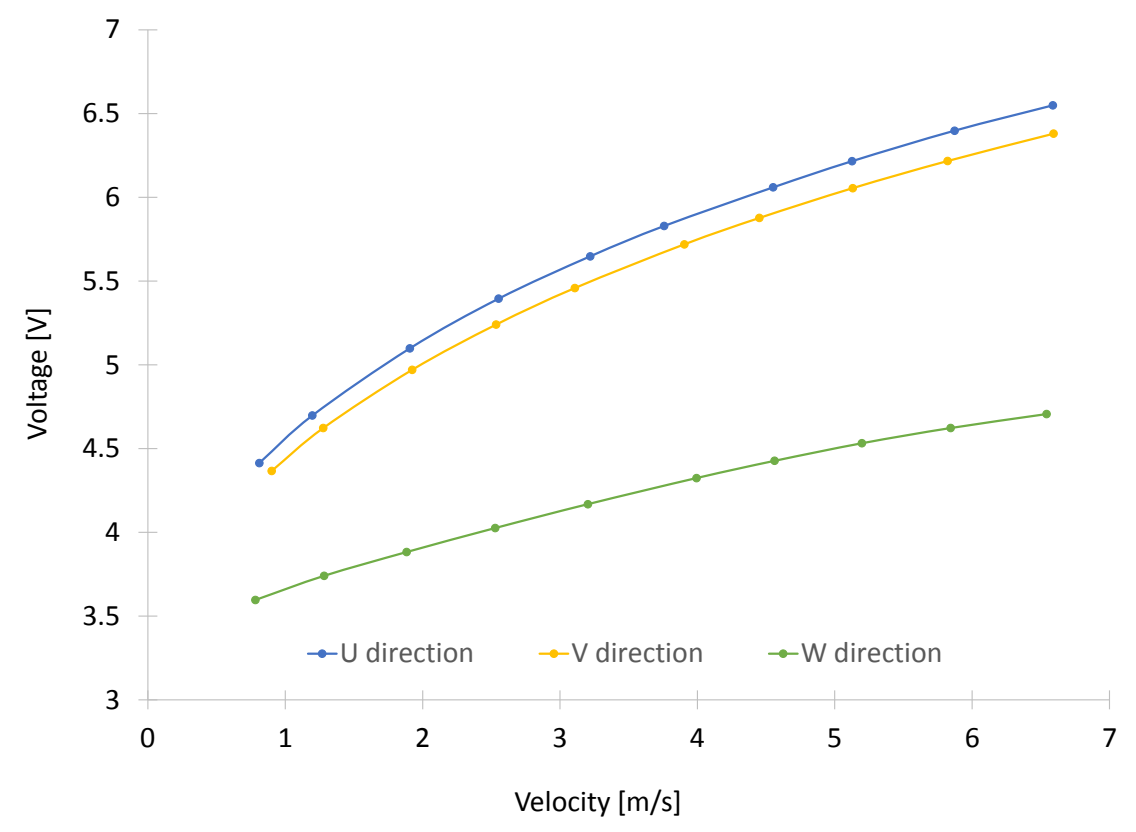

Figure 4.4: Three Directional Calibration Curves

The response equation follows the extended power law, of the form

$$
E^{2}=A+B Z^{0.5}+C Z
$$

where $\mathrm{A}, \mathrm{B}$, and $\mathrm{C}$ are calibration constants and $\mathrm{Z}$ is the effective cooling velocity which can be velocity components such as $u, v$ and $w$.

As mentioned in the previous section, when the hot-wire probe is placed in threedimensional flow field, following Jorgensen derivation, the effective cooling velocity Z is defined in terms of pitch and yaw factors as

$$
Z^{2}=v^{2}+G^{2} u^{2}+K^{2} w^{2}
$$


Since calibration curves in $\mathrm{v}$ direction are closer to the one in $\mathrm{u}$ direction than in $\mathrm{w}$ direction, the yaw factor is more sensitive to voltage fluctuation than the pitch factor. The pitch and yaw factors will be evaluated from the three calibration curves at a constant $E^{2}$ value.

To characterize a three dimensional flow field, three means and RMS velocity components are generally required. In order to solve six unknowns, six equations need to be obtained. A hot-wire probe is rotated six times around the probe axis where each position is spaced $30^{\circ}$ from each other, as shown in Figure 4.5. Due to the inability to distinguish between positive and negative directions, the positions have a circularity characteristic, meaning same reading is shared between positions 1 and 6 .

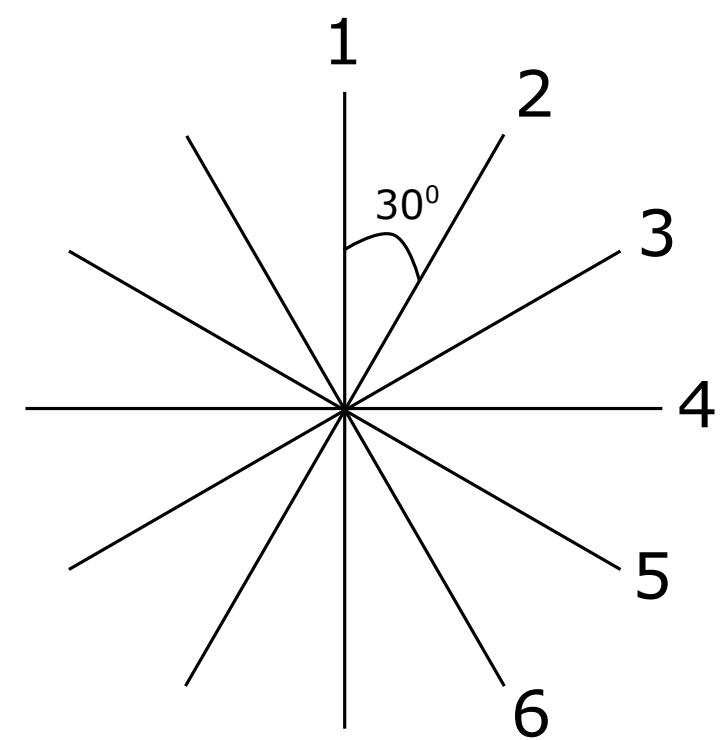

Figure 4.5: Six positions of measurement for single hot-wire probe

The measurement at first position is carried out where the wire is normal to the axial direction of the flow, and the probe coordinates coincide with the flow field coordinate system. As the probe rotates from position 1 to 6 , the effective cooling velocity equation for six positions, as given by King [55]are 


$$
\begin{gathered}
Z_{1}^{2}=V^{2}+G^{2} U^{2}+K^{2} W^{2} \\
Z_{2}^{2}=V^{2}+G^{2}\left(U \cos 30^{0}+W \sin 30^{0}\right)^{2}+K^{2}\left(W \cos 30^{0}-U \sin 30^{0}\right)^{2} \\
Z_{3}^{2}=V^{2}+G^{2}\left(U \cos 60^{0}+W \sin 60^{0}\right)^{2}+K^{2}\left(W \cos 60^{0}-U \sin 60^{0}\right)^{2} \\
Z_{4}^{2}=V^{2}+G^{2} W^{2}+K^{2} U^{2} \\
Z_{5}^{2}=V^{2}+G^{2}\left(U \cos 120^{0}+W \sin 120^{0}\right)^{2}+K^{2}\left(U \sin 120^{0}-W \cos 120^{0}\right)^{2} \\
Z_{6}^{2}=V^{2}+G^{2}\left(U \cos 150^{0}+W \sin 150^{0}\right)^{2}+K^{2}\left(U \sin 150^{0}-W \cos 150^{0}\right)^{2}
\end{gathered}
$$

Solving any three adjacent equations simultaneously provides expressions for the instantaneous values of three velocity components $\mathrm{U}, \mathrm{V}$ and $\mathrm{W}$ in terms of the equivalent effective cooling velocities. A general solution for three velocity components U, $\mathrm{W}$, and $\mathrm{V}$ is denoted as $\mathrm{F} 1, \mathrm{~F} 2, \mathrm{~F} 3$ where the value of $\mathrm{AO}, \mathrm{BO}$, and $\mathrm{CO}$ depend on the set of the three equations chosen.

$$
\begin{gathered}
F 1=\sqrt{\left[A O+\sqrt{\left.A O^{2}+\frac{B O^{2}}{3}\right]} *\left(\frac{1}{G^{2}-K^{2}}\right)\right.} \\
F 2=\sqrt{\left[-A O+\sqrt{\left.A O^{2}+\frac{B O^{2}}{3}\right] *\left(\frac{1}{G^{2}-K^{2}}\right)}\right.} \\
F 3=\sqrt{C O-\left(\frac{G^{2}+K^{2}}{G^{2}-K^{2}} * \sqrt{A O^{2}+\frac{B O^{2}}{3}}\right)}
\end{gathered}
$$

The value of variable $\mathrm{AO}, \mathrm{BO}$, and $\mathrm{CO}$ are given in Table 4.1. 


\begin{tabular}{|c|c|c|c|}
\hline Equation Set & $\mathrm{AO}$ & $\mathrm{BO}$ & $\mathrm{CO}$ \\
\hline $1,2,3$ & $Z_{2}^{2}-Z_{3}^{2}$ & $-2 Z_{1}^{2}+3 Z_{2}^{2}-Z_{3}^{2}$ & $Z_{1}^{2}-Z_{2}^{2}+Z_{3}^{2}$ \\
\hline $2,3,4$ & $Z_{2}^{2}-Z_{3}^{2}$ & $-Z_{2}^{2}+3 Z_{3}^{2}-2 Z_{4}^{2}$ & $Z_{2}^{2}-Z_{3}^{2}+Z_{4}^{2}$ \\
\hline $3,4,5$ & $Z_{3}^{3}-2 Z_{4}^{2}+Z_{5}^{2}$ & $Z_{3}^{2}-Z_{5}^{2}$ & $Z_{3}^{2}-Z_{4}^{2}+Z_{5}^{2}$ \\
\hline $4,5,6$ & $-Z_{5}^{2}+Z_{6}^{2}$ & $-2 Z_{4}^{2}+3 Z_{5}^{2}-Z_{6}^{2}$ & $Z_{4}^{2}-Z_{5}^{2}+Z_{6}^{2}$ \\
\hline $5,6,1$ & $-Z_{5}^{2}+Z_{6}^{2}$ & $-Z_{5}^{2}+3 Z_{6}^{2}-2 Z_{1}^{2}$ & $Z_{5}^{2}-Z_{6}^{2}+Z_{1}^{2}$ \\
\hline $6,1,2$ & $-Z_{6}^{2}+2 Z_{1}^{2}-Z_{2}^{2}$ & $-Z_{6}^{2}+Z_{2}^{2}$ & $Z_{6}^{2}-Z_{1}^{2}+Z_{2}^{2}$ \\
\hline
\end{tabular}

Table 4.1: $\mathrm{AO}, \mathrm{BO}$, and $\mathrm{CO}$ values for corresponding equation set

Following Janjua [56] and King [49] Fortran code, the equation set was chosen with respect to the minimum effective velocity. For example, if the minimum effective velocity $\mathrm{Z}$ was located at position 4 , the equation set would be chosen as 3 , 4, and 5. Six response equations 4.8 to 4.13 and the general expressions for $\mathrm{U}, \mathrm{W}$, and $\mathrm{V}$ are all in terms of instantaneous velocity. Moreover, it is impossible with a single hot-wire to obtain any set of three equations (i.e $Z_{1}, Z_{2}, Z_{3}$ ) at a single instant in time. Therefore, equations F1, F2, and F3 must be time-mean. In order words, they must be expressed in terms of mean and root-mean-square values.

\subsubsection{Statistical analysis}

A statistical method to establish time averaged velocities has been adopted from Dvorack and Syred with the assumption that the turbulence is stationary [54]. This assumption is necessary for any orientation technique since the turbulence must remain the same while the probe is placed into the flow. In a fully developed flow where there is no variation with time, this assumption seems to be reasonable. First, the instantaneous effective cooling velocity $Z_{i}$ can be written in term of a function $\phi$ of an instantaneous voltage $E_{i}$ by rearranging Equation 4.6. 


$$
\phi\left(E_{i}\right)=Z_{i}=\left[\frac{-B+\sqrt{B^{2}-4 C\left(A-E_{i}^{2}\right)}}{2 C}\right]^{2}
$$

Then, in order to obtain an expression for time-mean velocity of each individual position $\overline{Z_{i}}$ as a time-mean voltage, a Taylor series expansion of Equation 4.17 is carried out.

Since $Z_{i}=\phi\left(\overline{E_{i}}+E_{i}^{\prime}\right)$

$$
Z_{i}=\phi\left(\overline{E_{i}}+E_{i}^{\prime}\right)=\phi\left(\overline{E_{i}}\right)+\frac{E_{i}^{\prime}}{1 !} \cdot \frac{\partial \phi}{\partial E_{i}}+\frac{\left(E_{i}^{\prime}\right)^{2}}{2 !} \cdot \frac{\partial^{2} \phi}{\partial E_{i}^{2}}
$$

The Taylor series is truncated after second order term due to those high order terms which are relatively small in comparison with the first and second terms. Time averaging both sides of Equation 4.18 and taking into account the fact that $\overline{E_{i}^{\prime}}=0[57]$ to obtain

$$
\overline{Z_{i}}=\phi\left(\overline{E_{i}}\right)+\frac{1}{2} \frac{\partial^{2} \phi}{\partial E_{i}^{2}} \cdot \sigma_{E_{i}}^{2}
$$

Equation 4.19 is evaluated with mean voltage $\overline{E_{i}}$ and the $\sigma_{E_{i}}^{2}$ is taken the value of the square RMS voltage.

Second, to evaluate the fluctuation term $\sigma_{Z_{i}}^{2}$, Hinze's relationships [58] are used

$$
{\overline{Z_{i}^{\prime}}}^{2}=\sigma_{Z_{i}}^{2}=\operatorname{Expec}\left[Z_{i}^{2}\right]-\left(\operatorname{Expec}\left[Z_{i}\right]\right)^{2}
$$

The first part of Equation 4.20 can be approximated as

$$
\operatorname{Expec}\left[Z_{i}^{2}\right]=\overline{\phi^{2}}+\frac{1}{2} \frac{\partial^{2} \bar{\phi}^{2}}{\partial E_{i}^{2}} \cdot \sigma_{E_{i}}^{2}
$$


The differential in Equation 4.21 can be evaluated as

$$
\frac{\partial^{2} \bar{\phi}^{2}}{\partial E_{i}^{2}}=\frac{\partial}{\partial E_{i}} \cdot\left(2 \bar{\phi} \cdot \frac{\partial \bar{\phi}}{\partial E_{i}}\right)=2\left(\frac{\partial \bar{\phi}}{\partial E_{i}}\right)^{2}+2 \bar{\phi} \cdot \frac{\partial^{2} \bar{\phi}}{\partial E_{i}^{2}}
$$

Substituting Equation 4.22 into Equation 4.21 to obtain

$$
\operatorname{Expec}\left[Z_{i}^{2}\right]=\overline{\phi^{2}}+\frac{\partial \bar{\phi}}{\partial E_{i}} \cdot \sigma_{E_{i}}^{2}+\bar{\phi} \cdot \frac{\partial^{2} \bar{\phi}}{\partial E_{i}^{2}} \cdot \sigma_{E_{i}}^{2}
$$

The second part of Equation 4.20 is obtained by squaring Equation 4.19

$$
\left(\operatorname{Expec}\left[Z_{i}\right]\right)^{2}=\overline{\phi^{2}}+\left(\frac{1}{2} \frac{\partial^{2} \bar{\phi}}{\partial E_{i}^{2}} \cdot \sigma_{E_{i}}^{2}\right)^{2}+\bar{\phi} \cdot \frac{\partial^{2} \bar{\phi}}{\partial E_{i}^{2}} \cdot \sigma_{E_{i}}^{2}
$$

Finally, the variance of individual effective cooling velocity $\sigma_{Z_{i}}^{2}$ is reduced to

$$
{\overline{Z_{i}^{\prime}}}^{2}=\sigma_{Z_{i}}^{2}=\left(\frac{\partial \bar{\phi}}{\partial E_{i}}\right)^{2} \cdot \sigma_{E_{i}}^{2}-\left(\frac{1}{2} \frac{\partial^{2} \bar{\phi}}{\partial E_{i}^{2}} \cdot \sigma_{E_{i}}^{2}\right)^{2}
$$

Equation 4.19 and 4.25 provide the mean and variance of individual cooling velocities in terms of mean and variance of the according voltage. It is now possible to solve the three instantaneous velocity components $\mathrm{U}, \mathrm{V}$ and $\mathrm{W}$ in term of mean and variance individual cooling velocities.

In a three-dimensional flow, besides mean and variance values expressed in each velocity component equation, it is also required their cross correlations. The procedure to obtain the mean and variance of the individual velocity components is similar to the effective cooling velocities except that $\mathrm{U}, \mathrm{V}$ and $\mathrm{W}$ are functions of three random variables and there are extra terms in the Taylor expansion to account for the covariances of the effective cooling velocities. Thus the three mean velocities are given by 


$$
\bar{U}=F 1+\frac{1}{2} \sum_{i=1}^{3} \frac{\partial^{2} F 1}{\partial Z_{i}^{2}} \cdot \sigma_{Z_{i}}^{2}+\sum_{i<j}^{3} \frac{\partial^{2} F 1}{\partial Z_{i} \partial Z_{j}} \cdot K_{Z_{i} Z_{j}}
$$

and

$$
\bar{W}=F 2+\frac{1}{2} \sum_{i=1}^{3} \frac{\partial^{2} F 2}{\partial Z_{i}^{2}} \cdot \sigma_{Z_{i}}^{2}+\sum_{i<j}^{3} \frac{\partial^{2} F 2}{\partial Z_{i} \partial Z_{j}} \cdot K_{Z_{i} Z_{j}}
$$

and

$$
\bar{V}=F 3+\frac{1}{2} \sum_{i=1}^{3} \frac{\partial^{2} F 3}{\partial Z_{i}^{2}} \cdot \sigma_{Z_{i}}^{2}+\sum_{i<j}^{3} \frac{\partial^{2} F 1}{\partial Z_{i} \partial Z_{j}} \cdot K_{Z_{i} Z_{j}}
$$

where $K_{Z_{i} Z_{j}}$ is the covariance of the effective cooling velocity fluctuations and is defined as

$$
K_{Z_{i} Z_{j}}=\frac{1}{t} \int_{0}^{t}\left(Z_{i}-\overline{Z_{i}}\right)\left(Z_{j}-\overline{Z_{j}}\right) d t
$$

\subsubsection{Covariance}

King devised a mathematical procedure to calculate the covariances in his study of a vortex amplifier. The detail of this method can be found in his Ph.D thesis [49]. The covariances are calculated based on the relationship

$$
K_{Z_{i} Z_{j}}=\gamma_{Z_{i} Z_{j}}\left(\sigma_{Z_{i}}^{2} \cdot \sigma_{Z_{j}}^{2}\right)^{0.5}
$$

where $\gamma_{Z_{i} Z_{j}}$ is the correlation coefficient between the two cooling velocities $Z_{i}$ and $Z_{j}$. The covariances for two $30^{\circ}$ wire separation are denote as $K_{Z_{P} Z_{Q}}, K_{Z_{Q} Z_{R}}$, while the covariances for $60^{\circ}$ separation is written as $K_{Z_{P} Z_{R}}$. In case the covariance values are bigger than one, King fixed the values of the correlation coefficients as

$$
\gamma_{Z_{P} Z_{Q}}=0.9 \quad \gamma_{Z_{Q} Z_{R}}=0.9 \quad \gamma_{Z_{P} Z_{R}}=0.648
$$


In Janjua's work [56], he discovered that in case of turbulence measurement in a confined jet using the six-orientation technique, King's estimate of the covariances was not self-consistent. Therefore, Janjua employed those fixed values for correlation coefficients to calculate the covariances.

The first two values $\gamma_{Z_{P} Z_{Q}}$ and $\gamma_{Z_{Q} Z_{R}}$ are estimated based on the fact that if two consecutive measuring positions are separated by an angle of $30^{\circ}$, then the contribution of fluctuating signals from each hot-wire measurement position to the effective cooling velocity of the wire is related by the cosine value of that angle. Hence, $\gamma_{Z_{P} Z_{Q}}=\cos 30^{\circ}=0.87 \approx 0.9$ and $\gamma_{Z_{Q} Z_{R}}=\cos 30^{\circ}=0.87 \approx 0.9$. For the correlation coefficient where the two wires are set apart by $60^{\circ}, \gamma_{Z_{P} Z_{R}}$ is related to the other correlation coefficients by the expression below as

$$
\gamma_{Z_{P} Z_{R}}=\eta \cdot \gamma_{Z_{P} Z_{Q}} \cdot \gamma_{Z_{Q} Z_{R}}
$$

If $\eta$ takes the value of 0.8 , then

$$
\gamma_{Z_{P} Z_{R}}=0.8 \cdot 0.9 \cdot 0.9 \approx 0.648
$$

which is close to the value of $\cos 60^{\circ}$. Therefore the cosine relationship still holds in case of $60^{\circ}$ wire separation if $\eta=0.8$.

Three covariances are evaluated by substituting the corresponding values of the correlation coefficients into Equation 4.30. For the analysis in this thesis, since the flow at the condenser exit resembles the flow in the axisymmetric combustor of a gas turbine engine more than in the vortex amplifier's case, the estimate of correlation coefficients and the procedure to obtain covariances follow Janjua's work. 


\subsubsection{Coordinate system}

The hot-wire probe was placed at the condenser exit such that at position 1 , the hot-wire coordinate coincide with the velocity components of the flow field $\mathrm{U}, \mathrm{V}$, and W where:

$$
\begin{aligned}
\mathrm{U} & =\text { Radial Velocity Component } \\
\mathrm{V} & =\text { Axial Velocity Component } \\
\mathrm{W} & =\text { Tangential Velocity Component }
\end{aligned}
$$
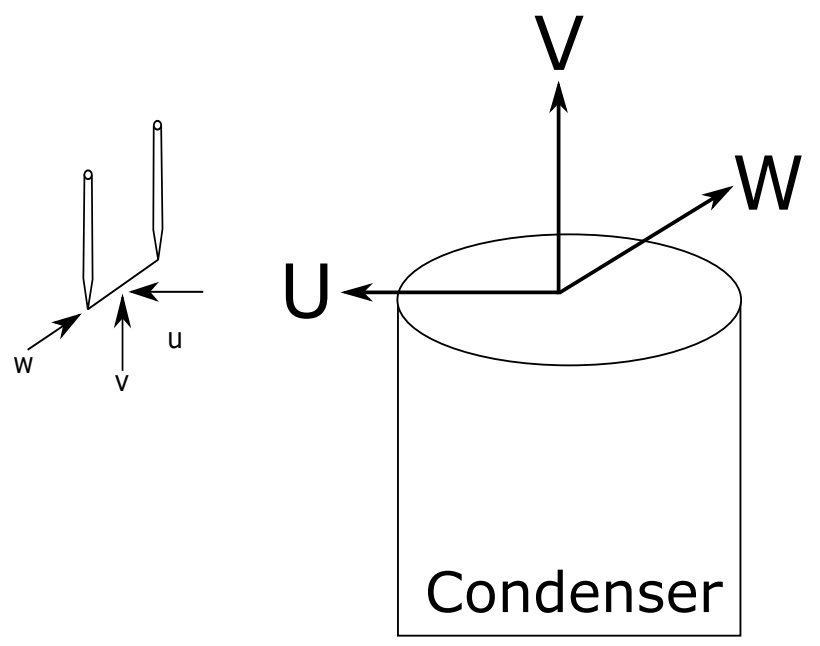

Figure 4.6: Hot-wire probe coordinate $\mathrm{u}, \mathrm{v}$, and $\mathrm{w}$ at position 1 in related to flow field coordinate system $\mathrm{U}, \mathrm{V}$ and $\mathrm{W}$

Relative to the hot-wire coordinate system, Figure 4.6 shows the positive direction of $\mathrm{U}, \mathrm{V}$, and $\mathrm{W}$ that will be applied in the data reduction analysis for SOM method.

\subsection{Calibration Setup}

Calibration was initially performed at the atmospheric boundary layer wind tunnel situated in room ME 2140 at Carleton University. However, the lowest operation speed in the wind tunnel was approximately $3.3 \mathrm{~m} / \mathrm{s}$ which was higher than some 
of the measuring points expected in the flow field at the condenser exit (where flow could be as low as $0.5 \mathrm{~m} / \mathrm{s}$ ). McTavish implemented a series of sandwiched screens which were placed upstream of the test section in order to reduce the wind speed. Despite this attempt, the speed was only brought down to $2 \mathrm{~m} / \mathrm{s}$ [59]. Therefore, there was a strong need for constructing a calibration facility that could produce flow as low as $0.5 \mathrm{~m} / \mathrm{s}$.

A simple, inexpensive, easily built calibration facility, following Grandchamp's design $[60,61]$ of a 'desktop' wind tunnel was created for the calibration process of the hot-wire in three different directions. All components were set up in a series. The facility consisted of a $1 / 4^{\prime \prime}$ Power First diaphragm-type pressure regulator, with maximum pressure of $160 \mathrm{psi}(1,103 \mathrm{kPa})$, to control the flow from the compress air line. The regulator was then connected to the Brooks Mass Flow Meter 5863S, via a uniform stainless steel duct of diameter $0.0096 \mathrm{~m}$. The air was then passed through another stainless steel duct of the same diameter before entering the building-block of the 'desktop' wind tunnel which comprised of:

1. A diffuser

2. A settling chamber

3. A contraction nozzle

The diffuser and contraction nozzle were printed using the Dimension BST threedimensional printer available in the department. The following descriptions outline the process of designing the main portion of the 'desktop' wind tunnel.

The diffuser is basically an expansion duct to reduce flow velocity in order to convert kinetic energy into pressure energy as efficiently as possible [62]. The area 


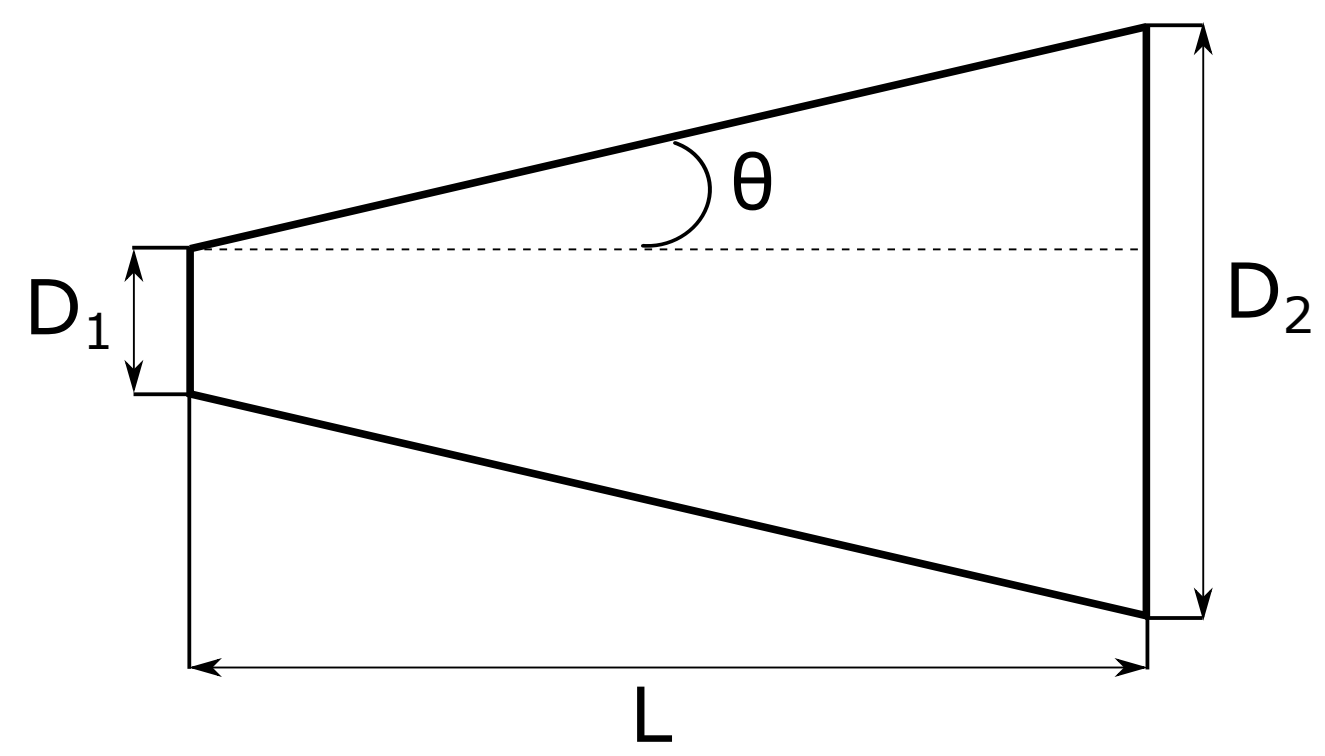

Figure 4.7: General geometry of diffuser section where $D_{1}$ is throat diameter, $D_{2}$ is exit diameter, $\mathrm{L}$ is diffuser length and $\theta$ is conical angle.

of the diffuser should increase gradually to prevent flow separation [63]. General geometry of the diffuser is shown in Figure 4.7.

Mehta's study indicated that the conical angle for a diffuser should be between $5^{\circ}$ (for best flow steadiness) and $10^{\circ}$ (for best pressure recovery) [64]. Thus it makes sense that general practice used cone angle of $7^{\circ}$ for the diffuser $[65,66]$. This angle was applied to the geometry of the diffuser in this setup. Besides the conical angle, two other factors dictate the performance of a conical diffuser are area ratio $A_{2} / A_{1}$, and length-to-throat diameter ratio $\mathrm{L} / D_{1}$. The area ratio of the diffuser is the ratio between the cross section of the stainless pipe and the PVC pipe which was around 17 in this setup. According to the performance data of a conical diffuser provided by Runstadler Jr. et al. [67], for conical angle of $7^{\circ}$ and area ratio of 17 , the lengthto-throat diameter ratio is approximately 13 which result in diffuser length of 0.165 $\mathrm{m}$.

A straight PVC pipe, separating the diffuser from the nozzle, acted a settling chamber to ensure total flow mixing. For internal incompressible viscous flow, the 
average velocity is given by

$$
V=\frac{Q}{A}
$$

where $\mathrm{Q}$ is the volume flow rate $\left[\mathrm{m}^{3} / \mathrm{s}\right]$ and $\mathrm{A}$ is the area of the cross section of the pipe $\left[m^{2}\right]$ and the Reynolds number is

$$
R e=\frac{\rho V d}{\mu}
$$

The maximum volume flow rate passing through the mass flow meter is $150 \mathrm{~L} / \mathrm{min}$ for standard atmospheric pressure air temperature at $20^{\circ} \mathrm{C}$. With the PVC pipe of diameter $0.0525 \mathrm{~m}$, the Reynolds number is approximately 4000 (3680).

The entrance lengths were also considered in the design process for the all straight pipe sections of this setup. According to White [68], for turbulence pipe flow, the entrance length is defined as

$$
\frac{L_{e}}{d} \approx 4.4 R e_{d}^{\frac{1}{6}}
$$

Table 4.2 shows some computed entrance lengths for corresponding Reynolds numbers

\begin{tabular}{c|c|c|c|c|c|c}
$R e_{d}$ & 4000 & $10^{4}$ & $10^{5}$ & $10^{6}$ & $10^{7}$ & $10^{8}$ \\
\hline$\frac{L_{e}}{d}$ & 18 & 20 & 30 & 44 & 65 & 95
\end{tabular}

Table 4.2: Corresponding $L_{e} / \mathrm{d}$ ratios for different Reynolds numbers. Reproduced from Frank M. White - Fluid Mechanics [68]

To achieve fully developed flow in the PVC pipe, it was cut to exactly $1 \mathrm{~m}$ long. The PVC pipe contained hexagonal honeycomb sections of length $0.15 \mathrm{~m}$ to remove swirl, flow unsteadiness and lateral velocity variations, hence to straighten 
the flow [69] before it entered the nozzle section. Both ends of PVC pipe sections were equipped with flanges in order to align with the flanges from the diffuser and nozzle sections. Also, all $0.0096 \mathrm{~m}$ diameter stainless steel pipe sections had a length of $0.04 \mathrm{~m}$ which well ensured fully developed flow in these pipe sections.

Convergent nozzle is a device that is used to accelerate the flow and also provides uniform velocity profile at the exit. The geometry of the contraction shape is shown in Figure 4.8 .

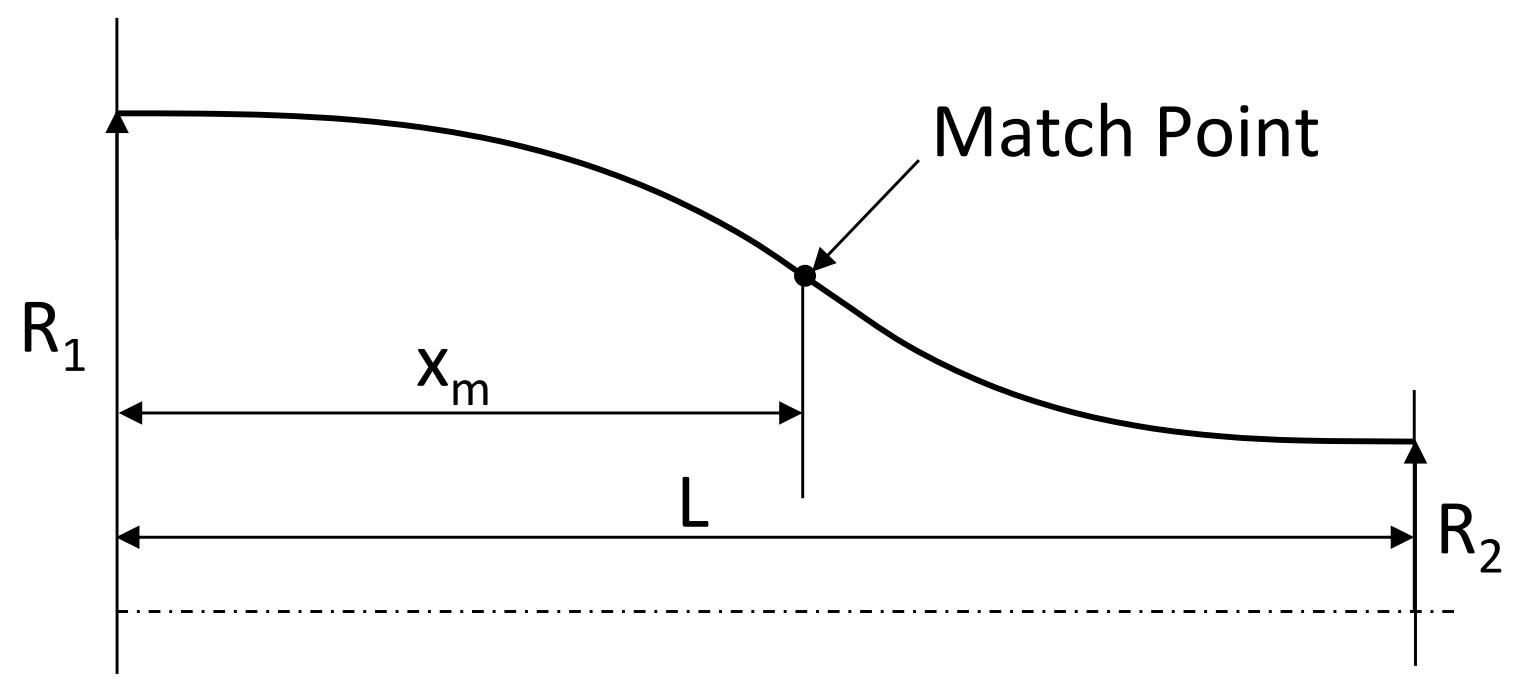

Figure 4.8: Schematic of the convergent nozzle with matched fifth order polynomial where $R_{1}$ and $R_{2}$ is are inlet and exit radii, $\mathrm{L}$ is the total length, $x_{m}$ is the distance from the inlet to the match point where the two polynomials of same curvature and slope meet $[70]$

The nozzle section followed Morel's contraction design criteria [71] due to its simplicity and effectiveness. Moreover, this method considered uniform flow at the exit as being the basic requirement in the design process, which was also the desired achievement in this setup. The criteria are listed below as

$$
\begin{gathered}
0.75 \leq \mathrm{L} / D_{1} \leq 1.25 \\
0.2 \leq x_{m} / \mathrm{L} \leq 0.8 \\
2 \leq \mathrm{CR} \leq 25
\end{gathered}
$$


The inlet diameter of the nozzle had a dimension as the straight PVC pipe while the exit diameter had a value of $0.018 \mathrm{~m}$ to produce a maximum velocity of approximately $10 \mathrm{~m} / \mathrm{s}$ (based on maximum flow rate of $150 \mathrm{~L} / \mathrm{min}$ ). The contraction area ratio $(\mathrm{CR})$ is then restricted to a value of 8.5 in this design. Based on the criteria above, the ratio $\mathrm{L} / D_{1}$ was chosen to be 1.25 while ratio $x_{m} / \mathrm{L}$ was selected as 0.55 . Hence the total length $\mathrm{L}$ of the nozzle was $0.0656 \mathrm{~m}$. As recommended by $\mathrm{Su}$, the contraction section after the settling chamber should follow a polynomial higher than 3 order [72]. In this case, the nozzle shape profile followed a fifth order polynomial with R-squared equals to 0.999. Schematic of the mini wind tunnel used to perform calibration is illustrated in Figure 4.9.

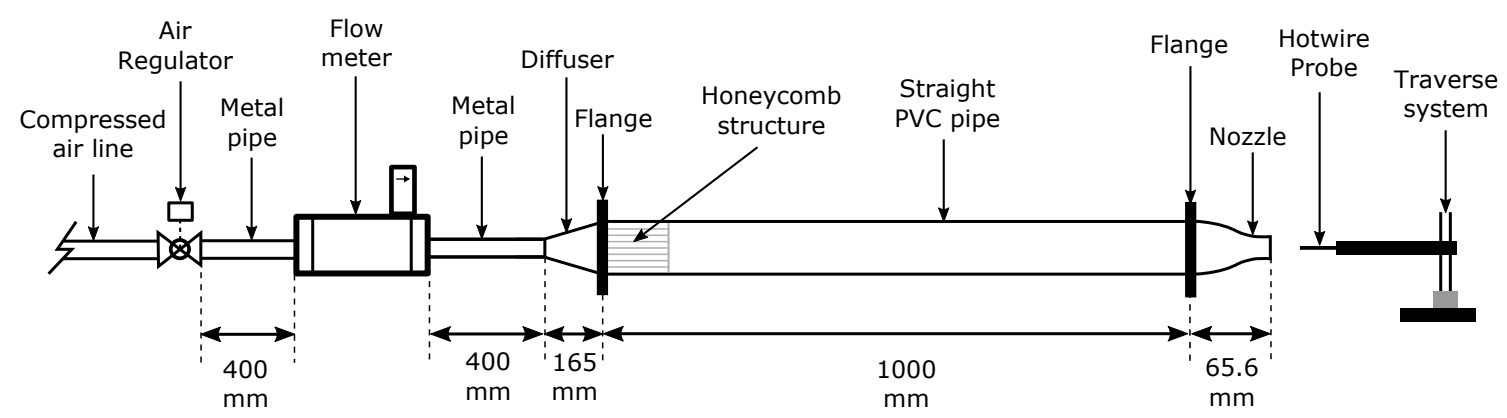

Figure 4.9: Schematic of a mini-version wind tunnel where calibrations in three directions were performed

\subsection{Temperature Correction}

For a CTA operation mode of hot-wire, one of the most significant sources of error needed to take into account, is the changes in velocity reading due to changes in ambient temperature. Generally speaking, the hot-wire should be calibrated and operated at the same temperature. In practice, if the temperature changes within \pm $0.5^{\circ} \mathrm{C}$ throughout calibration and measurement, it is not necessary to proceed with 
any correction [73]. However, when the fluctuation is greater than $0.5^{\circ} \mathrm{C}$, a correction must be performed.

Preliminary measurements showed temperatures at the condenser exit were different from calibration temperature and they also varied in a range of approximately $10^{\circ} \mathrm{C}$. Hence a temperature correction method must be used to minimize voltage drifting due to a temperature difference between calibration and measurements. Numerous techniques, based on the assumption of King's heat transfer law, have been developed by Collis and Williams [74], Grant and Kronauer [75], Bearman [76], AbdelRahman and Strong [77], Benjamin and Roberts [78], and the most recent by Tropea et al. [79]. But these techniques are cumbersome and inconvenient to incorporate in the data analysis. The most commonly used technique, derived by Brunn [43], is correcting the output voltage $E_{w}$ based on a reference temperature $T_{r}$ (usually corresponding to the calibration temperature) in the form of

$$
E_{w, r}=E_{w}\left[\frac{T_{w}-T_{r}}{T_{w}-T_{a}}\right]^{0.5}
$$

where $T_{w}$ and $T_{a}$ are wire and ambient temperatures while $E_{w, r}$ is voltage corrected. However, this method is only valid up to a drift of $3^{\circ} \mathrm{C}$ from the calibration temperature. A new correction scheme for the CTA mode presented by Hultmark [80] is examined. This method requires a minimal of additional calibration, it is not based on an assumed heat transfer law, and is simple to apply in the data analysis. Most importantly, Hultmark's correction method works effectively for a large range of elevated temperature of up to $15^{\circ} \mathrm{C}$ in the CTA mode. The detail of this method is described below.

Resistance and temperature of the sensor follows Hinze's relationship [58] as

$$
R_{s}=R_{o}\left[1+\alpha\left(T_{s}-T_{o}\right)+\alpha_{1}\left(T_{s}-T_{o}\right)^{2}+\ldots\right]
$$


where $\mathrm{T}$ and $\mathrm{R}$ stand for temperature and resistance. Two subscripts $s$ and $o$ represent sensor and reference values. $\alpha$ is the temperature coefficient of resistivity. Typical sensor materials such as platinum or tunsten, $\alpha \geq \alpha_{1}$, then the Equation 4.38 is reduced to

$$
R_{s}=R_{o}\left[1+\alpha\left(T_{s}-T_{o}\right)\right]
$$

An important factor when analyzing the heat transfer of the wire is the aspect ratio (AS) which is defined as

$$
A S=\frac{l}{d}
$$

where $l$ is the length of the wire and $d$ is its diameter. Dantec single hot-wire probe 55P11 has an AS of 250 [81]. According to Perry and Bruun [43,73], for wire with $A S \geq 200$, the end-conduction effects can be neglected. Also, the analysis considers only forced convection and excludes free convection effect. In CTA operation mode, the wire resistance is kept constant through the expression

$$
\frac{E^{2}}{R}=h \Delta T A=\frac{k N u}{d} A \Delta T
$$

where $h$ is the convection heat transfer coefficient, $k$ is the thermal conductivity of the fluid, $\Delta T=T_{w}-T_{a}$, A is the surface area of the wire, and Nusselt number $N u=h d / k$. In subsonic flow, the Nusselt number depends on both Reynolds number Re and Prandtl number $\operatorname{Pr}$ [82]. However, we can assume that $N u=f(R e)$ only as Prandtl number is a weak function of temperature. For a given wire, $d, \mathrm{~A}$, and $\mathrm{R}$ are constant, thus Equation 4.41 can be rewritten as

$$
E^{2}=f(R e) k \Delta T
$$


Rearranging Equation 4.42 to obtain $R e$ as

$$
R e=f_{2}\left(\frac{E^{2}}{k \Delta T}\right)
$$

or

$$
\frac{V}{\nu}=f_{2}\left(\frac{E^{2}}{k \Delta T}\right)
$$

where $f_{2}$ denotes an inverse function. Since $\nu$ and $k$ are functions of temperature, the corrected velocity can now be determined based on the recorded voltage. The thermal conductivity of air, evaluated at film temperature of $T_{f}=0.5 \cdot\left(T_{w}+T_{a}\right)$, is found using the correlation given by Kannuluik and Carman [83] as

$$
k=418.4 \cdot\left[5.75 \times 10^{-5}\left(1+0.00317 \cdot T_{f}-0.0000021 \cdot T_{f}^{2}\right)\right]
$$

While the kinematic viscosity $\nu$ of air can be found using the relation provided by Dixon [84] where

$$
\nu=\frac{1.458 \times 10^{-6}(273.15+T)^{1.5}}{\rho[(273.15+T)+110.4]}
$$

where $\rho$ is the density of air at the corresponding temperature $\mathrm{T}$ in Celsius degree.

Figure 4.10 (a) shows calibration curves obtained in Hultmark's study at different temperatures while (b) demonstrates the effectiveness of applying his correction method for the CTA operation mode. 


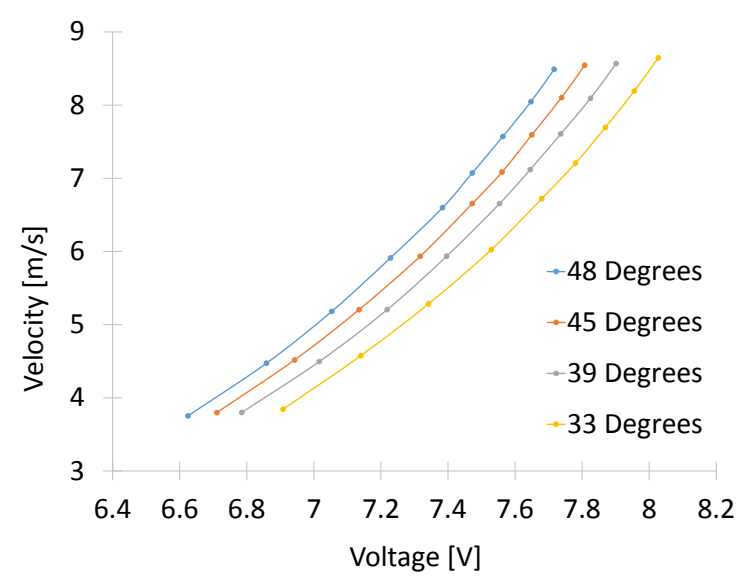

(a)

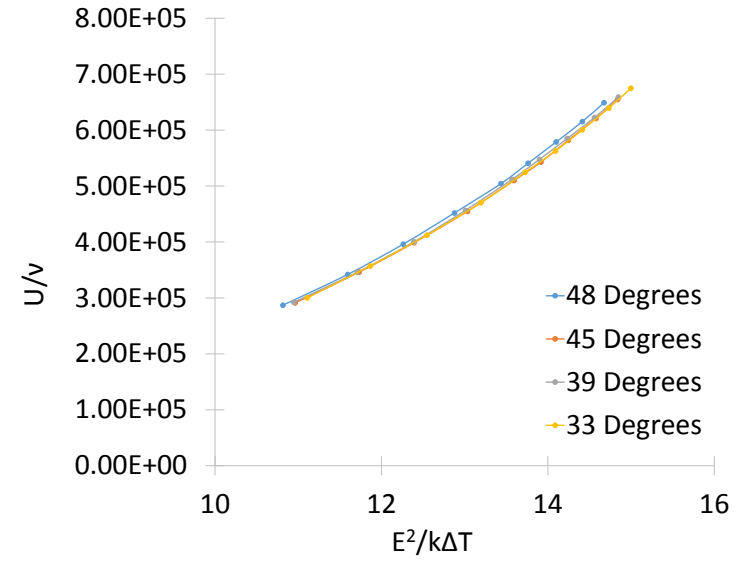

(b)

Figure 4.10: CTA mode calibration and correction curves from Hultmark's study - (a) Original calibration curves at different temperatures and (b) Curves replotted using similarity variable given by Equation 4.44. Reproduced from Ref [80]

To validate this method, calibration curves at different temperatures were collected by using the in-house 'desktop' wind tunnel on different days. The data were taken using Dantec single miniature probe 55P11, operated at wire temperature of $86^{\circ} \mathrm{C}$.

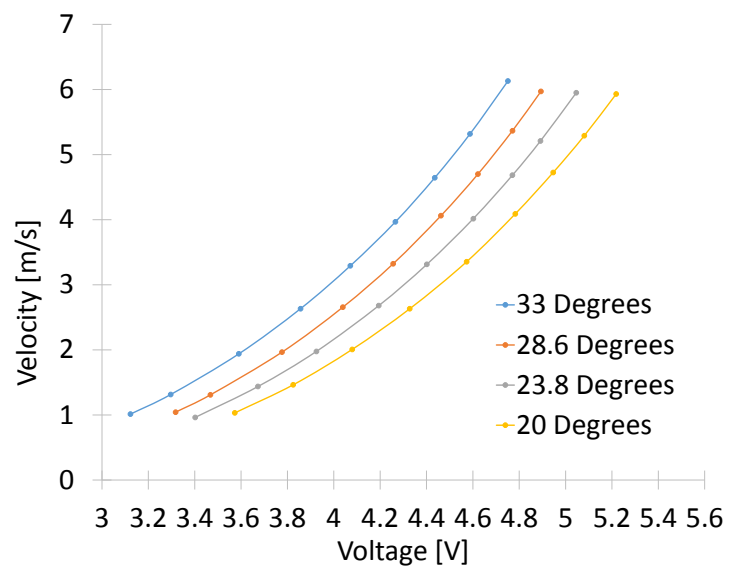

(a)

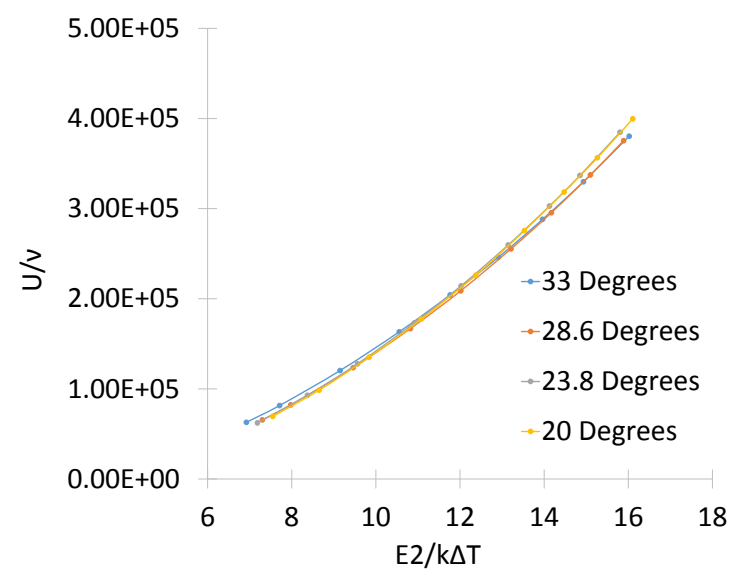

(b)

Figure 4.11: (a) In-house calibration curves at different temperatures and (b) Curves replotted following Hultmark's correction method 
As seen in Figure 4.11 (a), calibration curves at four different temperatures collapse to a single curve of fourth order polynomial with an $\mathrm{R}^{2}$ factor of 0.9988 . This demonstrates that Hultmark's technique captures the effects of temperature on the calibration process accurately and effectively.

\subsection{Experimental Setup}

The following section will describe in details experimental set-up for HWA measurements, as well as temperature measurements at the condenser exhaust.

\subsubsection{Hot-wire measurement}

\section{Six-axis rotation device}

In order to collect measurements at six orientations, a special device was designed to fulfill this task. Being machined at our Machine Shop, the SOM device consisted of four main parts: main body, mini ball-bearing, circular rotating disk, and straight hollow tube. Figure 4.12 illustrates the measuring device that was used to record the HWA data. The description for each individual part is described below.

The main body outfitted of five features:

- A $5.0^{\prime \prime} \times 2.5^{\prime \prime}(127.0 \times 63.5 \mathrm{~mm})$ plate and of thickness $0.21^{\prime \prime}(5.33 \mathrm{~mm})$

- An extruded support block acting as a guide for the hollow tube

- Two levels placed orthogonally on the plate body

- An L-bracket to be attached to the traverse system

- Twelve holes positioned in a circular pattern where each hole departed from the other by $30^{\circ}$ 


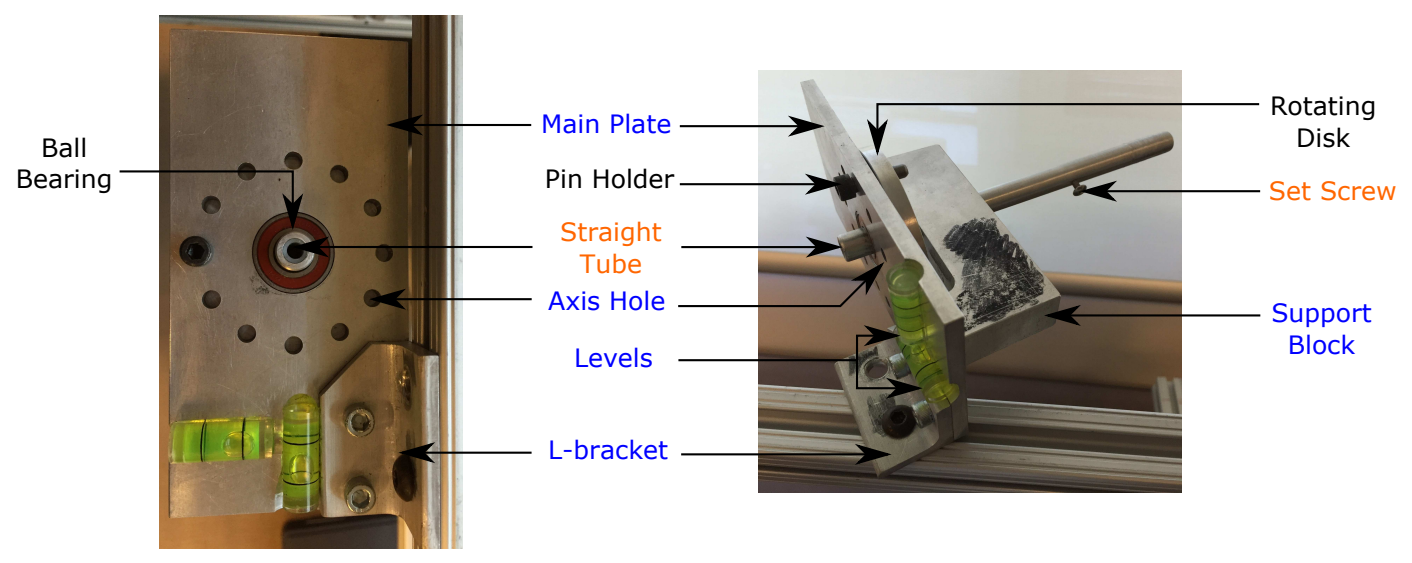

Figure 4.12: Six-orientation measurement device where blue labels represent different features of the main body part while orange labels show components of the hollow tube part

A KG-6900-2RS ball bearing was first press-fitted on to the body plate. A 2.5" diameter disk was held at the gap between main body's plate and its supporting block while the hollow tube was pressed-fit through an inner ring of the bearing, through the rotating disk and a supporting block. This permitted rotation between the hollow tube and twelve holes. A hole, following the exact same location and size as twelve of the ones setup on the main body, was drilled on the rotating disk. This allowed the probe holder to stop at desired location for measurements (i.e., every $30^{\circ}$ ).

A $1 / 32^{\prime \prime}$ thick plastic tube was inserted inside the hollow tube, allowing the probe holder to be rotated concentrically with twelve holes from the main body. A set screw was installed along the tube body to prevent the probe holder from sliding.

The hot-wire probe was connected to one end of a $235 \mathrm{~mm}$ long probe holder while the other end of the holder was connected to an single-channel AN-1005 constant temperature anemometry system from A.A Lab Systems Ltd. (located in Pennsylvania, US), through an coaxial cable. The signal from the anemometer was amplified, offset, and filtered by a signal conditioning unit [85]. Traditionally the voltage output of the anemometer could range from $-10 \mathrm{~V}$ up to $+10 \mathrm{~V}$. However, due to the requirement 
from the statistical analysis in Equation 4.17 where all anemometer voltage values E needed to be either positive or negative, to prevent double roots in the solution. Hence, the anemometer output voltage was set between $0 \mathrm{~V}$ and $+10 \mathrm{~V}$. The analog data from the anemometer was acquired by a National Instrument Data Acquisition (DAQ) 14-bit NI USB-6009 through a coaxial cable.

\section{Traverse system}

Aluminium T-slot beams purchased from CPI Automation Ltd. (Ontario, Canada) with square cross-section of size $2.54 \times 2.54 \mathrm{~cm}$ ( $1 \times 1$ in) were used to construct the 1D-traverse system. To perform hot-wire measurement, a fixed frame was built around the condenser where its fan centre of rotation was $1.24 \mathrm{~m}$ away from the wall and coincided with the centre of the frame. Sitting parallel to the condenser and the Air Director exit surfaces, the traverse beam was supported by two T-slot beam on both sides. A timing belt was installed along the whole length of the traverse beam. The probe system was fixed on the moving plate which was attached to the belt. This allowed manual translation in one direction for the probe system which consisted of the six-axis rotation device, the probe holder and the hot-wire probe.

Figure 4.13 provides an illustration of the setup for case with the VairTEX AD added on top of the condenser unit. It should be noted that the measuring line was offset from the exit surface of the air director by a distance of $1 \mathrm{~cm}$. For measurement without the $\mathrm{AD}$, the traverse beam was lowered down and distance from the traverse beam to the measuring line, and distance from the measuring line to the condenser exit surface remained the same. 


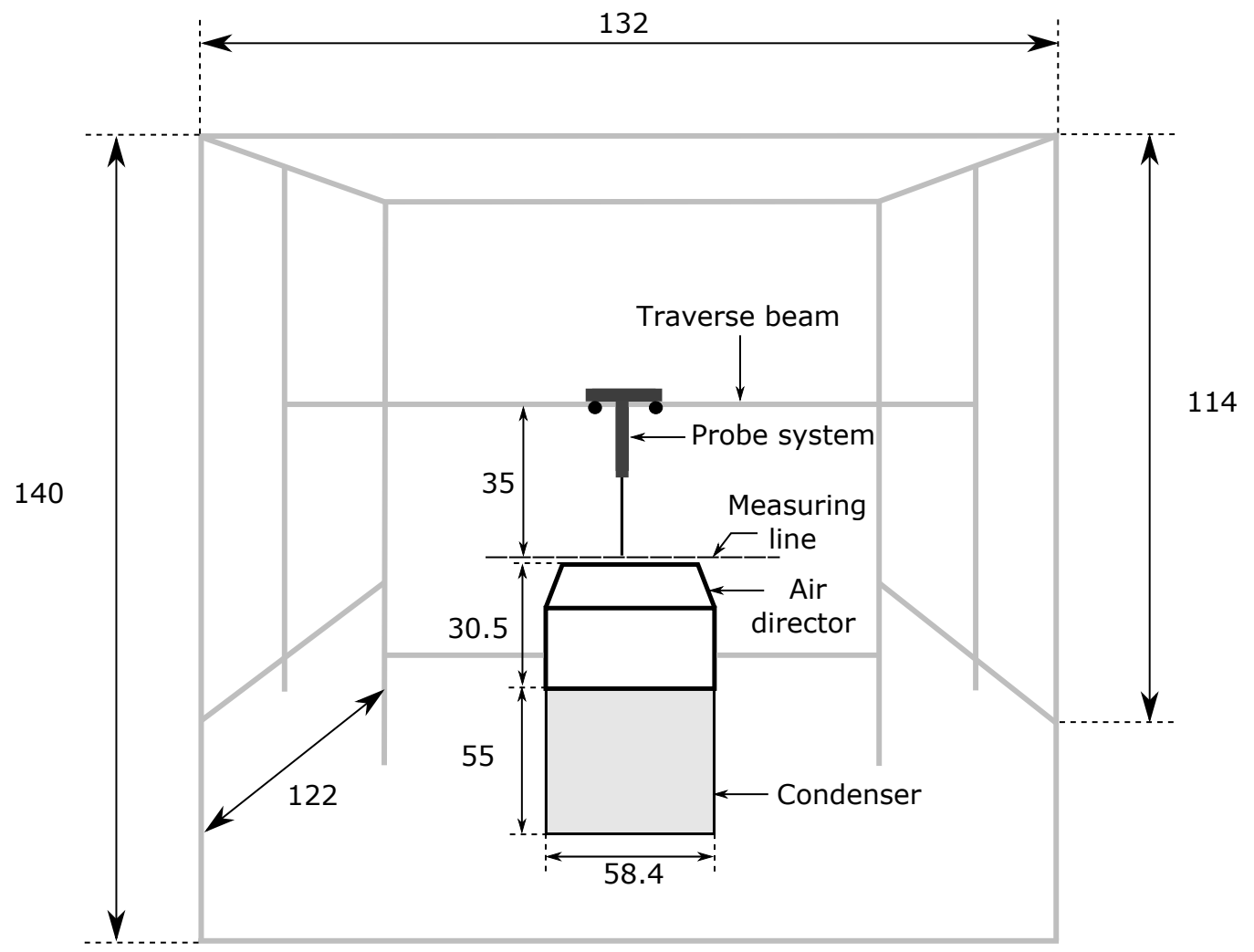

Figure 4.13: Schematic of a 1D traverse system surrounding the condenser unit in room ME2230-30 at Carleton University. Note that all dimensions are in $\mathrm{cm}$

A close-up view of the measuring lines for two study cases is shown in Figure 4.14. In the case without the $\mathrm{AD}$ applied on the condenser, a line of measurement at the condenser discharge contained 19 points which were placed symmetrically around the centre rotation of the condenser fan. While in the case with the AD added on, a total of 11 locations were measured symmetrically at the Air Director surfaces. It should be noted that the condenser has the outer diameter of $0.58 \mathrm{~m}$, however the top discharge surface has a diameter of $0.47 \mathrm{~m}$. The volumetric flow rate based on velocity measurement will be evaluated with respect to the top discharge diameter only. 


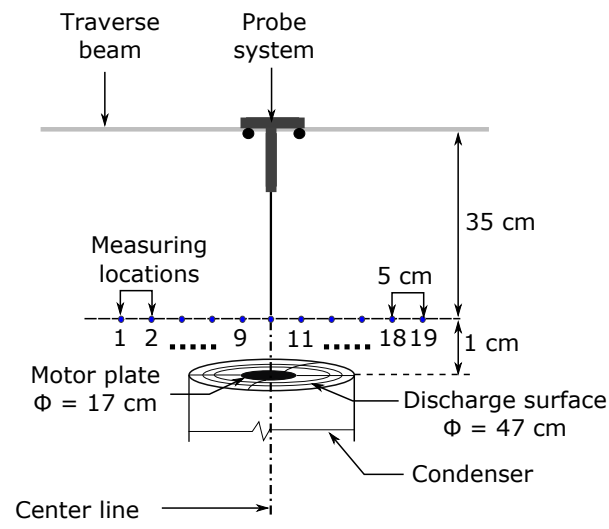

(a)

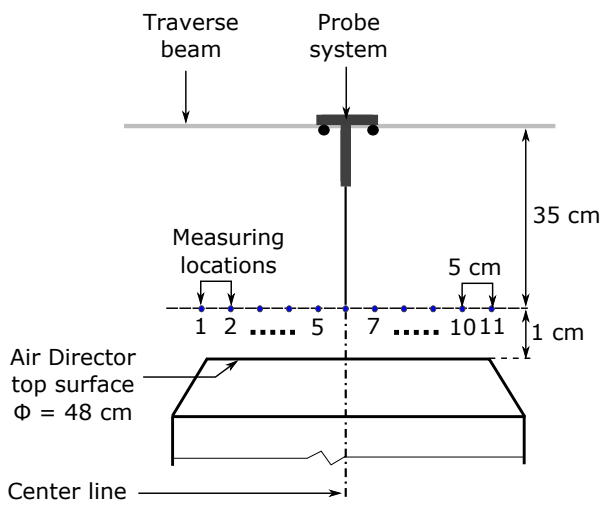

(b)

Figure 4.14: Hot-wire measuring locations in reference to the condenser (a) and Air Director (b) exit surfaces

\section{Hot-wire probe}

Manufactured by Dantec Dynamics, the single hot-wire probe consists of a platinumplated tungsten sensor of length $1.25 \mathrm{~mm}$ and of diameter $5 \mu \mathrm{m}$. The technical data for the hot-wire probe 55P11 used in this experiment is detailed in Table 4.3

\begin{tabular}{|c|c|}
\hline Sensor resistance & $3.15 \Omega$ \\
\hline TCR $^{1}$ & $0.36 \% /{ }^{\circ} \mathrm{C}$ \\
\hline Maximum sensor temperature & $300^{\circ} \mathrm{C}$ \\
\hline Maximum ambient temperature & $150^{\circ} \mathrm{C}$ \\
\hline Maximum velocity & $500 \mathrm{~m} / \mathrm{s}$ \\
\hline Frequency limit & $400 \mathrm{kHz}$ \\
\hline
\end{tabular}

1. Temperature coefficient of resistance

Table 4.3: Technical data for a miniature single-wire probe from Dantec Dynamics 


\section{Hot-wire sampling rate and duration}

The sampling duration for most axial flow fan studies found in literature varied from $15 \mathrm{~s}$ to up to maximum of $30 \mathrm{~s}$ [86-88], despite the difference in fan configuration (i.e.

fan speed [rpm], number of blades, hub size, etc.). Hence, at a single measurement location, each measurement position was sampled for $30 \mathrm{~s}$. This resulted in a total of 3 minutes of total sampling time for a single location. The condenser fan used in this experiment consisted of 2 blades.

An experimental study on an axial flow fan in a split-type air conditioner outdoor unit was performed by Zhao (2013) in which a frequency of $2.58 \mathrm{kHz}$ was selected for spectra analysis [89]. Furthermore, it was found in Xu's work that for axial flow fan, the frequency of interest was around $2 \mathrm{kHz}$ [90]. Thus, sampling rate was chosen as 4 $\mathrm{kHz}$, which covered the interest frequency of an axial flow fan. A further caution was taken to check whether the chosen sampling rate was adequate. HWA measurements at two locations (6 and 7) were sampled at four rates $(1,2,4$, and $8 \mathrm{kHz})$ to resolve for three velocity components: radial, axial, and tangential.

It can be seen in Figure 4.15 (a), (b) and (c), at location 6 the radial and axial components only varied slightly between all sampling rates, while tangential component converged after $2 \mathrm{kHz}$. For location 7, all components converged after $2 \mathrm{kHz}$. Hence, the chosen sampling rate $(4 \mathrm{kHz})$ was adequate. 


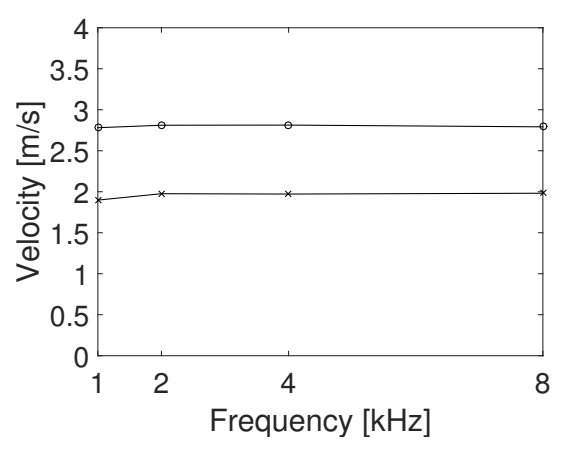

(a)

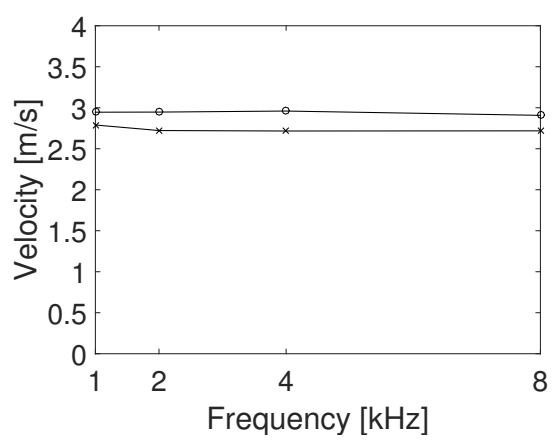

(b)

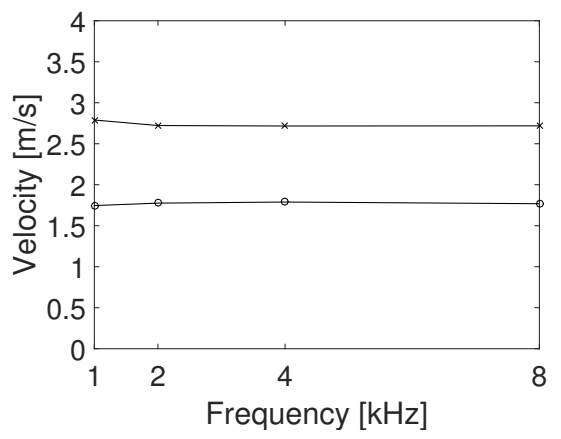

(c)

Figure 4.15: Three velocity components: Radial (a), Axial (b) and Tangential (c) were resolved after sampling at 1,2, 4 and $8 \mathrm{kHz}$, where ' $\mathrm{o}$ ' represented measurement taken for location 6 while ' $*$ ' stood for data points of location 7

\subsubsection{Temperature measurement}

Temperature measurements were recorded simultaneously with measurements from HWA. Readings from the thermocouple (TC) were acquired by a portable USB 2.0 full speed thermocouple/voltage input data acquisition module Omega DAQ USB 2401. Data was sampled at $1 \mathrm{kHz}$ which is the maximum rate of the Omega DAQ. A sealed junction thermocouple 30 -gauge-wire $(0.255 \mathrm{~mm})$ type-K with insulation thickness of $0.635 \mathrm{~mm}$ from J-KEM Scientific Inc. was used to perform temperature measurement at the exit surfaces of the condenser and the Air Director.

It was impossible to place the $\mathrm{TC}$ at same location as the hot-wire sensor because 
not only the TC can damage the fragile sensor but also, the TC could obstruct the air flow and contaminate the hot-wire reading if it was placed too close to the hot-wire sensor. Hence, the size of TC was chosen to minimize its obstruction in reading of the hot-wire sensor. In addition, carefully taped to the body of the hot-wire probe, the thermocouple was mounted $5 \mathrm{~mm}$ downstream from the hot-wire sensor. To ensure this distance was adequate, 10 measurements on the left side of the condenser, followed the same setup as in Figure 4.14 (a) - were taken to compare average voltage readings of the HWA with and without the TC installed.

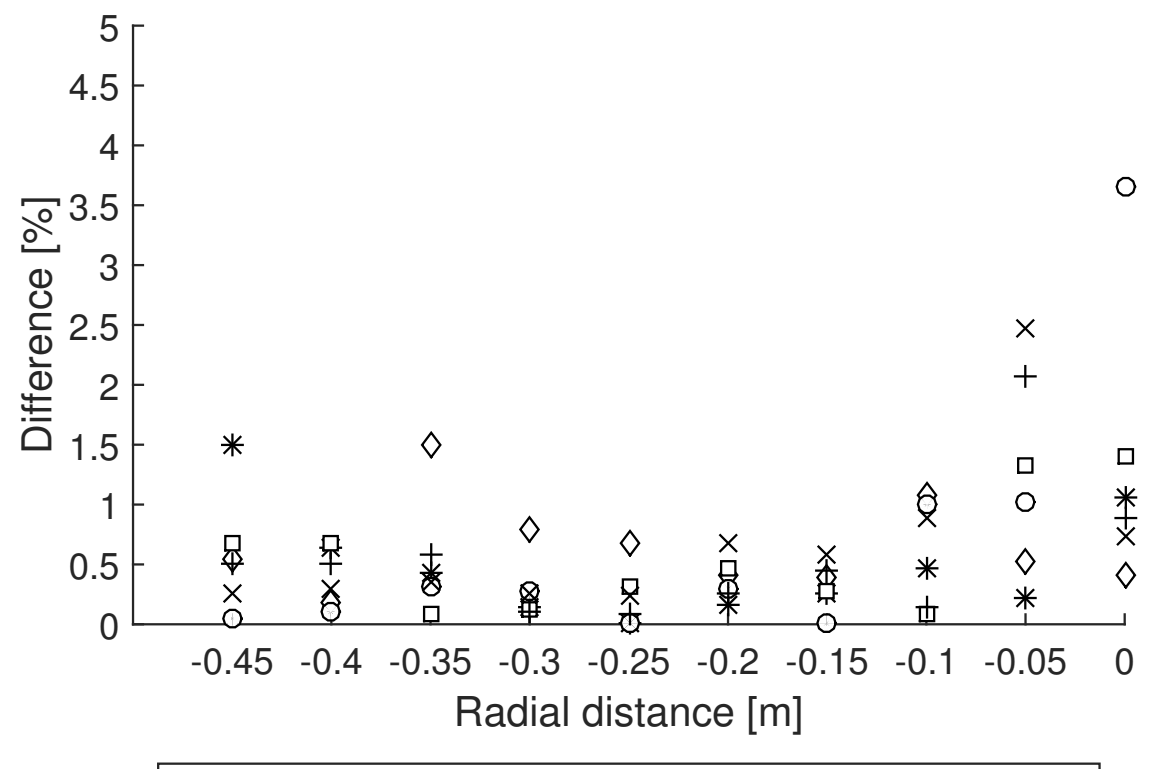

Figure 4.16: Percent differences of average voltages between with and without TC installed at six measuring positions referred to Figure 4.5 where P1, P2, ...., and P6 represent position 1 , position $2, \ldots \ldots$. , and position 6 .

Figure 4.16 shows percent differences of average voltages recorded between two cases: with and without TC for six measuring positions referred in Figure 4.5 where the maximum difference was $3.6 \%$. It is observed that higher percentage differences for 
average voltages were located toward the centre rotation of the condenser fan. From setup in Figure 4.14(a), it should be noted that the condenser fan plate was located at a radial distance of $-0.85 \mathrm{~m}$ to $0.85 \mathrm{~m}$ on the measuring line. Due to blockage and heat effects from the motor and its plate, velocities were expected to be close to zero while air temperatures in this region were warmer than room temperature. This warm air contributed to the natural convection buoyancy effect on the hot-wire sensor which increased error of hot-wire reading and resulted in higher difference between measurements. Where air flow was intense (i.e. from -0.25 to $-0.45 \mathrm{~m}$ on the radial distance scale), a maximum difference was about $1.5 \%$, which was small enough to compromise in order to make measurements possible.

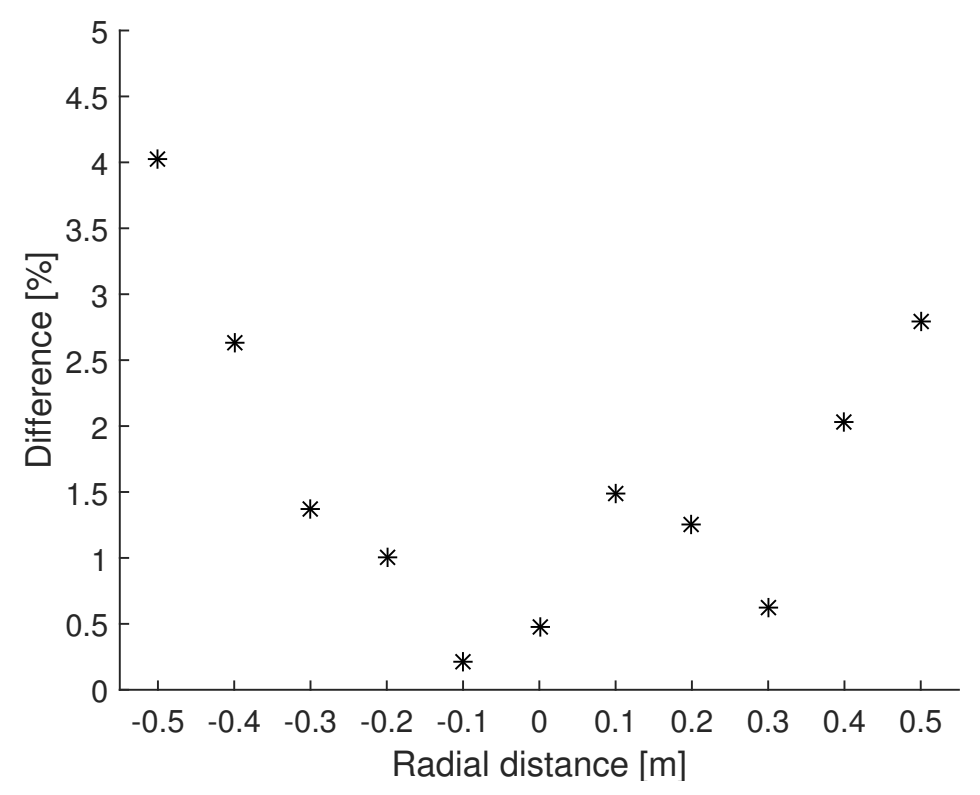

Figure 4.17: Percentage difference between temperature recorded at exact hot-wire sensor and offset locations

Moreover, temperature correction plays an important role in getting accurate velocity calculations from the SOM. It is necessary to evaluate the temperature difference between where the hot-wire sensor is located and the offset location where the 
thermocouple is actually measured. Due to the accuracy limit of type-K TC (approximately $\pm 2.2^{\circ} \mathrm{C}$ ), instead of examining half section of a measuring line, 11 locations were measured across the condenser exit surface. Temperature percentage difference between two setups is displayed in Figure 4.17. It is observed that the percentage difference slightly increased toward the two edges of the measuring line. However the maximum value (4\%) was still below the error produced by type- $\mathrm{K}$ thermocouple for the range of measurement in this study $\left(17-31^{\circ} \mathrm{C}\right.$ corresponding to $\left.6-12 \%\right)$.

\subsubsection{Experimental procedure}

Before any HWA measurements were taken for both cases - with and without the VairTEX AD, AC system was run for 40 minutes to reach a steady state at 0.35 $\mathrm{gal} / \mathrm{min}(1.32 \mathrm{~L} / \mathrm{min})$ refrigerant flow meter reading, at a low evaporator fan speed setting. This ensured condenser fan performance as well as air temperature exiting from the condenser discharge surface to reach a uniform state. For each study case, the following procedure was used for 3 experimental trials for velocity measurements collected by the HWA. Each trial was taken on a different day. It should be kept in mind that measurement "location" was referred to a point on a measuring line. While "position" was applied to 6 measuring orientations in the SOM.

- Probe system was locked to the furthest left measuring location - labelled 1 as indicated in Figure 4.2.4 (a) or (b).

- Measurements were started at position 1. During this period, both hot-wire signal and thermocouple signal were acquired simultaneously through LabVIEW software and Omega Data Acquisition software for 30 seconds.

- The hot-wire probe was manually rotated to the next position until it reached position 6. Measurements at each position followed the same acquiring process 
as position 1.

- The probe system was manually traversed to next location and the two previous steps were repeated until data of the last location was completely achieved.

Each location took approximately 3 minutes to complete data acquisition, excluding the manual rotating time which could take up to 2 minutes. 


\section{Chapter 5}

\section{Results and Discussion}

This chapter will summarize the results from the thermodynamic performance evaluation on the air conditioning system described in Chapter 3. In addition, the results from hot-wire and temperature measurements will also be discussed to characterize air flow from condenser exit and provide a comparison of three velocity components - radial, axial and tangential between two study cases: without and with VairTEX AD add-on.

\subsection{Air Conditioning Performance Evaluation}

The AC performance was tested at 2 flow meter readings of 0.25 and $0.35 \mathrm{gal} / \mathrm{min}$ which corresponded to refrigerant mass flow rate of $0.016 \mathrm{~kg} / \mathrm{s}$ and $0.022 \mathrm{~kg} / \mathrm{s}$, correspondingly, for two cases: with and without the AD. For simplification in the discussion, all results are presented with respect to the flow meter readings instead of refrigerant volumetric flow rate. Also, Figure 3.3 is reproduced in this section to help the readers following the discussion easier. 


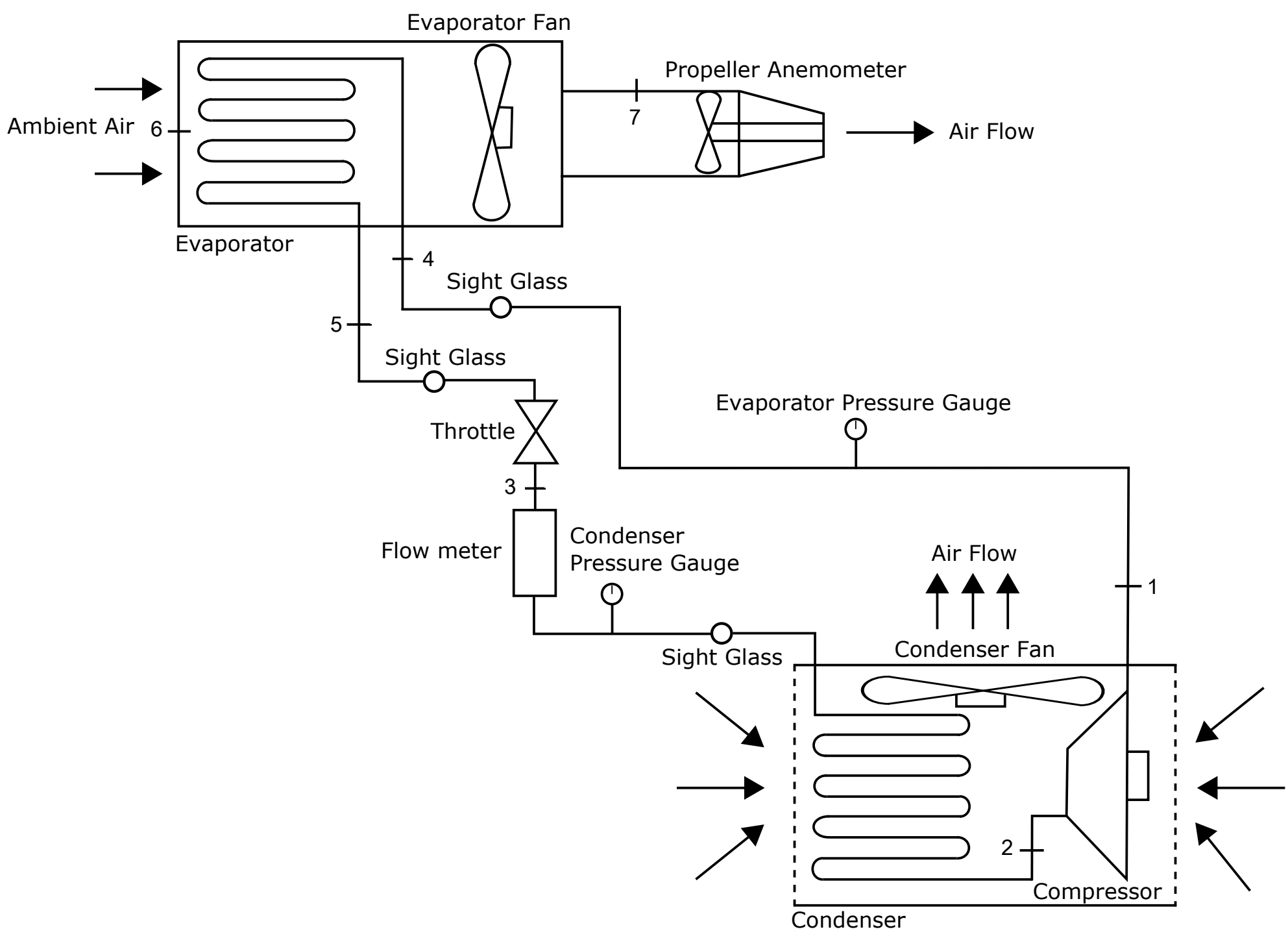

Figure 5.1: Carrier air conditioning system and instrumentation - Adapted from MAAE2400 Lab Manual 


\subsubsection{Temperature measurements}

\section{Refrigerant temperatures}

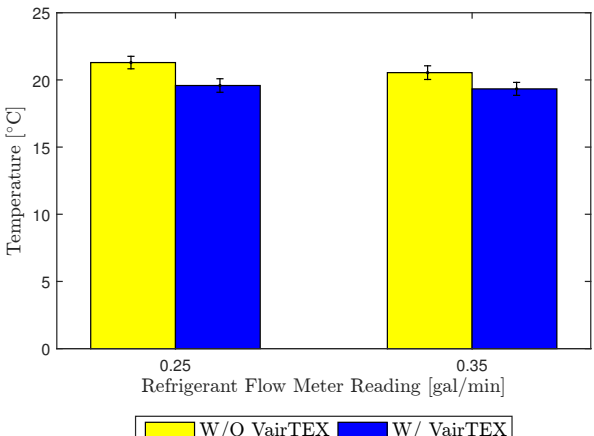

(a) T1 - At the compressor inlet

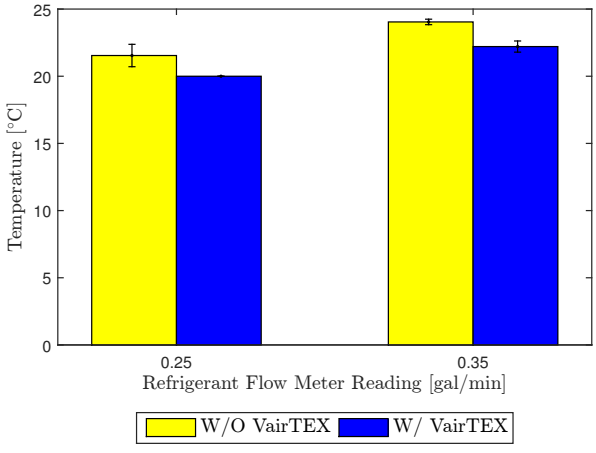

(c) T3 - At the throttle inlet

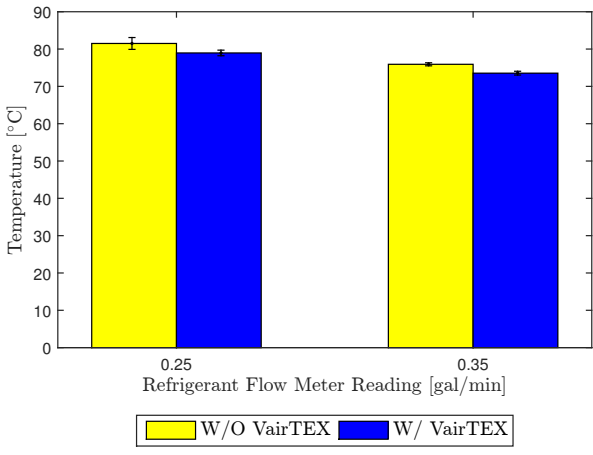

(b) T2 - At the condenser inlet

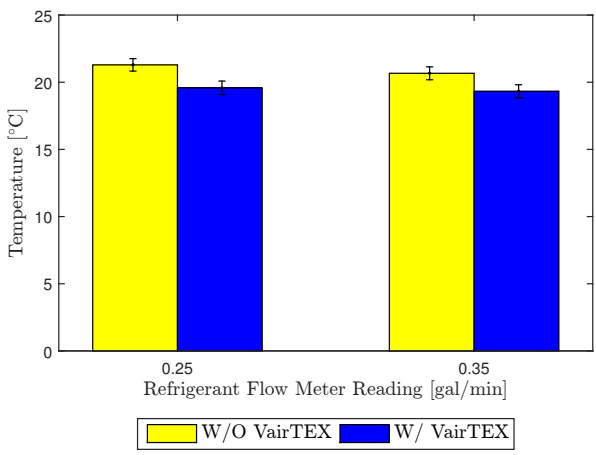

(d) T4 - At the evaporator exit

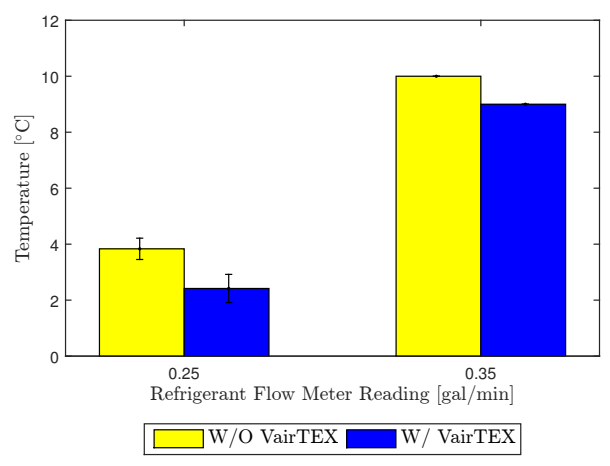

(e) T5 - At the evaporator inlet

Figure 5.2: Refrigerant temperatures recorded at five locations indicated in Figure 5.1 where (a), (b), (c), (d), and (e) corresponding to location 1, 2, 3, 4, and 5 with and without the $\mathrm{AD}$ added on the condenser exit surface for two refrigerant flow meter readings 0.25 and $0.35 \mathrm{gal} / \mathrm{min}$ 
Refrigerant temperatures were measured at 5 locations indicated in Figure 5.1 with and without the VairTEX AD added on. Comparisons of refrigerant temperatures between two cases: with and without the VairTEX AD are illustrated in Figure 5.2 where (a), (b), (c), (d), and (e) correspond to temperature at measuring location 1 , $2,3,4$, and 5 , respectively. It is intriguing that all refrigerant temperatures dropped when the $\mathrm{AD}$ was added on the condenser. The most significant drops were $2.5^{\circ} \mathrm{C}$ and $2.4^{\circ} \mathrm{C}$ for a flow meter readings of 0.25 and $0.35 \mathrm{gal} / \mathrm{min}$ respectively, which both occurred at location 2 (after the compressor). Table 5.1 summarizes mean refrigerant temperatures measured at five locations, as shown in Figure 5.1.

\begin{tabular}{ccccc} 
& \multicolumn{2}{c}{$\mathbf{0 . 2 5}[\mathrm{gal} / \mathbf{m i n}]$} & \multicolumn{2}{c}{$\mathbf{0 . 3 5}[\mathrm{gal} / \mathbf{m i n}]$} \\
\hline Variable & W/O AD & W AD & W/O AD & W AD \\
\hline$T_{1}$ & 21.3 & 19.6 & 20.5 & 19.3 \\
$T_{2}$ & 81.5 & 78.9 & 75.9 & 73.5 \\
$T_{3}$ & 21.5 & 20 & 24.0 & 22.2 \\
$T_{4}$ & 21.3 & 19.6 & 20.7 & 19.3 \\
$T_{5}$ & 3.8 & 2.4 & 10.0 & 9.0 \\
\hline
\end{tabular}

Table 5.1: Refrigerant temperature (measured in ${ }^{\circ} \mathrm{C}$ ) mean values obtained from three repeats at two refrigerant flow rates with and without the $\mathrm{AD}$

It was hypothesized that the AD increased air flow across the condenser and enhanced condenser coil heat rejection. Thus, the overall temperature of the refrigerant was reduced across 5 measuring locations in the system. The answer will be revealed in velocity measurement section.

\section{Air temperatures}

Figure 5.3 (a) and (b) displays air temperatures measured at the inlet and exit of the evaporator while their mean values are shown in Table 5.2. As the AC system 
is situated in a control environment, the evaporator inlet air temperature remained constant for two tests: with and without $\mathrm{AD}$ at both flow rates.

\begin{tabular}{ccccc} 
& \multicolumn{2}{c}{$\mathbf{0 . 2 5}[\mathrm{gal} / \mathbf{m i n}]$} & \multicolumn{2}{c}{$\mathbf{0 . 3 5}[\mathrm{gal} / \mathbf{m i n}]$} \\
\hline Variable & W/O AD & W AD & W/O AD & W AD \\
\hline$T_{6}$ & 20.1 & 20.1 & 20.3 & 20.3 \\
$T_{7}$ & 14.9 & 13.1 & 12.2 & 10.5 \\
\hline
\end{tabular}

Table 5.2: Air temperature (measured in ${ }^{\circ} \mathrm{C}$ ) mean values obtained from three repeats at two refrigerant flow rates with and without the $\mathrm{AD}$

As previously shown in Figure 5.2, when AD was added, refrigerant temperatures across the evaporator, specifically at locations 4 and 5, were reduced as compared to without the AD. This resulted in larger heat transfer between the air and the refrigerant. As a consequence, air temperatures at the evaporator exit were reduced by $1.78^{\circ} \mathrm{C}$ and $1.71^{\circ} \mathrm{C}$ when the $\mathrm{AD}$ was installed for both refrigerant flow rates.

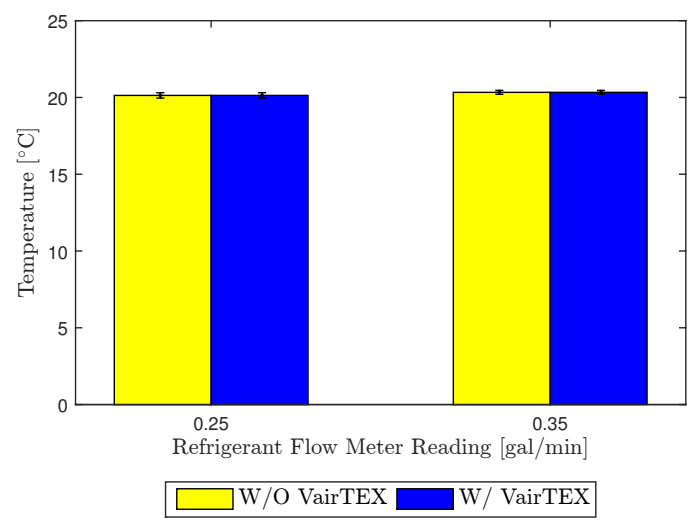

(a) T6 - At the evaporator inlet

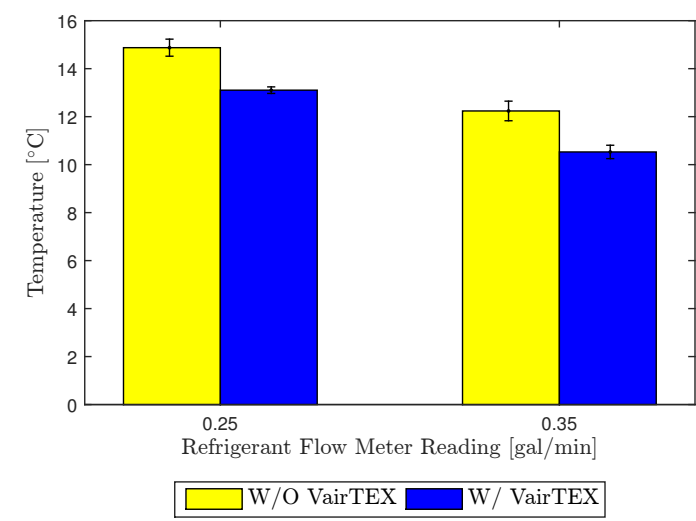

(b) T7 - At the evaporator outlet

Figure 5.3: Air temperature recorded at the inlet and exit of evaporator for two flow rates with and without $\mathrm{AD}$ applied on the condenser where (a) and (b) correspond to inlet and outlet measurements, respectively 


\subsubsection{Pressure measurements}

Two gauges in the AC set-up provided reading of refrigerant pressures at two locations: after the condenser and after the evaporator, as referred in Figure 5.1. Figure 5.4 (a) and (b) show recorded pressures after the condenser and after the evaporator, correspondingly, where the mean values are shown in Table 5.3.

\begin{tabular}{ccccc} 
& \multicolumn{2}{c}{$\mathbf{0 . 2 5}[\mathrm{gal} / \mathbf{m i n}]$} & \multicolumn{2}{c}{$\mathbf{0 . 3 5}[\mathrm{gal} / \mathbf{m i n}]$} \\
\hline Variable & W/O AD & W AD & W/O AD & W AD \\
\hline$P_{\text {cond }}$ & 171.2 & 163.4 & 180 & 172.3 \\
$P_{\text {evap }}$ & 56 & 56 & 70.7 & 70.7 \\
\hline
\end{tabular}

Table 5.3: Mean pressures [psi] measured at the condenser and evaporator gauges, obtained from three repeats at two refrigerant flow rates with and without the $\mathrm{AD}$

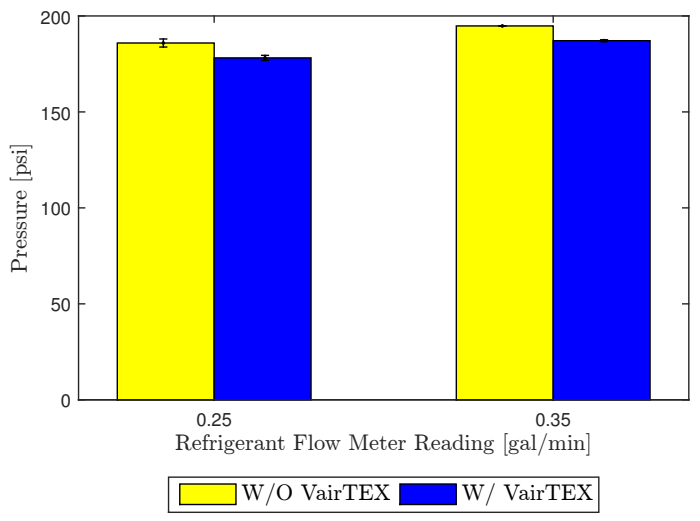

(a) Condenser pressure

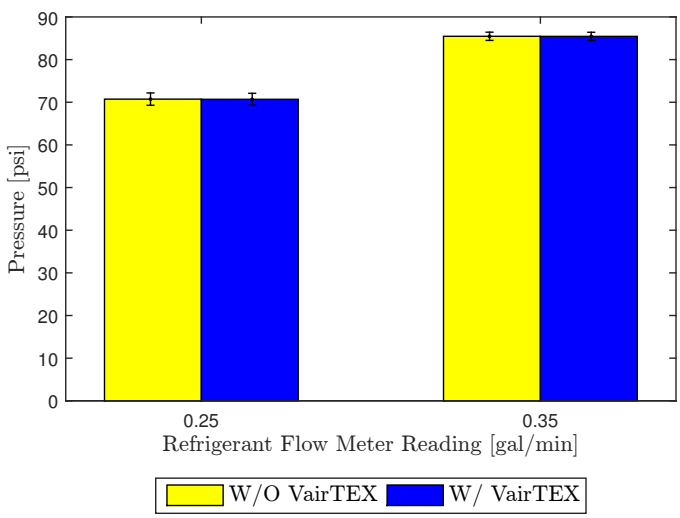

(b) Evaporator pressure

Figure 5.4: Pressured measured after (a) the condenser and after (b) the evaporator with and without VairTEX AD installed for two interested flow rates

It can be observed that pressures measured after the condenser dropped by 7.7 psi $(53.1 \mathrm{kPa})$ in case where the $\mathrm{AD}$ was installed compared to without the $\mathrm{AD}$ for both flow rates. According to Gay-Lussac's law, pressure is directly proportional to temperature [91]. As temperature at location 2 - T2 decreased when the AD was 
applied, pressure recorded after the condenser was also reduced. While pressures measured after the evaporator with and without the AD were maintained constant for both flow rates.

\subsubsection{Compressor power measurements}

Figure 5.5 depicts compressor power measured when the AC system ran with and without the AD installed on the condenser unit. An appreciable reduction in power consumption of $3.7 \%$ and $4.5 \%$ was observed for refrigerant flow rate of 0.25 and 0.35 gal/min respectively as the $\mathrm{AD}$ was applied on the condenser.

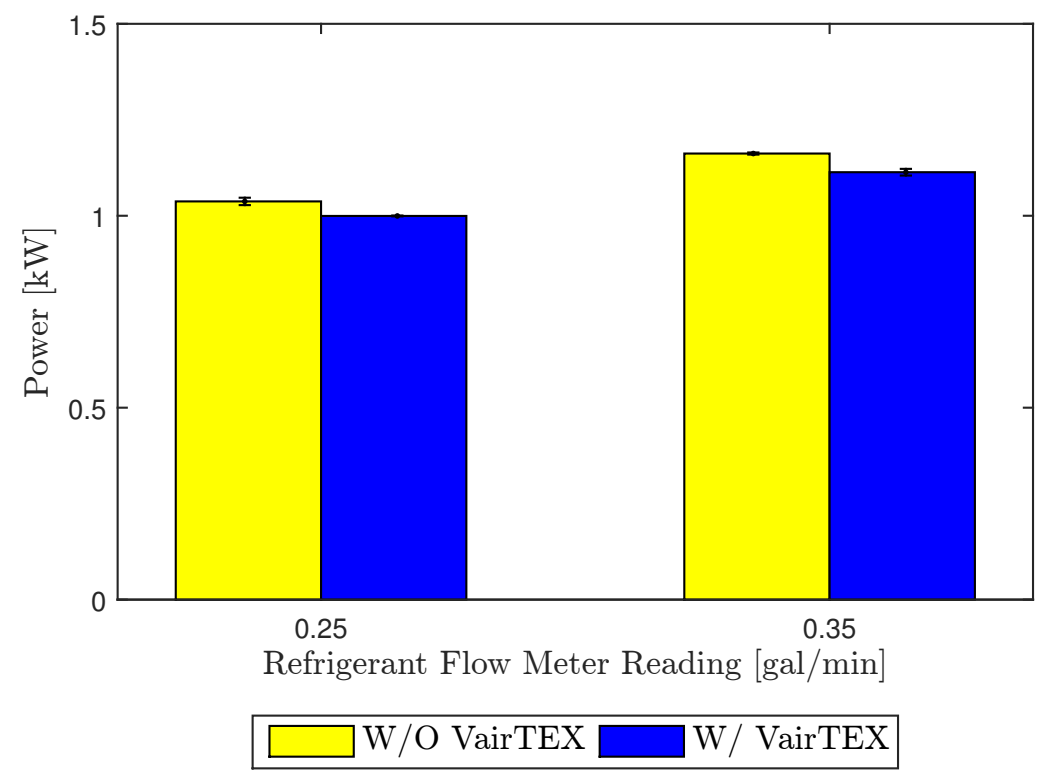

Figure 5.5: Power consumed by the compressor were recorded with and without VairTEX AD installed for two interested flow rates

It was found that T2 was lower in the case with the AD. As a consequent, power consumed by the compressor was reduced. Therefore, this result showed an agreement not only with the hypothesis made previously in which an increase in air flow across the condenser would lower refrigerant temperature, and thus reduce compressor power 
consumption. But also with finding from A. Elsayed as a reduction in compressor power consumption was reported at lower condensing temperature which was achieved by increasing air flow across the condenser [21].

As mentioned in Chapter 1, the amount of energy consumed for cooling in the southern states of the U.S reached 129 billion kWh, during the 2009 RECS survey. If one uses the average residential electricity rate in Texas which is 10.98 cents per $\mathrm{kWh}$. As the AD could reduce power consumption by $4.5 \%$, it would result in saving of 637.4 million U.S dollars, approximately. Currently, the VairTEX Canada Inc. has not revealed the unit price of the AD applied for residential AC systems. However, through internal discussion with the company, the unit could cost around $\$ 200 \mathrm{CAD}$. If a 2-ton AC system consumes $2 \mathrm{~kW}$ per hour and runs $24 / 7$, the electric bill could cost $\$ 144$ CAD per month for an average electric rate of 10 cents per hour. Hence, for $4.5 \%$ power saving obtained in this study, the payback would be 3 years.

\subsubsection{Refrigeration capacity}

Computed based on Equation 3.8, refrigeration capacities with and without AD installed for two flow rates are presented in Figure 5.6. The thermal size of a cooling system is known as its capacity, where it is dictated by the change in refrigerant temperature across the evaporator coil, besides the mass flow rate of refrigerant $\dot{m}_{R 22}$ through the coil. Higher cooling capacity is achieved by either increasing temperature change across the coil or increase the refrigerant flow rate. As demonstrated in Figure 5.6, cooling capacity increased from 0.9 tons to 1.2 tons as refrigerant flow rate raised from 0.25 to $0.35 \mathrm{gal} / \mathrm{min}$, respectively. Despite lower temperature was recorded at individual locations across the evaporator (i.e 4 and 5) in the case with the $\mathrm{AD}$, the temperature difference between location 4 and 5 remained constant regardless of the presence of $\mathrm{AD}$. This proved that the $\mathrm{AD}$ did not reduce or increase the cooling 
capacity of the system.

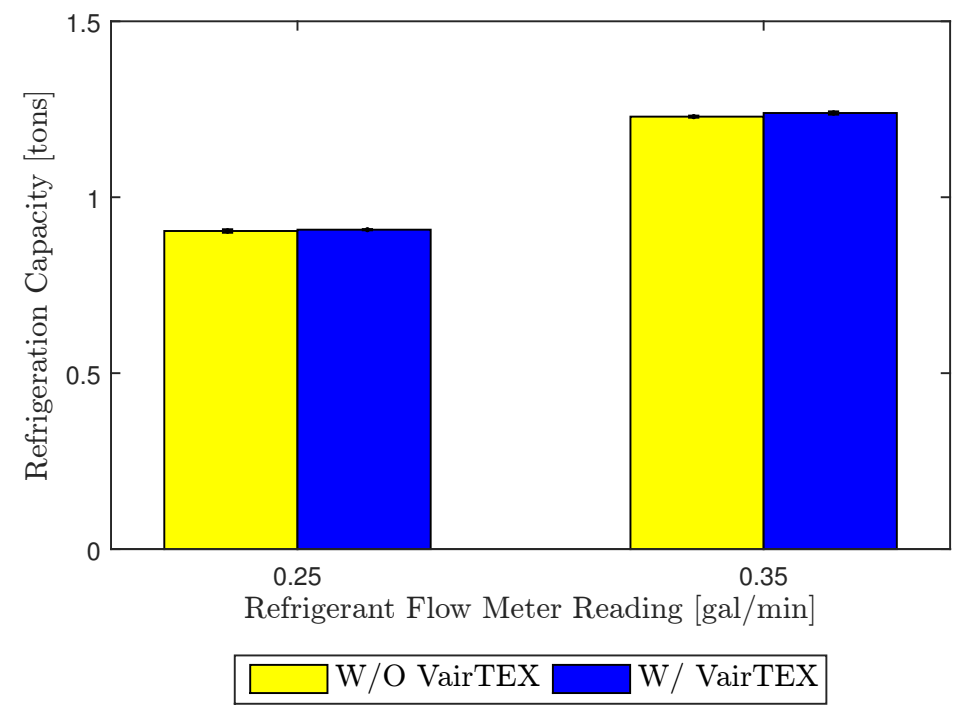

Figure 5.6: A comparison of calculated refrigeration capacity with and without the VairTEX AD on condenser unit at different flow rates

\subsubsection{Coefficient of performance (COP)}

COP is determined based on Equation 3.9 as the ratio between cooling effect over the total power input which includes power consumed by the compressor, condenser fan and evaporator fan. First, it should be noted that no modification was made to an inlet and outlet of the evaporator unit. Since the same working condition was applied, mass flow across the fan remained constant in both study cases. 


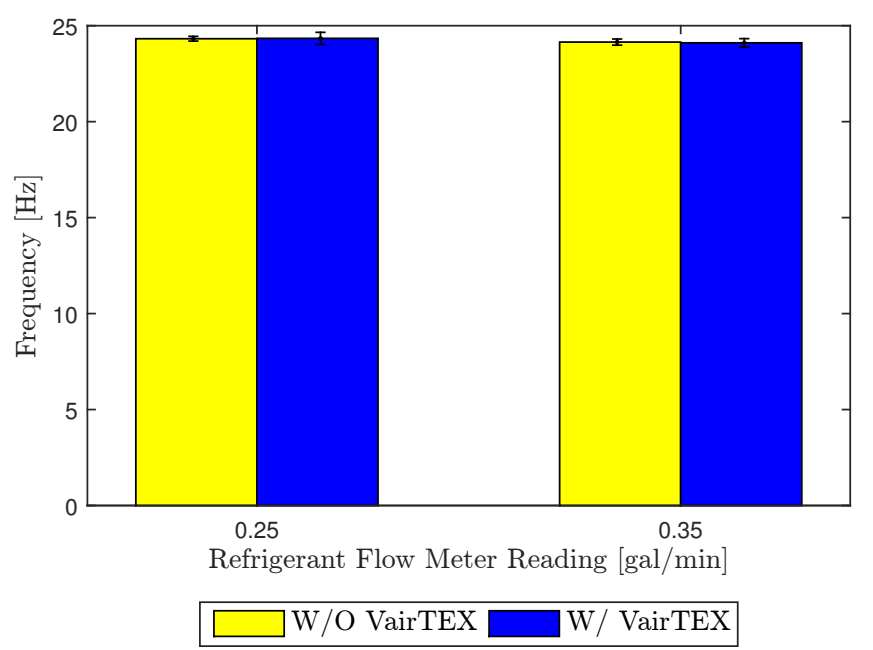

Figure 5.7: Propeller frequency measured for two designated flow meter readings with and without AD

Previously described in the experimental set-up of the AC system in Chapter 3, frequency reading of the photo-chopper transducer was used to calculate air mass flow rate across the evaporator. Figure 5.7 exhibits same frequency recorded between two cases at two refrigerant flow meter readings. Hence, it was appropriate to assume evaporator fan power consumption was constant between the two cases: with and without AD.

For condenser fan, a different approach was used to verify power consumption. The digital clamp meter Power First was used to measure the amperage drawn by the fan. The amp reading was then utilized to evaluate the power consumption. As shown in Figure 5.8, amperage drawn by the fan was reduced as the AD was installed for both flow rates. However, due to the resolution of the amp clamp, the reduction fell within the standard error of the device. Hence it is reasonable to assume the condenser fan demands the same amount of power with and without AD presence. 


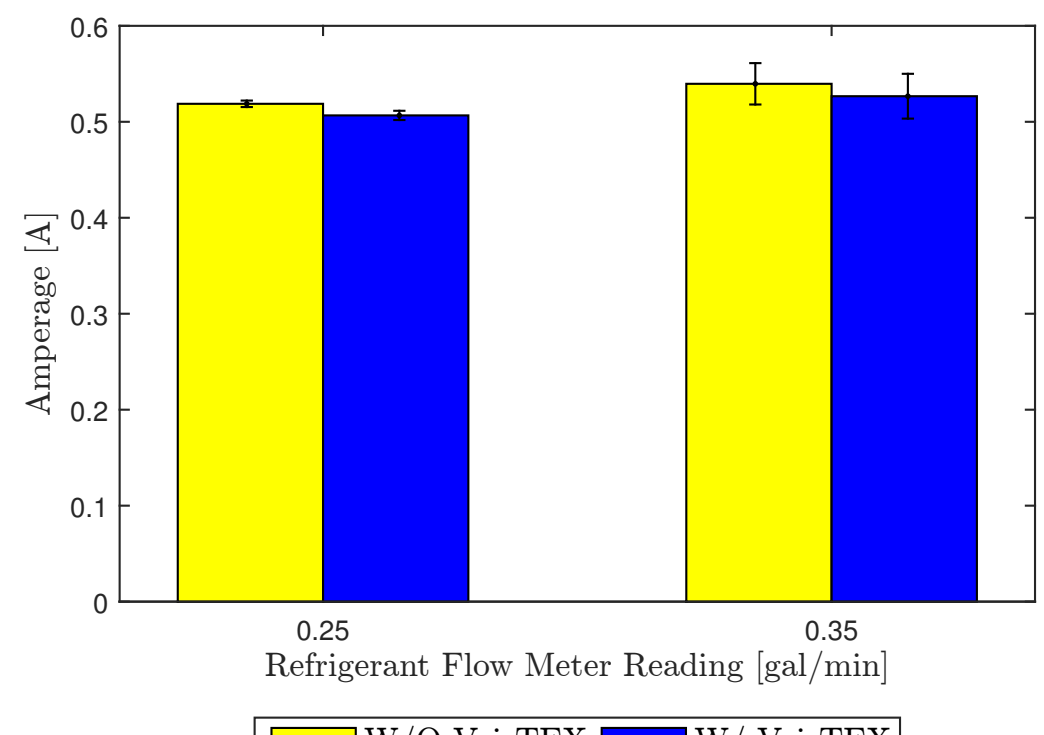

Figure 5.8: Amperage drawn by condenser fan with and without the VairTEX AD installed

Since power consumed by evaporator and condenser fans stayed constant between study cases, COP depends on two variables: compressor power and refrigeration capacity $Q_{i n}$. Increasing COP can be achieved by either increasing refrigeration capacity or reducing compressor power consumption. As displayed in Figure 5.5, compressor power consumption decreased when the AD was installed. Thus COP increased by $4 \%$ and $5 \%$ corresponding to flow rate of 0.25 and $0.35 \mathrm{gal} / \mathrm{min}$ when VairTEX AD was installed, as illustrated by Figure 5.9.

Table 5.4 provides a summary for mean values calculated from three repeats for several parameters displayed in previous figures and also calculated EER values for two refrigerant flow rates with and without the AD, using Equation 3.10. 


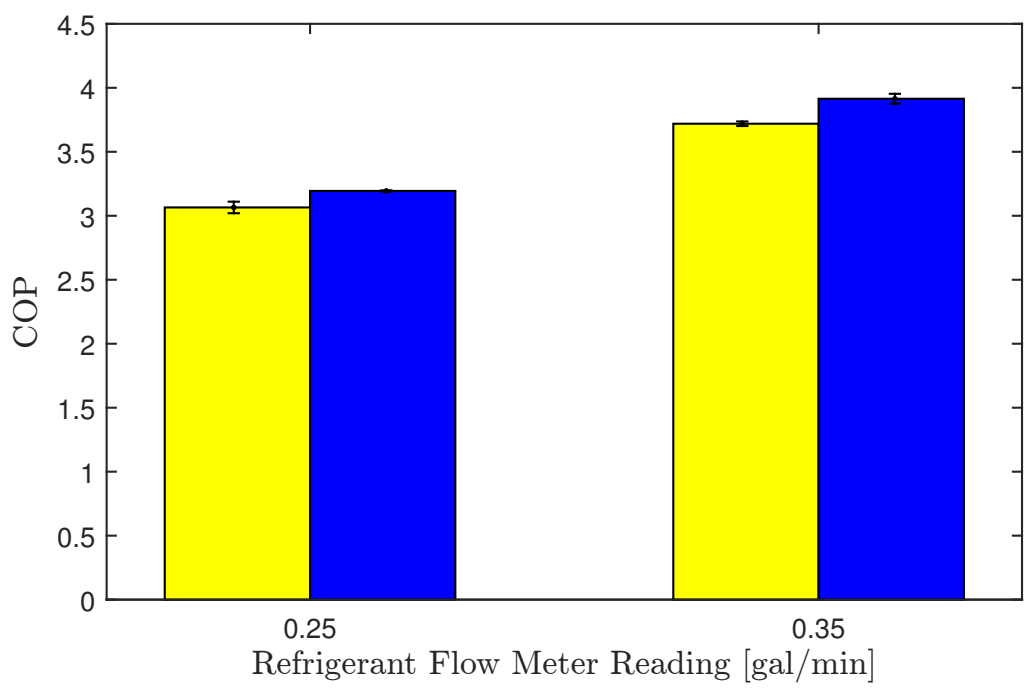

\begin{tabular}{|l}
$\square$ W/O VairTEX $\square$ W/ VairTEX \\
\hline
\end{tabular}

Figure 5.9: Computed COP for AC system

\begin{tabular}{ccccc} 
& \multicolumn{2}{c}{$\mathbf{0 . 2 5}[\mathrm{gal} / \mathbf{m i n}]$} & \multicolumn{2}{c}{$\mathbf{0 . 3 5}[\mathrm{gal} / \mathbf{m i n}]$} \\
\hline Variable & W/O AD & W AD & W $/$ O AD & W AD \\
\hline COP & 3.06 & 3.19 & 3.72 & 3.91 \\
EER & 10.5 & 10.9 & 12.7 & 13.4 \\
$\dot{Q}_{i n}[\mathrm{tons}]$ & 0.90 & 0.91 & 1.23 & 1.24 \\
$W_{C}[\mathrm{~kW}]$ & 1.04 & 0.99 & 1.16 & 1.11 \\
\hline
\end{tabular}

Table 5.4: Mean values obtained from three repeats at two refrigerant flow rates with and without the $\mathrm{AD}$

\subsubsection{T-s Diagram}

Based on mean values recorded at five measuring locations in the experimental setup, the T-s diagram for refrigerant flow rate of $0.35 \mathrm{gal} / \mathrm{min}$ was constructed, as shown in Figure 5.10. 


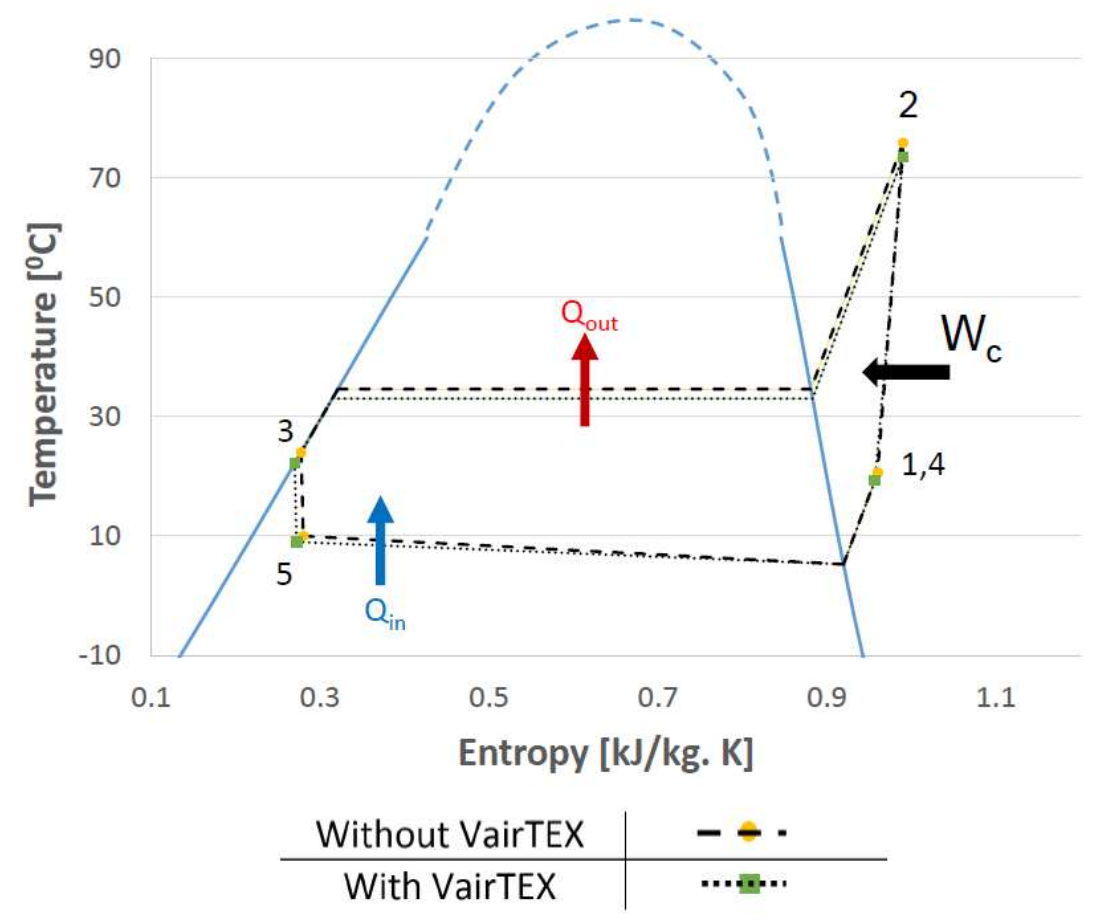

Figure 5.10: T-s diagram comparison with and without the $\mathrm{AD}$ at refrigerant flow rate reading $0.35 \mathrm{gal} / \mathrm{min}$

The blue dash line is an arbitrary line which represents the top of the liquidvapour dome due to the lack of data above $60^{\circ} \mathrm{C}$. The T-s diagram explains the performance difference between two study cases: with and without the AD from a thermodynamic point of view. Lower pressure during condensation process (2-3) was recorded in case with the $\mathrm{AD}$. As a consequence, the compressor work (1-2) $W_{C}$ was reduced. Moreover, the throttling process in case with the AD took placed at lower temperature, hence adding additional cooling effect to the cycle. From temperature and enthalpy obtained after the throttle (5), calculated pressure at this location indicated that there was a pressure drop across during the evaporation process (5-4) for both cases. By reducing the compressor power, a slight increase in refrigeration capacity increases COP, as the AD did in this case. Similarly, the same trend was obtained in case at refrigerant flow rate reading of $0.25 \mathrm{gal} / \mathrm{min}$. 


\subsection{Hot-wire Measurements}

By applying the SOM technique, mean velocity of three components: radial, axial and tangential, - were resolved where individual component will be compared between two study cases: with and without the VairTEX AD.

\subsubsection{Temperature component}

As temperatures were different between calibrations and measurements, it was crucial to obtain temperature data in order to perform a correction method presented in Section 4.4 accurately. Temperatures recorded at the designated measuring line across the condenser and the AD exits was established in Figure 5.11 below.

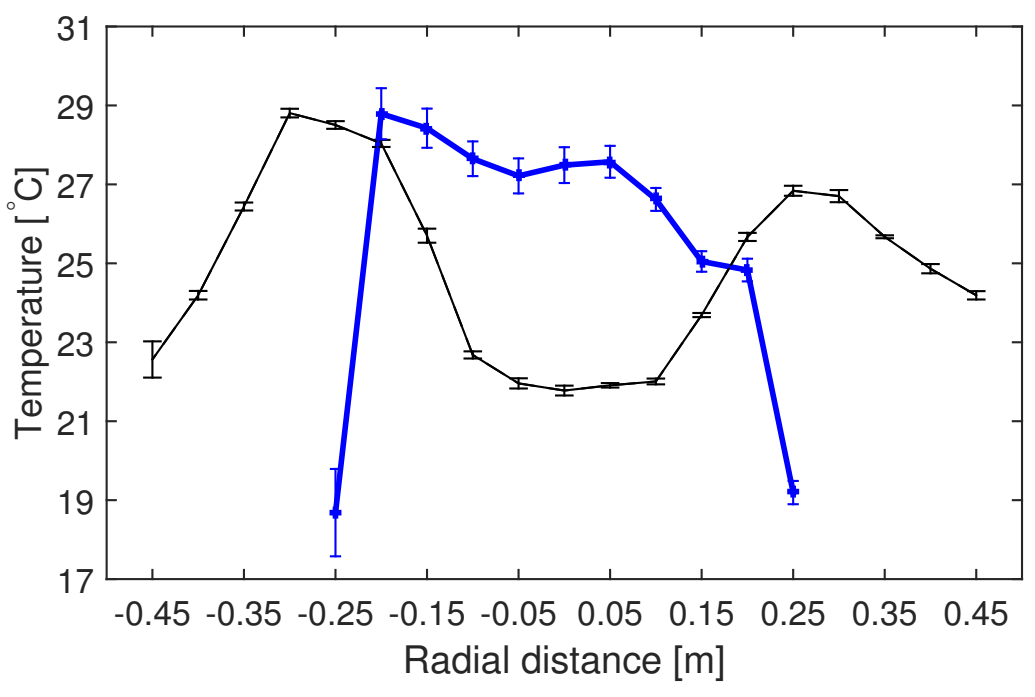

Without VairTEX AD ——With VairTEX AD

Figure 5.11: Temperature captured at condenser surface discharge and VairTEX AD exit top

In the case without the $\mathrm{AD}$, it can be seen that higher temperatures were measured at locations outside the condenser's diameter. The compressor was located slightly to 
the left side of centre of rotation. As condenser fan rotated in a clock-wise direction, the heat dissipated from the compressor was forced more to the left side which resulted in a slightly higher temperatures for this side.

The Air Director was designed to enhance the heat dissipation from the condenser unit while deliver uniform temperature at its exit. However, due to the asymmetry caused by the compressor, the temperature profile with the AD was slanted, where the higher temperature was acquired on the left side. Temperature tremendously increased across the exit of the $\mathrm{AD}$ where an average of $27.1^{\circ} \mathrm{C}$ was obtained in this case, compared to an average of $24.4^{\circ} \mathrm{C}$ without the AD. Temperature measurement has confirmed an increase in heat rejection from the condenser which contributed in an improvement of the condenser unit as a whole.

\subsubsection{Radial velocity component}

As displayed in Figure 5.12, mean radial component measured for 19 locations at the condenser exit is shown by black line while blue line represents measurements for 11 locations at the AD outlet. First, both radial components with and without the AD are subjected to a non-symmetrical profile. There are two possibilities. The imperfection of fan blades (i.e. imbalance when fan was installed, deformity of fan blades) could produce non-symmetrical flow downstream. Furthermore, the safe grill at the condenser exit does not arrange symmetrically with the fan flow exit and in reference to the measuring line.

The radial component curve without $\mathrm{AD}$ exhibits two domes where peak velocity on each dome appears symmetrical at the same radial distance of $0.25 \mathrm{~m}$ from the centre of rotation. The highest velocities recorded without the AD on both sides are closely matched where on the left side is $4.5 \mathrm{~m} / \mathrm{s}$ while that value is $4.6 \mathrm{~m} / \mathrm{s}$. Strong 


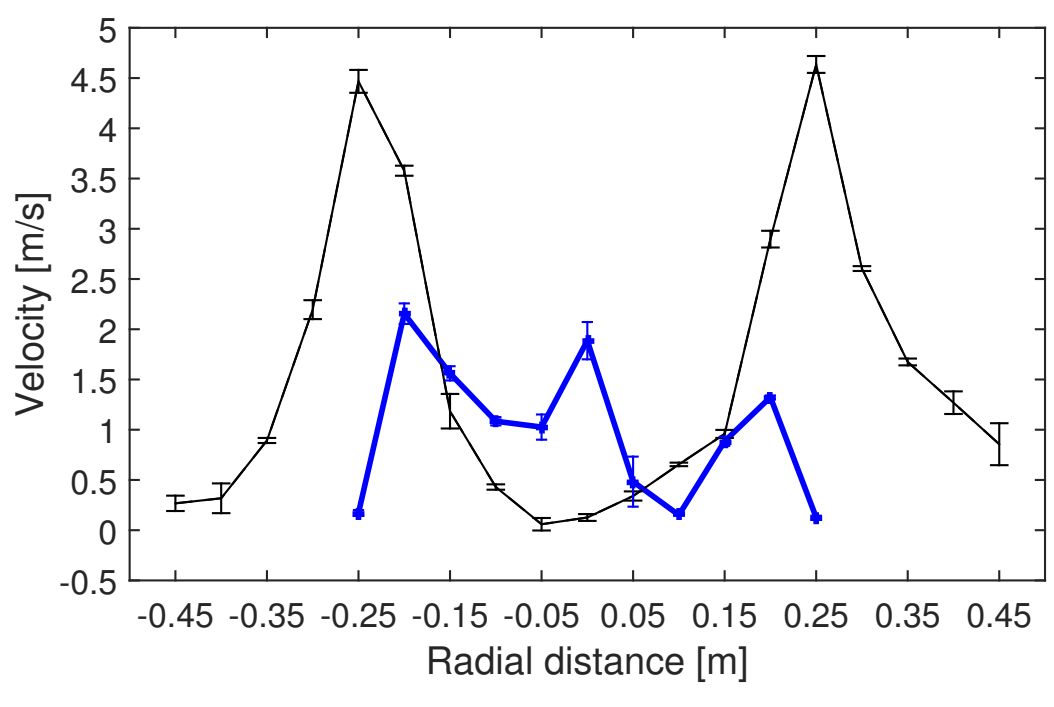

Without VairTEX AD $\longrightarrow$ With VairTEX AD

Figure 5.12: Radial velocity component measured at condenser surface discharge and VairTEX AD exit surface

and warm radial flow definitely affects air temperature at the intake region of the condenser which is located around its body.

In case without $\mathrm{AD}$, the region where motor's plate exists should expect zero velocity. However, it was shown that low velocities (maximum of $0.6 \mathrm{~m} / \mathrm{s}$ ) were recorded instead. As mentioned in Chapter 4, the hot-wire sensor produces a velocity of $0.2 \mathrm{~m} / \mathrm{s}$ from its own convection effect. Additionally, the heat from the fan motor intensifies a convection effect on the hot-wire sensor. As a consequence, velocity readings in this region do not resolve at absolute zero.

Interestingly, when applying at the condenser exit, the $\mathrm{AD}$ reduces radial component significantly. In particular, the peak velocities are reduced to a maximum of $2.2 \mathrm{~m} / \mathrm{s}$ which is more than half of the peak values found in without AD case. At locations where the motor plate exits, radial velocities emerged in this case caused by the blade effect from the AD. Due to the blade angles of the fan and the AD, 
their interactions could not cancel the radial components completely. Hence, the exit flow is slightly oblique and skewed with strong flow on the left side. Moreover, as mentioned in Chapter 1, there existed two gaps of $1.5 \mathrm{~cm}$ between three blade joints. The peak appearing at the centre of the $\mathrm{AD}$ is induced by the air rushing through those gaps.

\subsubsection{Axial velocity component}

Figure 5.13 illustrates a comparison of axial velocity component between two cases: with and without AD installed on the condenser exit. Double-peak feature and asymmetrical characteristics are observed for both cases. However, the AD reduces the difference between two peak values compared to without the AD. Maximum peak values of both curves appear on the left side from the centre of rotation where highest velocities of approximately $4 \mathrm{~m} / \mathrm{s}$ were obtained in both cases. Right peak velocity on with and without $\mathrm{AD}$ curves have values of $3.1 \mathrm{~m} / \mathrm{s}$ and $2.7 \mathrm{~m} / \mathrm{s}$, respectively.

The most noticeable improvement of axial component appears at the centre region where the motor plate is located. Without $\mathrm{AD}$, the plate causes stagnation in this region where maximum velocity is only $0.6 \mathrm{~m} / \mathrm{s}$. The same reason discussed in radial profile section is applied in this low flow region. However, when the AD is installed the axial flow is significantly increased at the centre. As exit flow from the fan was forced to escape through the cylindrical body of the AD, a sufficient height between the condenser exit and the AD blades allow the flow to develop at the centre.

In addition, by applying the trapezoid rule for two outlets: condenser and AD where the radial distance is kept constant from -0.25 to $0.25 \mathrm{~m}$ for comparison purpose, the volumetric flow rate $\mathrm{Q}$ can be approximated based on the axial velocity profile. A pronounced increment in volumetric flow rate of $48.7 \%$ was recorded when AD was 


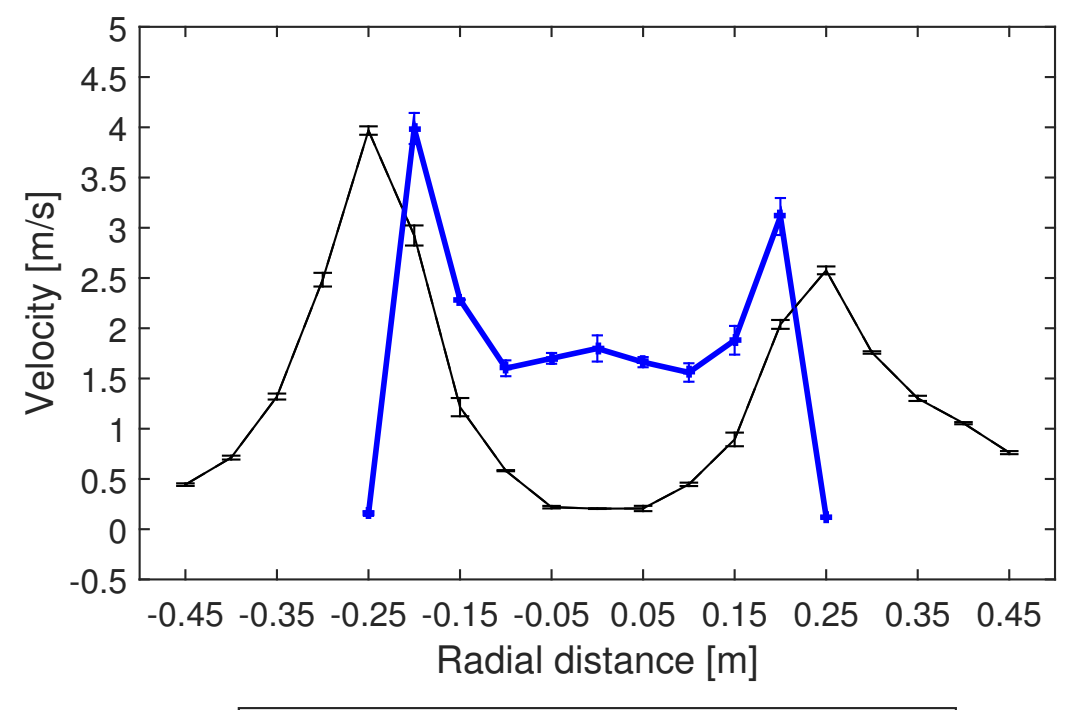

Without VairTEX AD —W With VairTEX AD

Figure 5.13: Axial velocity contour collected at condenser surface discharge and VairTEX AD exit surface

installed. Hence, the hypothesis discussed in section 5.1.1 is proven here. An increase in axial flow also enhances heat rejection by the condenser. Consequently, condensing temperature drops, thus compressor power consumption is reduced.

\subsubsection{Tangential velocity component}

As exit flow in both study cases is three dimensional, tangential component, also called swirling component, should be examined as well. Figure 5.14 displays tangential velocity component obtained from two study cases: with and without the VairTEX AD.

In the case without the $\mathrm{AD}$, tangential flow pattern follows a similar trend to radial and axial profiles as shown in Figure 5.12 and 5.13 above. No actual flow was recorded at stagnation region due to the presence of a motor plate. Values obtained in this region were caused solely by the convection effect from the hot-wire sensor. 


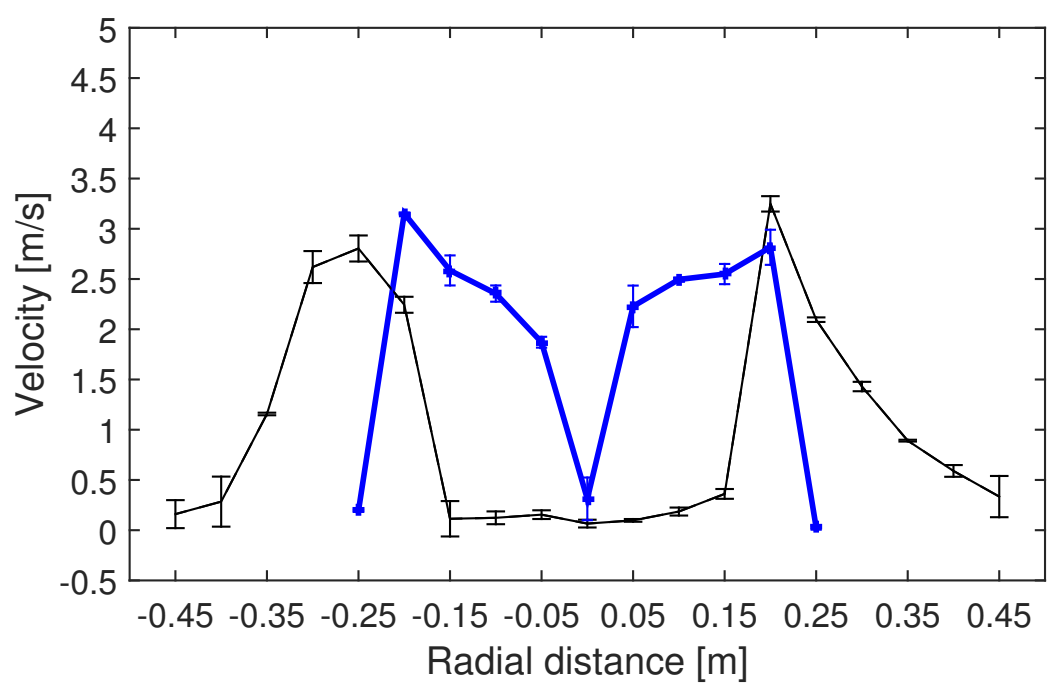

Without VairTEX AD —-With VairTEX AD

Figure 5.14: Tangential velocity profile obtained at condenser surface discharge and VairTEX AD exit surface

The asymmetrical arrangement between the safe grill and measuring locations greatly affects the values obtained for tangential component. On the left side, the dome has a smooth top while on the right side a steep slope is noticed. Moreover, peak velocity of $2.1 \mathrm{~m} / \mathrm{s}$ was found at $0.25 \mathrm{~m}$ from the centre of rotation on the left side while highest velocity of $2.8 \mathrm{~m} / \mathrm{s}$ was located at $0.2 \mathrm{~m}$ from centre of rotation.

It is intriguing to examine the tangential component in the case with the $\mathrm{AD}$ where its profile resembles tangential profiles of cyclone devices found in literature [92-94]. While tangential velocity increases with the increase of radius and after reaching its peak velocity decreases sharply, its value almost equals zero at the two edges and in the centre flow field. By reshaping the tangential component, the AD produced an almost perfect symmetrical profile where two peaks appeared at the same radial distance of $0.2 \mathrm{~m}$ on both sides. 


\subsection{Uncertainty Analysis}

No measurement can be performed with perfect certainty. Errors always exit in any experimental measurement where it exists in two forms: systematic errors and random errors. Systematic errors are defined as errors that affect the accuracy of a measurement. On the other hand, random errors are caused by the precision of a measurement. In this study, the systematic errors will be evaluated, following rules detailed in Appendix A.

\subsubsection{Velocity measurement}

\section{Calibration setup error}

The core of the calibration system used for hot-wire is the flow meter which has an accuracy of $\pm 0.7 \%$ on output reading, according to the manufacture calibration certificate. The nozzle was 3D printed where the design diameter was $18 \mathrm{~mm}$. To quantify the uncertainty on the nozzle outlet diameter, three measurements were taken using Mastercraft digital caliper with accuracy of $\pm 0.02 \mathrm{~mm}$. The average diameter of nozzle from three measurements is $17.84 \mathrm{~mm}$. By taking into account the error from caliper measurement, the nozzle diameter reading can be expressed as $17.84 \mathrm{~mm} \pm 0.2 \%$ which results in an uncertainty of $\pm 0.28 \%$ for nozzle area. The uncertainty of velocity calculated using Equation 4.34 is considered to be $\pm 0.75 \%$.

\section{Temperature correction error}

Errors in temperature correction are evaluated for both calibration and measurement. The lowest temperature recorded in calibration was $20^{\circ} \mathrm{C}$ while this value in measurement was $17.4^{\circ} \mathrm{C}$. Following Equation 4.44, when correction is performed, velocity is 
a function of temperature, thermal conductivity of air $k$ and kinematic viscosity $\nu$. Table 5.5 below lists corresponding errors associated with individual variables as well as total errors occurred during the calibration and measurement processes.

\begin{tabular}{ccc} 
Variable & Calibration & Measurement \\
\hline$k$ & $0.6 \%$ & $0.6 \%$ \\
$\rho$ & $0.75 \%$ & $0.76 \%$ \\
$\nu$ & $1.72 \%$ & $1.73 \%$ \\
$\mathrm{U}$ & $1.82 \%$ & $1.84 \%$ \\
\hline
\end{tabular}

Table 5.5: Uncertainty deduces from temperature correction for calibration process and measurements

\section{SOM technique error}

A MATLAB script was written to perform data reduction following the SOM technique. Validation of the script was conducted by obtaining hot-wire measurement at the potential core of calibration nozzle with two different orientations. The flow meter was adjusted to produce a flow rate of 40 LPM which provided a velocity of $2.62 \mathrm{~m} / \mathrm{s}$. The first case involved measurement by placing a hot-wire sensor so that the flow direction from the nozzle coincided with the v-direction on the hot-wire sensor coordinate, as referred to Figure 4.6. As a result, only one component V would be resolved if the script was applied. The computed $\mathrm{V}$ velocity differed from the expected by $0.5 \%$.

In the second case, the hot-wire sensor was arranged such that flow direction from the nozzle made up a $45^{\circ}$ to the hot-wire sensor. This generated two equal velocities of $1.85 \mathrm{~m} / \mathrm{s}$ in $\mathrm{u}$ and $\mathrm{v}$ direction with respect to the wire coordinate system. Computed $\mathrm{U}$ and $\mathrm{V}$ velocities were deviated from the expected value by a maximum amount of $1.3 \%$. 
Moreover, mean velocity of three components: radial, axial, and tangential were established using SOM technique derived by King [49]. The uncertainty associated with this method was reported by Janjua in mean velocities measurement of a confined jet with a value of $5 \%$ [95]. Hence, the uncertainty using the SOM technique in this work is assumed to be $5 \%$.

\section{Six-axis rotation device}

The CNC machine used to manufacture the six-axis rotation device has an accuracy of about $\pm 0.0254 \mathrm{~mm}\left(0.001^{\prime \prime}\right)$, therefore can be considered dimensionally accurate. Two levels were installed on the six-axis rotation device in order to align probe coordinate to the condenser's. Both indicators of two levels have accuracy of $\pm 0.1^{\circ}$. If misalignment occurred in the worse case scenario, one of the components would be off by a value of $\cos 0.1^{\circ} \times \cos 0.1^{\circ}$ which is insignificant for minimum considered velocity value of $0.4 \mathrm{~m} / \mathrm{s}$ (lowest value obtained after exclude values from convection effect). Hence this error can be neglected.

\section{Geometric scale of traverse system}

Marking at every $5 \mathrm{~cm}$ interval on the traverse beam was made using a metric ruler with graduation of $0.1 \mathrm{~cm}$. Thus, the precision can be considered to be $\pm 0.05 \mathrm{~cm}$. The largest uncertainty from geometric markings occurred in the case of velocity measurement without VairTEX AD at 19 locations which produced a combined uncertainty of $\pm 0.22 \mathrm{~cm}$. The probe system can be positioned by the user at each location with an accuracy of $\pm 0.1 \mathrm{~cm}$ approximately. The total error in the positioning process of 19 locations produces uncertainty of $\pm 0.44 \mathrm{~cm}$. Therefore, the combined uncertainty is estimated to be $\pm 0.49 \mathrm{~cm}$ or $\pm 0.54 \%$ for total measurement length of $90 \mathrm{~cm}$. 
Taking into account all discussed errors, the total uncertainty accumulated from velocity measurement is approximate $5.9 \%$ at $95 \%$ confidence level.

\subsubsection{AC Performace Evaluation}

\section{Refrigeration capacity}

Refrigeration capacity $Q_{\text {in }}$ is calculated based on mass flow rate of refrigerant and two enthalpies where their values are estimated based on pressure and temperature collected at locations 4 and 3 (assuming $h_{3}=h_{5}$ ).

The accuracy provide by the flow meter manufacture is $4 \%$ full scale of 0.7 GPM which corresponds to uncertainty of $\pm 11.2 \%$ at lowest flow rate reading of 0.25 GPM. Since $v_{R 22}$ varies insignificantly over a change in temperature of $\pm 2.2^{\circ} \mathrm{C}$ (maximum $0.73 \%$ change in value), the accuracy of $\dot{m}_{R 22}$ solely depends on accuracy of flow meter. Hence, $\dot{m}_{R 22}$ has an uncertainty of $\pm 11.2 \%$.

TC type $\mathrm{J}$ has an accuracy of $\pm 2.2^{\circ} \mathrm{C}$ while pressure gauges have accuracy of $2 \%$, based on manufacture technical specification. By varying temperatures and pressures within their accuracies, change in values of enthalpies $h_{4}$ and $h_{5}$. It was observed that temperature had a higher influence to value of $h_{4}$ in compare to pressure. However, the change in value of $h_{4}$ due to temperature change is insignificant as the highest percentage change was $0.6 \%$ which can be neglected. Enthalpy is assumed to be constant across the throttle, therefore, accuracy of $h_{5}$ depends on the temperature measured at location 3, as refrigerant is in saturated liquid state before the throttle. The error of $h_{5}$ is $3.9 \%$ obtained by varying temperature at measuring location 3 . Therefore, the error for enthalpy difference can be approximated using error in calculation of $h_{5}$.

Combining two uncertainties in refrigeration capacity calculation, the total error 
is about $11.8 \%$ for measurement at $0.25 \mathrm{gal} / \mathrm{min}$. Applying this procedure, the uncertainty of $Q_{i n}$ measured at $0.35 \mathrm{gal} / \mathrm{min}$ is approximately $8.9 \%$. It can be seen in this study, the accuracy of the flow meter has contributed greatly to the accuracy of $Q_{\text {in }}$ calculation.

\section{COP}

Since COP is calculated based on computed refrigeration capacity and measured power from the compressor. The Wavetek DM7 has accuracy of $\pm 0.8 \%$ while the refrigeration capacity has uncertainty of $11.8 \%$ and $8.9 \%$ for flow rate reading of 0.25 $\mathrm{gal} / \mathrm{min}$ and $0.35 \mathrm{gal} / \mathrm{min}$ correspondingly. Therefore the uncertainty associated with COP for two refrigerant flow rates are $11.8 \%$ and $8.9 \%$ approximately.

\subsubsection{Random error}

\section{AC performance}

The main purpose of this study was to compare the performance of an AC system with and without the VairTEX Air Director. Since same AC system was used throughout the whole study, both cases and systematic errors are 'one-sided' error. Therefore, it is more interesting to look into the statistical significance of data obtained.

Generally, p-value is used as a tool to evaluate a statistical significance. The P value is defined as the probability under the assumption of no effect or no difference (null hypothesis), of obtaining a result equal to or more extreme than what was actually observed. The P stands for 'Probability' and measures how likely it is that any observed difference between groups is due to chance [96]. To find p-value between two sets of data, a 'Student-t-test' is employed. Typically, in most engineering works,

a difference is said to be statistically significance if p-value is less than 0.05 . Hence, 
in this work, critical p-value of 0.05 will be used.

P-values in this study are assessed based on data from three trials performed for each case of interest: with and without the VairTEX AD. The most important factors to evaluate an $\mathrm{AC}$ system performance include: $\mathrm{COP}$, refrigeration capacity $\left(Q_{\text {in }}\right)$, power consumption (specifically in this study power consumed by the compressor), and air temperature produced after passing through the evaporator (T6). Table 5.6 shows several p-values obtained from comparison data of interest variables listed above between with and without using the AD at two flow meter reading 0.25 and $0.35 \mathrm{gal} / \mathrm{min}$. A p-value of less than 0.05 indicates that there is a significant difference between two cases: with and without $\mathrm{AD}$ applied on the condenser. In particular, there exists an improvement by using the AD. It can be seen that p-values of COP, compressor power, and $T_{6}$ for both flow meter reading are all less than 0.05 . Hence, it is demonstrated that they are statistically significant differences.

\begin{tabular}{ccc} 
& \multicolumn{2}{c}{ Flow meter reading $[\mathrm{gal} / \mathbf{m i n}]$} \\
\hline Variable & $\mathbf{0 . 2 5}$ & $\mathbf{0 . 3 5}$ \\
\hline COP & 0.008 & 0.001 \\
$Q_{\text {in }}$ & 0.29 & 0.03 \\
$W_{c}$ & 0.0025 & 0.0008 \\
$\mathrm{~T} 6$ & 0.0009 & 0.0065 \\
\hline
\end{tabular}

Table 5.6: Summary p-values for several interested variables collected from AC performance evaluation

\section{Velocity and temperature measurements}

Three velocity components: radial, axial, and tangential along with temperature measurement at each measuring location were averaged from three trials. Since hot-wire has minimum velocity sensitivity of $0.2 \mathrm{~m} / \mathrm{s}$, therefore uncertainties for three velocity components with values less than $0.2 \mathrm{~m} / \mathrm{s}$ will not be computed due to error 
from the convection effect of the sensor. Moreover, when forced-convection velocity is reduced (low velocity regions at condenser discharge), a mixed-flow regime is encountered both forced- and natural- convection phenomena, and thus influences the hot-wire extended power law response equation [43]. It was noted that below the lowest calibration velocity of $0.8 \mathrm{~m} / \mathrm{s}$, the extended power law does not estimate values accurately from its equation for mix-flow regime. Therefore, the uncertainty will only consider velocity component greater than $0.8 \mathrm{~m} / \mathrm{s}$.

The highest uncertainties (expressed in the form of $\sigma$ /Mean) along with their means and computed standard deviations $\sigma$ from velocity and temperature measurements are shown in Table 5.7.

\begin{tabular}{ccccccc} 
& \multicolumn{2}{c}{ W/O VairTEX AD } & \multicolumn{3}{c}{ W VairTEX AD } \\
\hline Component & Mean & $\boldsymbol{\sigma}$ & $\boldsymbol{\sigma} /$ Mean & Mean & $\boldsymbol{\sigma}$ & $\boldsymbol{\sigma} /$ Mean \\
\hline $\mathrm{U}[\mathrm{m} / \mathrm{s}]$ & 1.18 & 0.17 & 0.14 & 1.03 & 0.13 & 0.12 \\
$\mathrm{~V}[\mathrm{~m} / \mathrm{s}]$ & 0.89 & 0.07 & 0.08 & 1.88 & 0.14 & 0.08 \\
$\mathrm{~W}[\mathrm{~m} / \mathrm{s}]$ & 2.62 & 0.16 & 0.06 & 2.59 & 0.15 & 0.06 \\
Temperature $\left[{ }^{\circ} \mathrm{C}\right]$ & 22.56 & 0.46 & 0.02 & 18.68 & 1.11 & 0.06 \\
\hline
\end{tabular}

Table 5.7: Maximum uncertainties for each component resulted from velocity measurements with and without AD

Since temperature corrections were performed throughout the entire velocity measurements for both study cases using hot-wire probe, uncertainties for velocity components could come from fluctuation in temperature recording. Moreover, the SOM technique has an uncertainty itself which could contribute to the total uncertainty for each component. Maximum uncertainties for both study cases occurred at radial component $\mathrm{U}$ where uncertainties of $12 \%$ and $14 \%$ obtained for study cases with and without the AD, respectively. This could be due to the orientation of the hot-wire 
probe with radial velocity direction. In other words, the prong effect from the hotwire probe caused greater aerodynamic disturbance in radial component than other velocity components.

For temperature measurements, maximum uncertainty of $6 \%$ came from the measuring point located just outside of discharged surface of the AD. Refer to Figure 4.14 (b) measurements at two edges basically represent room temperatures. As the lab room temperature dropped suddenly during a recording of one data set, the mean temperature resulted to this high standard deviation. Other than this, if measurement is considered just within the plumes, the highest uncertainty is about $2.25 \%$. 


\section{Chapter 6}

\section{Conclusions and Recommendations for Future Work}

\subsection{AC Performance Evaluation}

Conclusion from AC performance evaluation will be summarized in the section below. Also, recommendations for future work in this particular study will be discussed.

\subsubsection{Conclusion}

Despite the maturity of the AC system, there is still room available for improvement. VairTEX has demonstrated its advantage in enhancing performance AC system, in particular reducing power consumption by the compressor while allowing the evaporator unit deliver cooler air at its exit. The following section summarizes findings throughout the performance evaluation of the $\mathrm{AC}$ system. P-values were computed to ensure differences were statistically significant.

- COP was improved by an appreciable of $4 \%$ at refrigerant flow meter reading of $0.25 \mathrm{gal} / \mathrm{min}$ while at $0.35 \mathrm{gal} / \mathrm{min} \mathrm{COP}$ was enhanced by $5 \%$, with respect to mean values for both flow rates. Caution is advised from using these values 
because of the uncertainty level for COP calculation.

- Compressor power demand reduced by $3.7 \%$ and $4.5 \%$ with respect to mean values for refrigerant flow meter readings of 0.25 and $0.35 \mathrm{gal} / \mathrm{min}$, respectively.

- AC system operated with VairTEX produced same refrigeration capacity as when it ran without the device.

\subsubsection{Recommendations}

- Improvement was demonstrated on a 20 year-old AC system. Majority AC systems using in Canada however have a maturity age of approximately 10 years, as discussed in Chapter 2. To convince more residential customers, testing should be performed on a more modern unit, as well as units from broader AC manufacturers. In addition, CSA test standards CSA C656-05 and CAN/CSAC656-14 should also be consulted for performance evaluation.

- In order to provide a more in-depth evaluation on the effectiveness of the AD, the condenser unit should be installed in a controlled environment - separately from the evaporator unit - where temperatures surrounding the condenser can be adjusted to represent a 'real-world' situation, for example summer seasonal temperatures. In addition, cross-wind has proven to effect dispersion of plumes discharged at an air-cooled condenser [9]. Hence, an artificial cross-wind can be introduced at the condenser unit to further assess the effectiveness of the VairTEX AD.

- Pressures on the refrigerant line were measured at two locations: after the condenser and after the evaporator. It was assumed that pressure remained constant across the condenser and evaporator. This does not reflect pressure 
loss which does occur along the refrigerant line. More gauges could be installed to obtain more accurate thermodynamic data at selected measuring locations on refrigerant line, for example: before and after the compressor, after the throttle, and before the evaporator coil.

- Besides an already existing power meter for a compressor, an additional power meter could be installed for the whole AC system to eliminate an assumption on evaporator fan power consumption.

- Also, the AC system could be installed in a higher ceiling room to minimize the effect of the ceiling on the plume discharge, especially in the case with the AD installed on top of the condenser unit.

\subsection{Velocity and Temperature Measurements}

Velocity measurements at condenser exit and AD exit were performed by applying the six-orientation measurement technique on a single hot-wire. Temperature measurements were also conducted not only to correct hot-wire data but also to explain such improvements in thermodynamic performance at the condenser unit. Similar to previous section, a conclusion and future work for velocity measurement will be detailed below.

\subsubsection{Conclusion}

- The AD completely modified profiles of each individual velocity component. Especially at the stagnation region where the motor plate was located, additional flow was introduced at this region. 
- The dominant velocity in case without the $\mathrm{AD}$ was a radial component while it was found to be an axial component with the presence of the AD.

- With the presence of the $\mathrm{AD}$, the radial profile was reduced significantly and redistributed to the axial component which resulted in an increase of volumetric flow rate by a substantial amount of $48.7 \%$. This demonstrated that exit flow was not only straightened by the AD but also increased volume flow rate through its top surface.

- By straightening the exit flow, the $\mathrm{AD}$ isolated exit plumes from the intake flow of the condenser unit which then allowed cooler air to enter the condenser unit.

- Additionally, cyclonic behaviour was also observed in the case with the AD, as its tangential velocity profile was similar to one found in studies of cyclone devices.

- Temperature profile measured at the AD top exit demonstrated an increase in heat dissipation from the condenser unit. As a result, refrigerant temperature was reduced - hence, reducing compressor work.

\subsubsection{Recommendations}

- To have a more accurate velocity measurement in three-dimensional turbulent flow field, cross-wire or triple-wire hot-wire probe should be used. In addition, flow visualization methods such as PIV can provide precise details at circulation zone where HWA is incapable of providing similar information.

- A thermal camera such as infrared camera could be use to provide a graphic illustration on dissipation of heat from the condenser with and without the AD. 
- Besides, a parametric study on different body sizes (diameter, height) and shapes (diffuser, nozzle, straight cylinder with and without blades), blade angles and dimensions is interesting to investigate in order to optimize performance of the $\mathrm{AD}$, and thus maximize improvement on the $\mathrm{AC}$ system.

- Lastly, a numerical work could also be used to perform parametric study on blade shape and angle, as well as body augmentation of the AD. 


\section{List of References}

[1] US Department of Energy, "History of Air Conditioning." https://energy . gov/articles/history-air-conditioning/, 2017. Accessed: 10/10/2017.

[2] US Department of Energy, "Heating and cooling no longer majority of U.S home energy use." https://www.eia.gov/todayinenergy/detail.php?id=10271\& src $=\%$ E2 $\% 80 \%$ B9 $\% 20$ Consumption $\% 20 \% 20 \% 20 \% 20 \% 20 \% 20$ Residential $\% 20$ Energy $\%$ 20Consumption\%20Survey\%20 (RECS)-f1\#, 2013. Accessed: 10/10/2017.

[3] howstuffworks, "How to Repair Central Air Conditioner." http: //home.howstuffworks. com/home-improvement/heating-and-cooling/ how-to-repair-central-air-conditioners.htm, $2017 . \quad$ Accessed: $10 / 10 / 2017$.

[4] Goverment of Canada, "2011 survey of household energy use (sheu)," tech. rep., Natural Resources Canada, 2015. http://www.nrcan.gc.ca/energy/ efficiency/17097.

[5] Goverment of Canada, "Energy efficiency trends in canada 1990 to 2013," tech. rep., Natural Resources Canada, 2016.

[6] Natural Resources Canada, "Central Air CConditioner." http://www. nrcan.gc.ca/energy/products/categories/cooling-ventilating/ air-conditioning/central/16183, 2017. Accessed: 11/10/2017.

[7] "2008 standard for performance rating of unitary air-conditioning \& air-source heat pump equipment."

[8] VairTEX Canada Inc., "Vairtex technical description," tech. rep., VairTEX Canada Inc., 2017.

[9] K. Khankari, "Optimum placement for air-cooled chillers," ASHRAE, vol. 58, 2016. 
[10] G. A. Godbout and D. A. C. Godbout, "Air conditioner turbulence creating energy saver," Jan. 2015.

[11] VairTEX Canada Inc., "Internal communication report." October 2017.

[12] E. G. Pita, Air Conditioning Principles and Systems - An Energy Approach. John Wiley \& Sons, 1989.

[13] V. V. Birangane and A. M. Patil, "Comparison of air cooled and evaporatively cooled refrigeration systems - a review paper," International Journal of Engineering Research and Applications, vol. 4, pp. 208-211, June 2014.

[14] T. C. Kandpal, "Improved efficiency ccompressor for air conditioning," in International Compressor Engineering Conference, School of Mechanical Engineering - Purdue University, 1978.

[15] A. Sakuda, K. Sawai, N. Lida, A. Hiwata, and T. Morimoto, "Performance improvement of scroll compressor with new sealing-oil supply mechanism," in Compressors and Their Systems: Tth International Conference, 2001.

[16] J. K. Sonne, D. S. Parker, and S. F. Barhaszi, eds., Measured Impacts of Air Conditioner Condenser Shading, Florida Solar Energy Center, American Council for an Energy-Efficient Economy, 2002.

[17] A. I. ElSherbini and G. P. Maheshwari, eds., Effectiveness of Shading Air-cooled Condensers of Air-conditioning systems, (Kuwait), Proceedings of the Tenth International Conference for Enhanced Building Operations, Oct 2010.

[18] G. H. Donovan and D. T. Butry, "The value of shade: Estimating the effect of urban trees on summertime electricity use," Energy and Buildings, vol. 41, no. 6, pp. 662-668, 2009.

[19] M. A. Hoeschele, M. J. Berman, L. E. Elberling, and M. B. Hunt, eds., Evaporative Condensers: The Next Generation in Residential Air Conditioning, Davis Energy Group and Pacific Gas \& Electric Company, American Council for an Energy-Efficient Economy, 1998.

[20] D. S. Parker, J. R. Sherwin, and R. A. Raustad, "Improving best air conditioner efficiency by 20-30stage coupled with an evaporative condenser pre-cooler," tech. rep., Florida Solar Energy Center, 2014. 
[21] A. O. Elsayed and A. S. Hariri, eds., Effect of condenser air flow on the Performance of split air conditioner, World Renewable Energy Congress, (Linkoping, Sweden), University of Dammam, Saudi Arabia, Low-Energy Architecture, May 2011.

[22] P. N. Ananthanarayanan, Basic Refrigeration and Air Conditioning. Tata McGraw-Hill, 2005.

[23] Gemaire Distributors, "Fan blades." https://gemaire.com/. Accessed: $10 / 17 / 2017$.

[24] R. C. Monroe, "Improving cooling tower fan system efficiencies," in Seventh Turbomachinery Symposium, vol. 50, Hudson Products Corporation, May 1978.

[25] D. S. Parker, J. R. Sherwin, and B. Hibbs, "Development of high efficiency air conditioner condenser fans," ASHRAE Transactions, 2005. Florida.

[26] N. C. Kernstock, "Slashing through the noise barrier," Aviation Today, August 1999.

[27] T. Iwase, E. Katayama, S. Sekiya, and T. Kishitani, "Development of high efficiency fan system for outdoor unit of air-conditioner," JRAIA International Symposium, 2016.

[28] ebmpapst, "The axitop diffuser," tech. rep., ebmpapst Group, 2017.

[29] O. Igra, "Research and development for shrouded wind turbines," Energy Conversion and Management, vol. 21, no. 1, pp. 13-48, 1981.

[30] Y. Ohya and T. Karasudani, "A shrouded wind turbine generating high output power with wind-lens technology," Energies, vol. 3, pp. 634-649, 2010.

[31] Y. Ohya, T. Karasudani, T. Nagai, and K. Watanabe, "Wind lens technology and its application to wind and water turbine and beyond," Renewable Energy and Environmental Sustainability, vol. 2, no. 2, 2017.

[32] P. B. Kosasih, N. Bryce, A. Tondelli, and A. Beazley, "Experimental study of the performance of bare and nozzle - diffuser shrouded micro wind turbine under axial and non-axial inflow condition," in 18th Australasian Fluid Mechanics Conference, School of Mechanial, Materials and Mechatronics Engineering, University of Wollongong, New South Wales, Australia, 2012. 
[33] G. Balaji and I. Gnanambal, "Wind power generator using horizontal axis wind turbine with convergent nozzle," Journal of Scientific $\&$ Industrial Research, vol. 73, pp. 375-380, 2014.

[34] N. A. Pambudi, D. L. Pristiandaru, Basori, D. S. Wijayanto, H. Bugis, B. D. Wahyudi, C. Sudibyo, K. M.W., N. Rahman, N. Sriwardani, and Subagsono, "Experimental investigation of wind turbine using nozzle-lens at low wind speed condition," in Energy Procedia, vol. 105, pp. 1063-1069, 2017. 8th International Conference on Applied Energy ICAE2016.

[35] D. C. Look Jr. and H. J. Sauer Jr., Engineering Thermodynamics. PWS Engineering, 1986.

[36] American Chemical Society, "Chlorofluorocarbons and Ozone Depletion." http://www .acs.org/content/acs/en/education/whatischemistry/ landmarks/cfcs-ozone.html, 2017. Accessed: 2/10/2017.

[37] M. J. Moran, H. N. Shapiro, D. D. Boettner, and M. B. Bailey, Fundamentals of Engineering Thermodynamics. Wiley and Sons, eight ed., 2014.

[38] Mechanical and A. Engineering, MAAE 2400 Thermodynamics and Heat Transfer Laboratory Instructions. Carleton University.

[39] Wavetek, "Wavetek dm7 handheld digital multimeter manual," tech. rep.

[40] A. Inc., "2071a contractor pressure gauge," tech. rep., 2017.

[41] C. G. Lomas, Fundamentals of Hot Wire Anemometry. Cambridge University Press, 1986.

[42] G. Comte-Bellot, "Hot-wire anemometry," Fluid Mechanics, vol. 8, pp. 209-231, 1976.

[43] H. H. Bruun, Hot-Wire Anemometry Principles And Signal Analysis. Oxford University Press, 1985.

[44] E. Rathakrishman, Theoretical Aerodynamics. Wiley and Sons, 2013.

[45] F. E. Jorgensen, "How to measure turbulence with hot-wire anemometers," tech. rep., Dantec Dynamics, 2002. 
[46] A.A. Lab Systems Ltd., "How to adjust the frequency response of a CT anemometer." http: //www.lab-systems.com/products/flow-mea/Adjusting $\% 20$ the $\%$ 20 frequency $\% 20$ response/Adjusting $\% 20$ the $\% 20$ frequency $\% 20$ response. html, 2017. Accessed: 4/10/2017.

[47] L. V. King, "On the convection of heat from small cylinders in a stream of fluid: Determination of the convection constants of small platinum wires with applications to hot-wire anemometry," Philosophical Transactions of the Royal Society of London, May 1914.

[48] H. H. Bruun, M. A. Khan, H. H. Al-Kayiem, and A. A. Fardad, "Velocity calibration relationships for hot-wire anemometry," Journal of Physics E: Scientific Instruments, vol. 21, no. 2, p. 225, 1988.

[49] C. F. King, Some Studies of Vortex Devices - Vortex Amplifier Performance Behavior. PhD thesis, University College of Wales, Cardiff, Wales, 1978.

[50] F. E. Jorgensen, "Directional sensitivity of wire and fiber-film probes," DISA Information, May 1971.

[51] N. Syred, J. M. Beer, and N. A. Chigier, "Turbulence measurements in swirling recirculating flows," in Proceedings: Salford Symposium on Internal Flows, pp. B27-B36, London, England: Institute of Mechanical Engineering, 1971.

[52] I. Wygnanski and H. Fielder, "Some measurements in the self preserving jet," Journal of Fluid Mechanics, vol. 38, p. 577, 1969.

[53] B. D. Pratte and J. R. Keffer, "The swirling turbulent jet," Journal of Basic Engineering, vol. 94, pp. 739-748, 1972.

[54] K. Dvorak and N. Syred, "The statistical analysis of hot-wire anemometry signals in complex flow fields," in Proceeding DISA Conference, University of Leicester, vol. 1, pp. 136-144, Leicester University Press, 1972.

[55] C. F. King, "Vortex amplifier internal geometry and its effect on performance," International Journal of Heat and Mass Transfer, vol. 6, pp. 160-170, September 1985.

[56] S. I. Janjua, "Turbulence measurements in a complex flowfield using a sixorientation hot-wire probe technique," Master's thesis, Oklahoma State University, 1981. 
[57] A. A. Sveshnikov, Problems in Probability Theory - Mathematical Statistics and Theory of Random Functions. W.B. Saunders Company, 1968.

[58] J. O. Hinze, Turbulence. McGraw Hill, 2nd ed., 1975.

[59] S. McTavish, Identification of wind turbine testing practices and investigation of the performance benefits of closely-spaced lateral wind farm configurations. phdthesis, Carleton University, 2013.

[60] X. Grandchamp, A. V. Hirtum, and X. Pelorson, "Hot-film/hot-wire calibration for low to moderate flow velocities," Measurement Science and Technology, vol. 21, May 2010.

[61] X. Grandchamp, Y. Fujiso, B. Wu, and A. Van Hirtum, "Steady laminar axisymmetrical nozzle flow at moderate reynolds numbers: Modmodel and experiment," Journal of Fluids Engineering, vol. 134, 2012.

[62] M. Gad-el-Hak, Frontiers in Experimental Fluid Mechanics. Springer Berlin Heidelberg, 1989.

[63] L. Cattafesta, C. J. Bahr, and J. Mathew, "Fundamentals of wind-tunnel design," Experimental Techniques for Fluid Dynamics and Thermal Science, 2010.

[64] R. D. Mehta, "The aerodynamic design of blower tunnels with wide-angle diffusers," Progress in Aerospace Sciences, vol. 18, pp. 59-120, 1979.

[65] W. H. Rae Jr. and A. Pope, Low-Speed Wind Tunnel Testing. John Wiley \& Sons, 1984.

[66] V. Chandavari and S. Palekar, "Diffuser angle control to avoid flow separation," International Journal of Technical Research and Applications, vol. 2, pp. 16-21, Sep-Oct 2014.

[67] P. W. Runstadler Jr., "Diffuser data book," Tech. Rep. Note 186, Creare Inc. Tech., Hanover, NH, 1975.

[68] F. M. White, Fluid Mechanics. McGraw Hill, fifth ed., 2003.

[69] J. H. Bell and R. D. Mehta, "Design and calibration of the mixing layer and wind tunnel," tech. rep., Department of Aeronautics and Astronautics - Standford University and NASA, 1989. 
[70] G. G. Borger, "The optimization of wind tunnel ccontraction for the subsonic range," tech. rep., NASA, 1976.

[71] T. Morel, "Comprehensive design of axisymmetric wind tunnel contractions," Journal of Fluid Engineering, 1975.

[72] Y. Su, "Flow analysis \& design of three-dimensional wind tunnel contractions," AIAA Journal, vol. 29, no. 11, 1992.

[73] A. E. Perry, Hot-wire Anemometry. Oxford Science Publications, 1982.

[74] D. C. Collis and M. J. Williams, "Two-dimensional convection from heating wires at low reynolds numbers," Journal of Fluid Mechanics, vol. 6, pp. 357-84, 1959.

[75] H. P. Grant and R. E. Kronauer, "Fundamentals of hot-wire anemometry," Symp. on Measurements in Unsteady Flow, pp. 44-53, 1962. Worcester,MA: American Society of Mechanical Engineers.

[76] P. W. Bearman, "Corrections for the effect of ambient temperature drift on hotwire measurements in incompressible flow," DISA Information, no. 11, pp. 25-30, 1971.

[77] A. Abdel-Rahman, C. Tropea, P. Slawson, and A. Strong, "On temperature compensation in hot-wire anemometry," Journal of Physics E: Scientific Instruments, no. 20, pp. 315-9, 1987.

[78] S. F. Benjamin and C. A. Roberts, "Measuring flow velocity at elevated temperature with a hot-wire anemometer calibarted in cold flow," International Journal of Heat and Mass Transfer, no. 45, pp. 703-706, 2002.

[79] C. Tropea, A. L. Yarin, and J. F. Foss, Springer Handbook of Experimental Fluid Mechanics. Springer Berlin Heidelberg, 2007.

[80] M. Hultmark and A. J. Smits, "Temperature corrections for constant temperature and constant current hot-wire anemometers," Measurement Science and Technology, 2010.

[81] D. Dynamics, Single sensor miniature wire Probes. Dantec Dynamics, 2017.

[82] A. Van Dijk and F. T. M. Nieuwstadt, "The calibration of multi-hot-wire probe: 1. temperature calibration," Experiments in Fluids, vol. 36, pp. 540-9, 2004. 
[83] W. G. Kannuluik and E. H. Carman, "The temperature dependence of the thermal conductivity of air," Australian Journal of Scientific Research, vol. 4, pp. 305-14, 1951.

[84] J. C. Dixon, The shock absorber handbook. John Wiley \& Sons Ltd, second ed., 2007.

[85] A.A. Lab Systems Ltd., AN-1005 Hot-wire 86 hot-film anemometry Systems: User's Manual.

[86] S. C. Morris, J. J Good, and J. F. Foss, "Velocity measurements in the wake of an automotive cooling fan," Experimenteal Thermal and Fluid Science, vol. 17, pp. 100-106, 1998.

[87] N. L. Gifford, A. G. Hunt, E. Savory, and R. J. Martinuzzi, "Experimental study of low-pressure automotive cooling fan aerodynamics under blocked conditions," CSME Forum, 2006.

[88] M. B. Sekularac, "Experimental determination of tunnel ventilation axial ducted fan performance," Thermal Science, vol. 20, no. 1, pp. 209-221, 2016.

[89] X. Zhao, J. Sun, and Z. Zhang, "Prediction and measurement of axial flow fan aerodynamic and aeroacoustic performance in a split-type air-conditioner outdoor unit," International Journal of Refrigeration, vol. 36, pp. 1098-1108, 2013.

[90] C. Xu and R. S. Amano, "Unsteady pressure field investigation of an axial fan - blade unsteady pressure field measurement," International Journal of Rotating Machinery, vol. 8, no. 6, pp. 385-395, 2002.

[91] K. M. Tenny and J. S. Cooper, "Chemistry, ideal gas behavior." https://www . ncbi.nlm.nih.gov/books/NBK441936/, Oct 6 2017. Accessed: 10/30/2017.

[92] F. Kaya, I. Karagoz, and A. Avci, "Effects of surface roughness on the performance of tangential inlet cyclone separators," Aerosol Science and Technology, vol. 45, pp. 988-995, 2011.

[93] J. Cernecky and K. Plandorova, "The effect of the introduction of an exit tube on the separation efficiency in a cyclone," Brazilian of Chemical Engineering, vol. 30, pp. 627-641, July-September 2013. 
[94] L. Liu, H. S. Dou, X. P. Chen, and H. Z. Zhang, "Analysis of vortex flow in a cyclone separators based on the energy gradient theory," in IOP Conference Series: Materials Science and Engineering, no. 72, 2015.

[95] S. I. Janjua, D. K. Mclaughlin, D. G. Lilley, and T. Jackson, "Turbulence measurements in a confined jet using a six-orientation hot-wireprobel technique," techreport, NASA, 1982.

[96] S. N. Goodman, "P value hypothesis and likelihood: implications for epidemiology of a neglected historical debate," American Journal Epidemiology, vol. 137, pp. 485-96, 1993.

[97] Michigan State University, "Error propagation." http://lectureonline.cl. msu.edu/ mmp/labs/error/e2.htm, Aug. 2016. Accessed: 11/13/2017. 


\section{Appendix A}

\section{Uncertainty Quantification}

Typically, experimental results are often expressed in the form of sample mean, $\bar{x}$ and its associated uncertainty quantity, $U_{x}$ as:

$$
x=\bar{x} \pm U_{x}
$$

For confidence interval based on $95 \%$ probability, the total error can be given by the following equation where $t_{\nu, 95 \%}$ is the Student t-distribution at $95 \%$ confidence level.

$$
U_{x}=\sqrt{S_{x}^{2}+\left(t_{\nu, 95 \%} R_{x}\right)^{2}}
$$

where $t_{\nu, 95 \%}$ was evaluated at degree of freedom $\nu=\mathrm{N}-1$. For repeats $\mathrm{N}=3$, the $t_{\nu, 95 \%}=4.303$.

The random errors from measurements were estimated to be the standard deviation between repeats, as expressed in the equation below

$$
R_{x}=\frac{\sum\left(x_{i}-\bar{x}\right)^{2}}{N-1}
$$

The following rules of addition/subtraction, multiplication/division, exponential 
and function propagations are used to compute uncertainties where $\partial X$ stands for uncertainty associated with the units measured $\mathrm{X}$ while $\mathrm{V}$ and $\partial V$ represent resultant value and its uncertainty [97].

\section{Addition/Subtraction:}

$$
\begin{gathered}
V=X-Y+Z \\
\partial V=\sqrt{\partial X^{2}+\partial Y^{2}+\partial Z^{2}}
\end{gathered}
$$

\section{Multiplication/Division:}

$$
\begin{gathered}
V=\frac{X Y}{Z} \\
\partial V=V \sqrt{\left(\frac{\partial X}{X}\right)^{2}+\left(\frac{\partial Y}{Y}\right)^{2}+\left(\frac{\partial Z}{Z}\right)^{2}}
\end{gathered}
$$

\section{Exponents:}

$$
\begin{gathered}
V=X^{n} \\
\partial V=n \frac{\partial X}{X} V
\end{gathered}
$$

\section{Functions:}

If a parameter is function of several variables, the below equation can be implemented. 


$$
\begin{gathered}
V=V(X, Y, Z) \\
\partial V=V \sqrt{\left(\frac{d V}{d X} \partial X\right)^{2}+\left(\frac{d V}{d Y} \partial Y\right)^{2}+\left(\frac{d V}{d Z} \partial Z\right)^{2}}
\end{gathered}
$$

It should be noted that $\mathrm{Y}$ and $\mathrm{Z}$ represent different measurement values that are involved in the calculation. Also, if a parameter is assumed to be constant, its associated uncertainty is considered to be 0 . 